\title{
Characterization of LWRS Hybrid SiC-CMC- Zircaloy-4 Fuel Cladding after Gamma Irradiation
}

Isabella J van Rooyen

September 2012

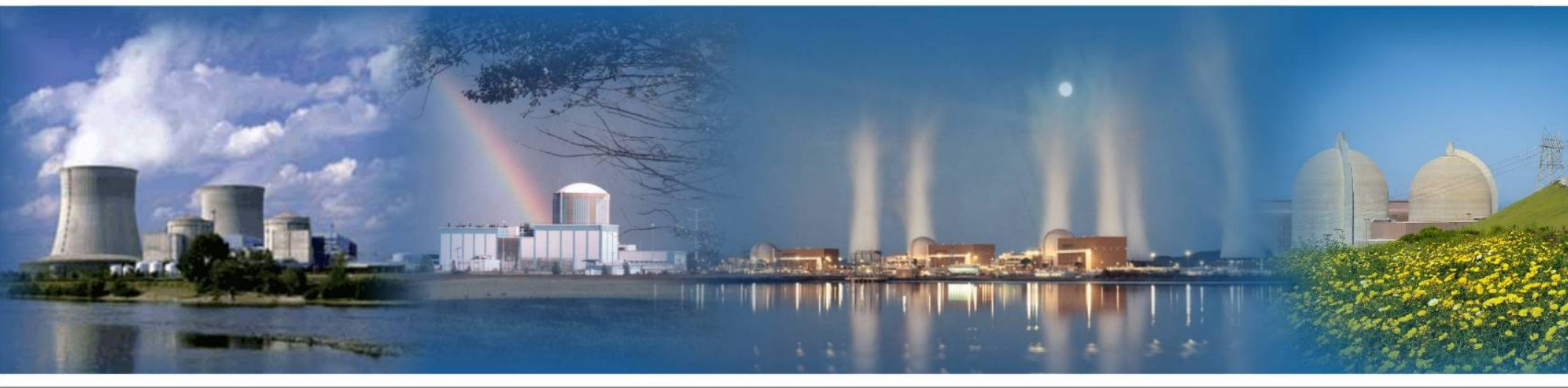

The INL is a U.S. Department of Energy National Laboratory operated by Battelle Energy Alliance 


\section{DISCLAIMER}

This information was prepared as an account of work sponsored by an agency of the U.S. Government. Neither the U.S. Government nor any agency thereof, nor any of their employees, makes any warranty, expressed or implied, or assumes any legal liability or responsibility for the accuracy, completeness, or usefulness, of any information, apparatus, product, or process disclosed, or represents that its use would not infringe privately owned rights. References herein to any specific commercial product, process, or service by trade name, trade mark, manufacturer, or otherwise, does not necessarily constitute or imply its endorsement, recommendation, or favoring by the U.S. Government or any agency thereof. The views and opinions of authors expressed herein do not necessarily state or reflect those of the U.S. Government or any agency thereof. 


\title{
Characterization of LWRS Hybrid SiC-CMC-Zircaloy-4 Fuel Cladding after Gamma Irradiation
}

\author{
Isabella J van Rooyen
}

September 2012

Idaho National Laboratory Idaho Falls, Idaho 83415

http://www.inl.gov

\author{
Prepared for the \\ U.S. Department of Energy \\ Office of Nuclear Energy \\ Under DOE Idaho Operations Office \\ Contract DE-AC07-05ID14517
}




\section{EXECUTIVE SUMMARY}

The purpose of the gamma irradiation tests conducted at the Idaho National Laboratory (INL) was to obtain a better understanding of chemical interactions and potential changes in microstructural properties of a mock-up hybrid nuclear fuel cladding rodlet design (unfueled) in a simulated PWR water environment under irradiation conditions. The hybrid fuel rodlet design is being investigated under the Light Water Reactor Sustainability (LWRS) program for further development and testing of one of the possible advanced LWR nuclear fuel cladding designs. The gamma irradiation tests were performed in preparation for neutron irradiation tests planned for a silicon carbide $(\mathrm{SiC})$ ceramic matrix composite (CMC) zircaloy-4 (Zr-4) hybrid fuel rodlet that may be tested in the INL Advanced Test Reactor (ATR) if the design is selected for further development and testing. Although the effects of gamma irradiation on the hyrbrid design was expected to be different than effects from neutron irradiation, no data were currently available on the effects of any type of irradiation (gamma or neutron) on the $\mathrm{SiC}-\mathrm{CMC}$ matrix processed via polymer impregnation pyrolosis (PIP). There was concern that degradation of the PIP processed SiC$\mathrm{CMC}$ matrix may be enhanced due to irradiation effects. In addition, the gamma irradiation tests would provide information on the chemical stability of a proposed bonding agent to bond the SiC-CMC tube to the inner $\mathrm{Zr}-4$ tube. Preliminary testing in a gamma irradiator was easy, quick, safe (fully contained samples) and inexpensive, therefore the tests were conducted to support a better understanding of the behavior of the SiC-CMC material.

Two gamma irradiation experiments, denoted gamma irradiation test 1 and test 2, were conducted using a Nordion gamma cell $220 \mathrm{E}$ gamma irradiator with cobalt-60 source at a dose rate of $7.2 \mathrm{kGy} / \mathrm{hr}$ for 96 hours for test 1 and 167 hours for test 2. Selected specimens were contained in synthetic ATR primary coolant system water to test the potential effect of constituent chemicals in the water affecting the experiment samples. The $\mathrm{pH}$ of this synthetic water was 5.07 and 5.03 respectively for the two tests. The total irradiation dose was $60 \mathrm{mRad}$ and $104.6 \mathrm{mRad}$ respectively for the two experiments and the irradiation temperature was $50^{\circ} \mathrm{C}$.

A set of initially fabricated SiC-CMC-Zr-4 hybrid cladding tubes were chemically bonded together during the PIP process to cure the SIC-CMC tubes. The the high temperature bonding processing caused the inner Zircodyne 702 to embrittle and therefore this set of hybrid tubes were not representative of the final design preventing the rodlets from being used for further testing in the ATR. Due to the failure of this bonding technique, a decision was made by the program to continue with the development and testing of a non-bonded hybrid design until an improved bonding technique could be developed and tested. An attempt was made to salvage the SiC-CMC braided tubes chemically bonded to the $\mathrm{Zr}-702$ embrittled tubes by acid leaching the $\mathrm{Zr}-702$ out of the assembly so the SiC$\mathrm{CMC}$ tubes could be used for prototype characterization testing. At the time, it was assumed that the $\mathrm{SiC} \mathrm{CMC} \mathrm{braided} \mathrm{tubes} \mathrm{would} \mathrm{not} \mathrm{be} \mathrm{damaged} \mathrm{or}$ chemically altered due to the acid leaching, however this assumption was not validated (major lesson learned). The salvaged $\mathrm{SiC}-\mathrm{CMC}$ tubes were used in the gamma irradiation test 1 . As part of this lesson learned, the gamma irradiation 
test 2 used SiC CMC tubes that had not been acid leached and were representative of the hybrid final design.

Two samples sets were fabricated namely bonded and non-bonded sleeve samples. Characterization focus was placed on the non-bonded samples as this was the design to be initially irradiated in the ATR until an improved bonding technique could be developed and tested. The main findings of the first experiment is that the reclaimed sleeves were not very representative of the prototypes as most of the $\mathrm{SiC}$ matrix material was removed during the acid leaching process. However, irrespective of this fact, valuable information was gained on the bonded samples where the instability and lack of bonding agent integrity under these experiment conditions were highlighted. The various bonding agents used for gamma irradiation test 1 resulted in an increased Cl-, Fand $\mathrm{Si}$ concentrations soluble in the water during irradiation with the $\mathrm{Cl}$ content exceeding the ATR control limit. The metallurgical examination of the bonded samples further also shows that cracking and degrading of the bonded layer and $\mathrm{SiC}$ matrix material occurred which may be the reason for the increased Cl-, Fand $\mathrm{Si}$ concentrations found. The XRD analysis after gamma irradiation shows predominantly $\beta$-SiC with a trace of $\alpha$-SiC. It was found that the $2 \mathrm{D} x$-ray radiographic inspection provided no significant information as comparative purposes to evaluate the effect of gamma irradiation.

Many of the lessons learned from the first gamma test were corrected during the second gamma irradiation test. One of the biggest lessons learned was the loss of data because of the unknown conditions of the samples prior to gamma cell insertion and the speed in which the samples were prepared and not integrated with the rest of the program to ensure specific characterization was done prior to gamma irradiation. The main reason for the speed of gamma irradiation insertion was due to the push to irradiate quickly in the ATR. The advantages of pre-gamma irradiation characterization are fully demonstrated by the battery of characterization test results in the second gamma irradiation experiment.

Both a 1-ply and a 2-ply set of SiC-CMC tube samples were prepared for the second gamma irradiation test to support the final design selection. Various subsamples from the two sample sets were prepared which included a mock-up mini tube ( 2 ply SiC-CMC tube) and one pre-cleaned SiC-CMC sleeve subsample. One sample was cleaned with ethanol prior to irradiation as it was found that no cleaning was done prior to the first gamma irradiation test. It was decided to pre-clean one sample for comparative reasons to determine the effect of cleaning on the water chemistry. Program management advised that the 2 ply sample was technically representative of the prototypes although dimensionally non-compliant. The 1 ply sample was included to provide comparative data for development purposes.

Density measurements of the gamma irradiation 2 tests showed no large differences in the density values between the 1- and 2 ply SiC-CMC tubes and that no change in density could be conclusively determined due to gamma irradiation in either the 1 or 2 ply samples. However, this finding needs to be validated with a larger sample set to determine statistical variations and significance. . The XRD patterns showed that no $\alpha$-SiC was present in either prior or after the irradiation. Leach test analysis on representative sub-samples prior to gamma irradiation revealed that more $\mathrm{Cl}$ (20 times) and $\mathrm{Si}$ (3 times) are 
released for the 2 ply braided SiC-CMC tube compared to the 1-ply tube. Similar results were observed in the water analysis after gamma irradiation for the $\mathrm{Cl}$ content of the 1 ply tube water generally lower than for the 2-ply tube water samples with exception of the pre-cleaned 2-ply SiC-CMC tube water which had the overall lowest $\mathrm{Cl}$ dissolution during gamma irradiation. Significant higher $\mathrm{Cl}$, $\mathrm{F}$ and $\mathrm{Si}$ dissolution from the mini tube (2-ply) suggest possible contamination during the fabrication/sample preparation process. The SEM microstructural examination of the 2-ply samples shows that visibly more cracks and flakes are visible in the $\mathrm{SiC}$ matrix material after the gamma irradiation treatment.

The application and advantages of 3D Tomography as a characterization technique were demonstrated during this experiment by showing gaps between the $\mathrm{SiC}-\mathrm{CMC}$ sleeve and $\mathrm{Zr}-4$ tube at any distance alongside the tube, the inner and outer surface morphology, identification of open porosity can be evaluated and the braided weave patterns were observed.

These two preliminary gamma irradiation tests provided relevant technical information for the improvement of the $\mathrm{SiC}-\mathrm{CMC}$ sleeve design of the prototypes. Specifically, the post gamma irradiation characterization revealed a chemical and mechanical breakdown of the bonding processes used and assist the program managements to make a decision not to continue with a non-bonded hybrid cladding design for the initial neutron irradiation due to the immaturity of the bonding technique. It is recommended that the gamma irradiation experiment results be used as an input for design selections and neutron reactor insertion. It is further recommended that the future gamma irradiation experiments include EBSD, FTIR and TEM examinations to provide insight in possible changes on nano level which typically will provide more detail on the actual irradiation effects. Updates and modifications to the various test plans are needed based on the lessons learned during the execution of the tests/characterization techniques. These modifications must be in place prior to the gamma irradiation experiment of the actual prototypes. As these samples were processed using 5 PIP cycles which is different than the anticipated 7 PIP cycles of the prototypes, it is recommended that the gamma irradiation test prior to reactor insertion be executed on samples of fully representative processing cycles and therefore be fully be classified as "prototype" samples. 


\section{ACKNOWLEDGEMENTS}

Acknowledgements are given to the following persons:

- Karen Wendt for the X-ray examination.

- Byron White for the water analysis.

- Although not working anymore on the project, we would like to acknowledge Lynn Wendt and Julie Chapman for the initial work on visual inspection and dimensional measurements.

- Arnie Erikson for XRD and density measurements.

- Tammy Trowbridge for leach testing, bend test and SEM, EDX and visual examinations

- Todd Morris for microscopic sample preparation.

- Amber Miller for assistance with the water analysis and review of this report.

- Kristine Barrett for the initiation and arranging of the first gamma irradiation, review of this report and other recommendations throughout the characterization activities.

- Bruce Mincher for the gamma irradiation execution.

- Shannon Bragg-Sitton for the review of this report.

- John Garnier as the Development PI and the development planning and fabrication of the Gamma irradiation test 1 samples. 


\section{CONTENTS}

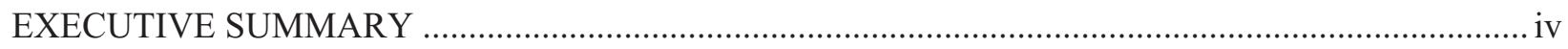

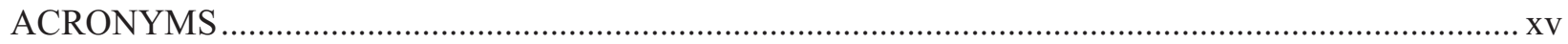

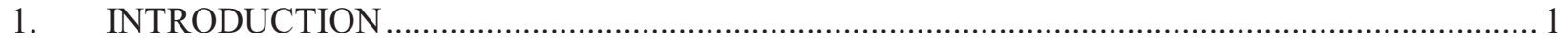

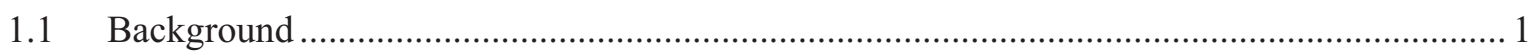

1.2 Scope

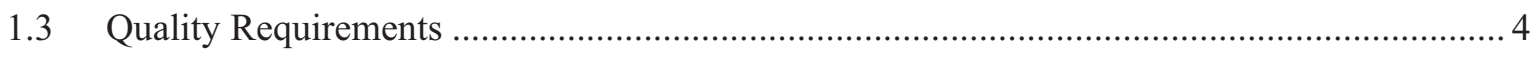

2. MATERIALS AND CHARACTERIZATION METHODS ......................................................... 4

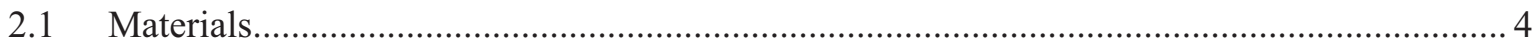

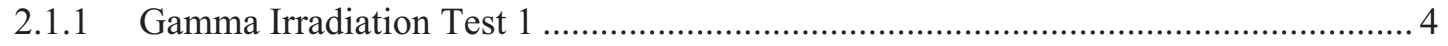

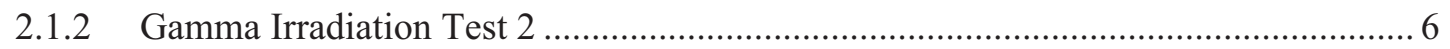

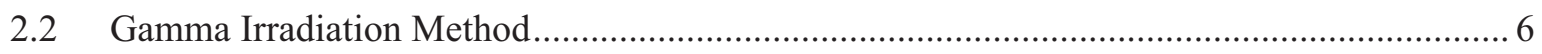

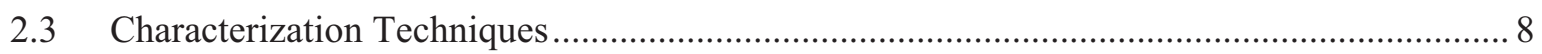

2.3.1 Visual Examination, Dimensional, and Weight Measurements ................................ 8

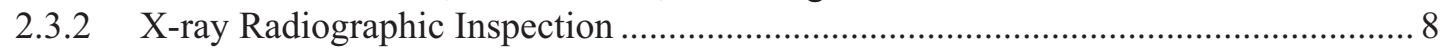

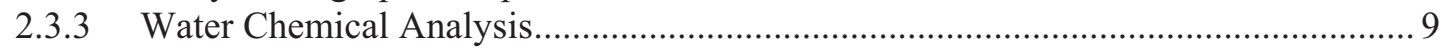

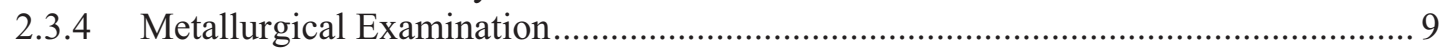

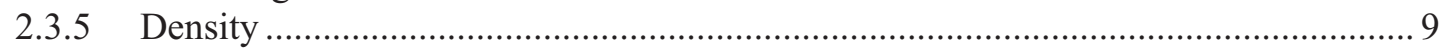

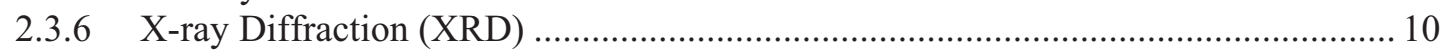

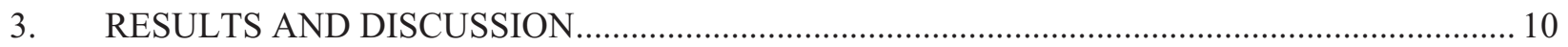

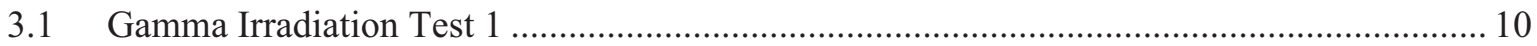

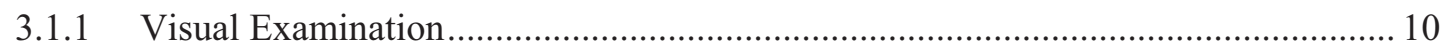

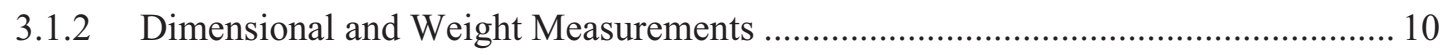

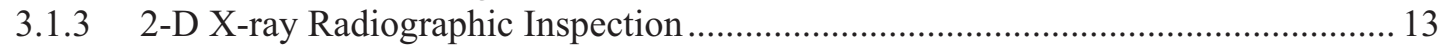

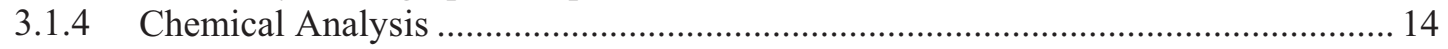

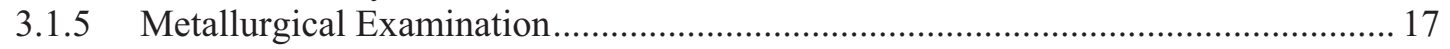

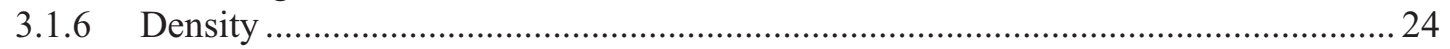

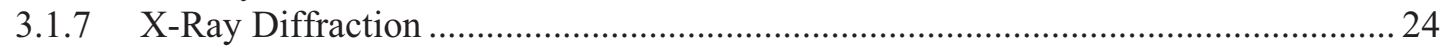

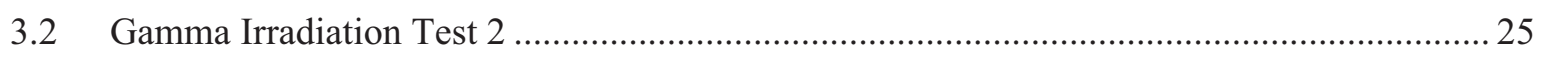

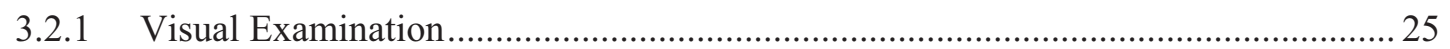

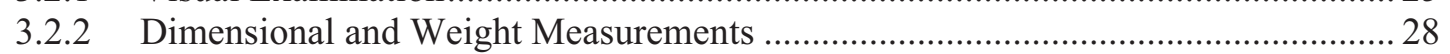

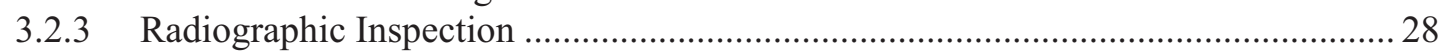

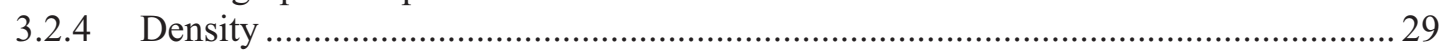

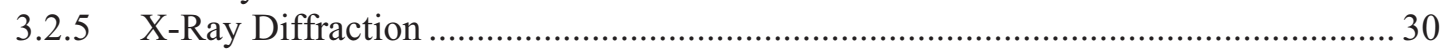

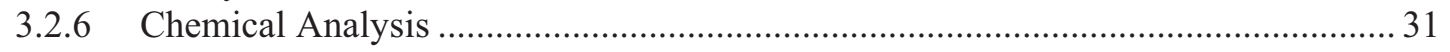

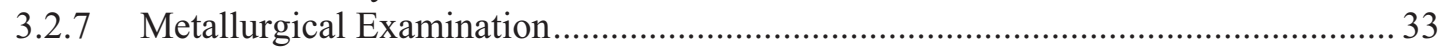

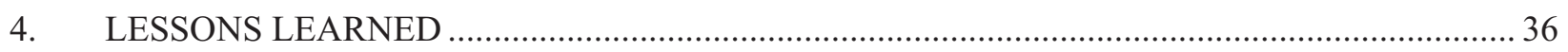

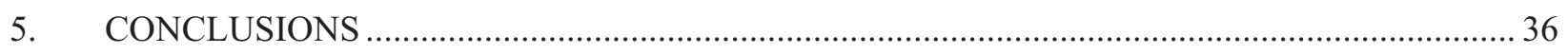

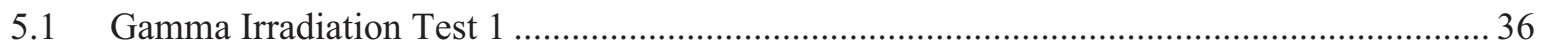

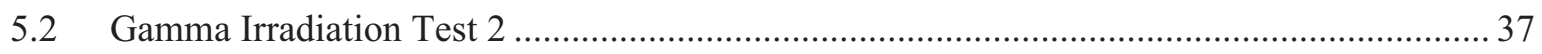




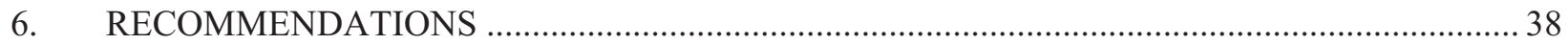

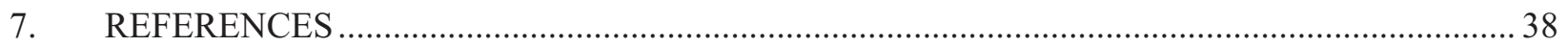

Appendix A Quality Labels of the SiC-CMC Sleeves and Mock-Up Mini Tubes Used for

Gamma Irradiation Tests 1 and 2

Appendix B Ion Chromatography Spectra Showing Spectrum of Calibration Standard and

Sample $2 \mathrm{~W}$ as an Example.....

Appendix C Detail of Dimensional and Weight Measurements of Gamma Irradiation Test 1

Samples

Appendix D Typical Elemental Composition of Zicaloy-4 and Zircodyne 702 Alloys

Appendix E SEM-EDS Analysis of Various Areas of Zr-4 Tube Samples (LWRS-67 and LWRS-

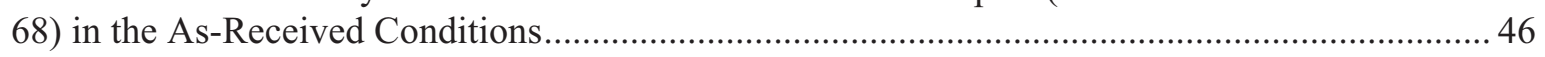

Appendix F Detail of Density Measurements: Gamma Irradiation Test 1 ......................................... 47

Appendix G Original XRD Results of Gamma Irradiation Test 1 Samples ......................................... 49

Appendix H Detail of Dimensional Measurements: Gamma Irradiation Test 2 .................................. 53

Appendix I Detail of Density Measurements: Gamma Irradiation Test 2 …....................................... 54

Appendix J Detail of Chemical Analysis: Gamma Irradiation Test 2 ................................................ 56

\section{FIGURES}

Figure 1. Figure showing the LWRS SiC-CMC hybrid cladding characterization test plan [2]. This test classification was designed specifically for a SiC-CMC hybrid technology being tested at the Idaho National Laboratory; however it can be used as a template for alternate technologies (acronyms used in this table are described on page xiv). 2

Figure 2. Geometry of the LWRS capsule assembly design for the Si-CMC hybrid Zr-4 cladding rodlet[3].

Figure 3. Figure showing mini-rodlet tube mock-up sample (mini tube 1) and glass vial used for gamma irradiation of mini tube 1. Sample $2 \mathrm{~W}$ and the other samples were placed in similar glass vials.

Figure 4. Schematic presentation of the sampling plan (sub-samples) and characterization planned for SiC-CMC sleeve samples LWRS-1-6-A-1.

Figure 5. Schematic presentation of the sampling plan (sub-samples) and characterization planned for SiC-CMC sleeve samples LWRS-1-6-A-3.

Figure 6. Figure showing comparative images of the mini-tube (sample 10-482 Zr-4). Although the images of the samples prior to gamma irradiation were taken in the glass vial which obscures the image slightly, the visual examination shows no significant changes due to gamma irradiation. 
Figure 7. Figure showing comparative images of samples 2 to 5. Although the images of the samples before gamma irradiation were taken in the glass vial which obscures the images slightly, the visual examination shows no significant changes due to gamma irradiation. Differences are noted due to the different bonding techniques.

Figure 8. Figure showing the variance in length and diameter of the $\mathrm{SiC} / \mathrm{CMC}$ sleeve due to gamma irradiation.

Figure 9. Example of the x-ray radiographic examination completed on the mock-up mini tube used in the first gamma irradiation experiment.

Figure 10. X-ray radiographic micrographs showing the 2D x-ray technique used is not sensitive enough to show visual differences between the non-bonded and bonded samples.

Figure 11. SEM-EDS analysis of the Zr-4 tube used for the gamma irradiation tests (sample number LWRS-67).

Figure 12. Water analysis results show an increase in $\mathrm{Cl}$ and $\mathrm{F}$ due to the gamma irradiation test.

Figure 13. Water analysis results show a significant increase in Si in the bonded samples 3 to 5 and a slight increase in $\mathrm{Al}$ due to gamma irradiation test (mean \% error $-0.8 \pm 1.3$ and $0.9 \pm 0.3$ for $\mathrm{Al}$ and Si respectively)......

Figure 14. Planned sub-sample locations identification for the metallurgical examination of the mini tube (sample 10-472 Zr-4)......

Figure 15. SEM micrographs showing the metallurgical examination of the longitudinal cut (location 1) through the welds of mini tube (sample 10-472 Zr-4). Full weld penetration is noted with no defects visible.

Figure 16. SEM metallurgical examination of the mini tube (sample 10-472 Zr-4) at locations 2a and $2 \mathrm{~b}$ after gamma irradiation. PIP matrix seems to be removed by the $\mathrm{HF}-\mathrm{HNO}_{3}$ leaching, thus the mini-tube 1 is not representative of the real prototypes.

Figure 17. SEM metallurgical examination of the mini tube (sample 10-472 Zr-4) at position $2 \mathrm{~b}$ after gamma irradiation shows only "flakes" of the PIP matrix remains after $\mathrm{HF}-\mathrm{HNO}_{3}$ leaching.

Figure 18. SEM-EDS analysis in the two areas shown in Figure 17, shows that the flakes are mainly $\mathrm{Si}, \mathrm{C}$, and $\mathrm{O}$.

Figure 19. SEM metallurgical examination of the Zircaloy 4 tubes for samples 2 and $2 \mathrm{~W}$. No significant chemical reactions (pitting) are observed on the surface of sample 2, but pitting is observed in sample $2 \mathrm{~W}$ surface.

Figure 20. SEM metallurgical examination of two representative samples of the Zircaloy-4 tubes used for the gamma irradiation experiments. Fabrication marks are observed on both samples as expected but sample LWRS-67 has already a pitted surface which made the interpretation on the corrosion surfaces observed after gamma irradiation nearly impossible.

Figure 21. SEM metallurgical examination of samples 2 and $2 \mathrm{~W}$ comparing the inner and outer diameters of the Zircaloy- 4 tubes used for the gamma irradiation experiments. A thin layer of changed microstructure are observed in the inside of the $\mathrm{Zr}-4$ tube of sample $2 \mathrm{~W}$ are observed.

Figure 22. SEM-EDS analysis on the inner diameter of the $\mathrm{Zr}-4$ tube of sample $2 \mathrm{~W}$ show no difference in the chemical composition in areas at the inner edge and approximately 30 
$\mu \mathrm{m}$ away from inside edge. Possible changes in oxide content cannot be quantified with the SEM-EDS technique.

Figure 23. SEM micrographs showing typical breakages, pitting and flaking on the Zr-4 and SiCCMC bonding surface. All bonded samples (3 to 5) showed similar features irrespective if there was water present or not.

Figure 24. Combined figure of the XRD patterns of the original SiC-CMC sleeve without acid washing (LWRS-18-1) and the non-bonded samples (2 and $2 \mathrm{~W})$.

Figure 25. Visual examination of samples LWRS-1-6- A-1 and LWRS-1-6- A-3 showing the masking tape labeling as received form PSI. This is a deviation from the delivery requirements and is communicated to the supplier PSI by the experiment manager. 26

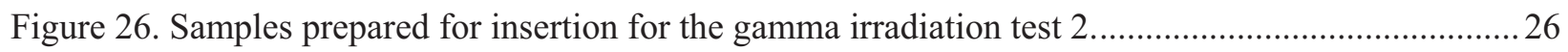

Figure 27. Photograph showing the samples in glass vials after the gamma irradiation cycle. Samples in glass vials after discoloration of the glass vials are again observed as in the case with the gamma irradiation test 1 . Additionally, the water of subsample LWRS-16-A-1-3 appears "milky" after gamma irradiation whilst the other four samples appear clear.

Figure 28. Photograph showing the comparative visual examination for the samples before and after gamma irradiation. No significant visual differences are observed, except for the white discoloration on sample 1-6-A-1-3, which is also the sample showing the "milky" appearance of the water after gamma irradiation.

Figure 29. Graphical presentation of the dimension- and weight variances due to the gamma irradiation test (standard measurement error of $5 \%$ ).

Figure 30. Advantages of the $3 \mathrm{D}$ tomographic inspection in comparison of the $2 \mathrm{D} x$-ray technique are demonstrated by these photos.

Figure 31. Surface condition and details of the gap between the interfaces in a non-bonded sleeve and $\mathrm{Zr}-4$ tube.

Figure 32. Comparative XRD patterns of the gamma irradiated SiC-CMC sleeve (LWRS-1-6-A3-3) with the sleeves as received (LWRS-1-6-A-3-1) showing now significant changes in the 2 theta angles or peak width due to the gamma irradiation test. Only $3 \mathrm{C} \mathrm{SiC}$ is observed......

Figure 33. Comparative XRD patterns of the gamma irradiated SiC-CMC sleeve (LWRS-1-6-A1-3, LWRS-1-6-A-1-2) with the sleeves as received (LWRS-1-6-A-1-5) showing now significant changes in the 2 theta angles although indications of slight peak broadening are observed in the two samples after the gamma irradiation test.

Figure 34. Figure showing the water analysis before and after gamma irradiation test 2 and is showing the increased $\mathrm{F}$ and $\mathrm{Si}$ content of the mini tube 2 sample (A-1-1) if compared with the rest of the gamma irradiated samples. The decreased $\mathrm{F}$ and $\mathrm{Cl}$ content of the cleaned sample A-1-2 are clearly visible.

Figure 35. Figure showing the increased Si content of all SiC-CMC sleeve samples. The highest release was measured for the mini tube 2 sample (A-1-1) if compared with the rest of the gamma irradiated samples.

Figure 36. Micrographs showing the microstructure of the representative SiC-CMC sleeve subsamples of LWRS-1-6-A-1. More cracks in the SiC matrix material are observed 
after the gamma irradiation treatment and some of the $\mathrm{SiC}$ material broke off from especially sample LWRS-1-6-A-1-2 after the irradiation test.

Figure 37. Micrographs showing the microstructure of the representative SiC-CMC sleeve subsamples of LWRS-1-6-A-3. The SiC matrix is removed during the gamma irradiation process.

Figure 38. Micrographs showing the microstructure of the representative SiC-CMC sleeve subsamples of LWRS-1-6-A-3. The SiC matrix is "eroded" during the gamma irradiation process

Figure B-1. Calibration Standard for Ion Chromatography Spectrum................................................... 40

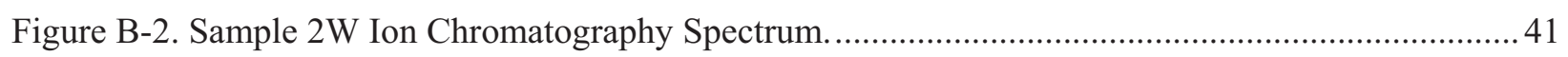

\section{TABLES}

Table 1. Sample description of Gamma Irradiation Test 1. .................................................................. 5

Table 2. Sample description of Gamma Irradiation Test 2 ................................................................ 6

Table 3. Original SiC-CMC Fiber Sample Results for Ion Chromatography ( $1 \mu \mathrm{g} / \mathrm{mL}$ is

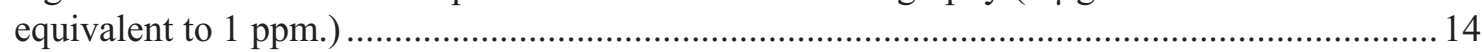

Table 4. Water analysis after gamma irradiation test 1 compared to the water analysis before the gamma irradiation test 1 .

Table 5. Density measurements of representative samples before and after gamma irradiation test 2. 30

Table 6. Leach test water analysis on representative samples prior to gamma irradiation test 2.

Table 7. Water analysis after gamma irradiation test 2 compared to the water analysis before the gamma irradiation test 2 .

Table C-1. Gamma irradiation test 1: SiC dimensional measurements prior and after gamma irradiation.

Table C-2. Gamma irradiation test 1: Zr-4 tube dimensional measurements prior and after gamma irradiation. 42

Table C-3. Weight measurements of total assembly. 43

Table D-1. Composition of Zircaloy Alloys. 44

Table D-2. Chemical Composition of Zircadyne Alloys. 45

Table H-1. Gamma irradiation test 2: SiC-CMC sleeve dimensional measurements prior and after gamma irradiation. (All numbers are following the designation LWRS-1-6- ). .53

Table H-2. Weight measurements of SiC-CMC sleeves. .53 


\section{ACRONYMS}

ATR Advanced Test Reactor (ATR)

EDS energy dispersive spectroscopy

EPMA electron probe micro-analysis

FTIR Fourier transform infrared spectrometry

GTAW gas tungsten arc welding

LWR light water reactor

LWRS light water reactor sustainability

N/A not applicable

PB parallel beam

PI principal investigator

PIP polymer infiltration pyrolysis

PSI Physical Sciences Inc.

QADP quality assurance program document

SEM scanning electron microscopy

SiC-CMC SiC ceramic matrix composites

SIMS secondary ion mass spectrometry

WDS wave length dispersive spectrometry

XRD $\quad \mathrm{X}$-ray diffraction

Zr-4 Zircaloy-4 


\section{Characterization of LWRS Hybrid SiC-CMC-Zircaloy-4 Fuel Cladding after Gamma Irradiation \\ 1. INTRODUCTION}

Nuclear fuel performance is a significant driver of nuclear power plant operational performance, safety, economics and waste disposal requirements. The Advanced Light Water Reactor (LWR) Nuclear Fuel Development Pathway focuses on improving the scientific knowledge basis to enable the development of high-performance, high burn-up fuels with improved safety and cladding integrity and improved nuclear fuel cycle economics. To achieve significant improvements, fundamental changes are required in the areas of nuclear fuel composition, cladding integrity, and fuel/cladding interaction.

\subsection{Background}

Selection of alternate cladding and structural materials must first take into account physical (geometric) and chemical compatibility with currently operating LWR designs. Cladding options under consideration have focused on the use of silicon carbide ( $\mathrm{SiC}$ ). Both monolithic $\mathrm{SiC}$ and $\mathrm{SiC}$ composite have been studied by a variety of international research programs, resulting in a substantial body of data available to guide the current LWRS effort. Early research in the LWRS Fuels Pathway has focused on developing a better understanding of $\mathrm{SiC}$ ceramic matrix composites (SiC-CMC). Various candidate materials and designs are investigated of which a fully ceramic or a "hybrid" design, which would incorporate $\mathrm{SiC}$ as a structural material supplementing an inner metal tube (possibly Zircaloy-4), are specific examples of.

The light water reactor sustainability (LWRS) fuel development plan [1] focuses on addressing critical-path items in fielding of advanced clad technology. In addition to an appropriate level of mechanistic and systems-level modeling, significant out-of-pile testing is anticipated to fully characterize mechanical, physical and chemical properties of candidate materials and designs and to demonstrate performance under nominal operating conditions and postulated accident conditions. Nonnuclear tests will provide a basis for initial down selection of candidate advanced cladding designs.

Advanced cladding materials must provide substantial benefit over the current zirconium-based cladding (e.g. Zircaloy-4, Zircaloy-2, ZIRLO and other). The planned tests are intended to either produce quantitative data or to demonstrate the properties required to achieve two initial performance conditions relative to standard $\mathrm{Zr}-4$ cladding:

1. Decreased hydrogen uptake (corrosion).

2. Decreased fretting of the cladding tube under normal operating and postulated accident conditions.

3. Increased coping time under postulated accident conditions (i.e. loss of coolant accident).

4. Reduced exothermic reaction rate with steam under postulated accident conditions (reduced hydrogen generation).

5. Possibility for power uprates and operation to higher burnup.

A series of out-of-pile tests will be performed to fully characterize candidate materials and an example of the characterization plan for the hybrid cladding system is shown in Figure 1 (acronyms are described on page xiv). Cold characterization testing will establish baseline properties in advance of any future irradiation testing. These data will be compared to the current zirconium-based cladding in operating LWRs to inform the down selection process for an advanced clad system. Full characterization of cladding materials and designs will require a variety of test equipment and will encompass both non-destructive and destructive testing. 


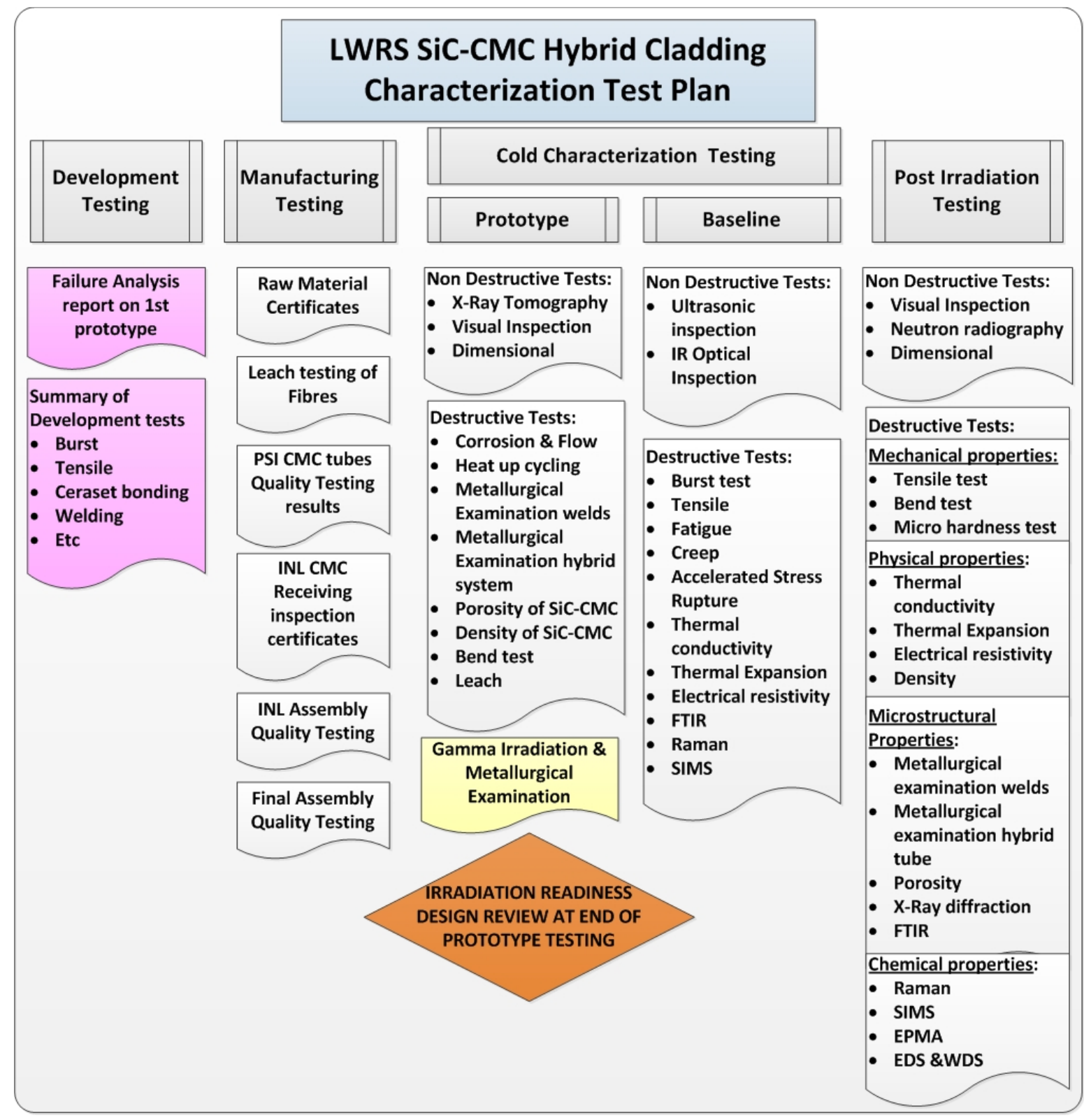

Figure 1. Figure showing the LWRS SiC-CMC hybrid cladding characterization test plan [2]. This test classification was designed specifically for a SiC-CMC hybrid technology being tested at the Idaho National Laboratory; however it can be used as a template for alternate technologies (acronyms used in this table are described on page xiv).

\subsection{Scope}

The purpose of the gamma irradiation tests conducted at the Idaho National Laboratory (INL) was to obtain a better understanding of chemical interactions and potential changes in mechanical properties of a mock-up hybrid fuel rodlet design in a simulated PWR water environment under irradiation conditions. Although the effects of gamma irradiation on the hybrid design were expected to be different than effects from neutron irradiation, no data were currently available on the effects of any type of irradiation (gamma or neutron) on the SiC-CMC matrix processed via PIP. There was concern that degradation of the PIP processed SiC CMC matrix may be enhanced due to irradiation effects. In addition, the gamma irradiation 
tests would provide information on the chemical stability of a proposed bonding agent to bond the $\mathrm{SiC}$ $\mathrm{CMC}$ tube to the inner Zr-4 tube. Preliminary testing in a gamma irradiator was easy, quick, safe (fully contained samples) and inexpensive, therefore the tests were conducted to support a better understanding of of the SiC-CMC sleeve behavior.

The hybrid SiC-CMC fuel rodlet design is being investigated as one of the potential cladding designs under the LWRS program for further development and testing. The gamma irradiation tests were performed in preparation for neutron irradiation tests planned for a silicon carbide ( $\mathrm{SiC}$ ) ceramic matrix composite (CMC) zircaloy-4 (Zr-4) hybrid fuel rodlet that may be tested in the INL Advanced Test Reactor (ATR) if the design is selected for further development and testing. Figure 2 shows the geometry of the LWRS capsule assembly design for the $\mathrm{SiC}-\mathrm{CMC}$ hybrid $\mathrm{Zr}-4$ cladding rodlet [3].

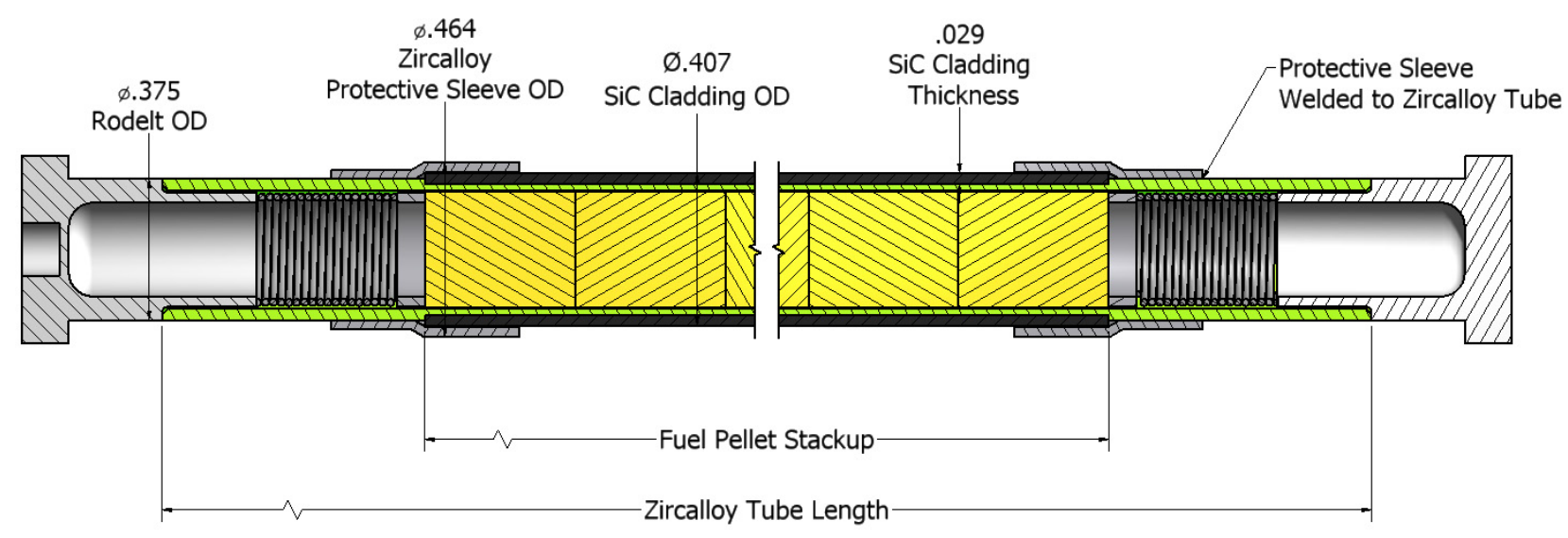

Figure 2. Geometry of the LWRS capsule assembly design for the Si-CMC hybrid Zr-4 cladding rodlet[3].

The objective of the gamma irradiation tests is to identify potential issues associated with the hybrid design under irradiation in a sealed, water filled container prior to insertion into the ATR where the rodlet would be exposed to the reactor primary coolant system. The gamma irradiator results presented in this report are for early hybrid design materials (denoted tests 1and 2) and although the results do not support ATR insertion readiness, results from these gamma irradiation tests support rodlet design changes and validate methods for examining chemical, mechanical and physical properties of the rodlet materials before and after irradiation. As this is a first of a kind design and the irradiation behavior is unknown, it was decided to perform the irradiation tests with hybrid samples and standard $\mathrm{Zr}$-4 tube samples as comparison of potential different behavior.

The purpose of this report is to describe all the details of the two gamma irradiation tests and reporting the materials, methods used and all the results with preliminary conclusions reached. This report does not include the examination results of the original manufactured tube from the vendor, Physical Sciences Inc. (PSI) from the first prototypes that had the Polymer Infiltration Pyrolysis (PIP) processed SiC-CMC on Zircodyne 702 directly (see Section 2.1.1 for short description of these samples). This will be discussed in a separate report.

Please note that this report is describing only the results relevant to the gamma irradiation tests and that the preliminary conclusions are based on these results only. These results needs to be integrated with the whole battery of "prototype" tests prescribed in the cold characterization plan [2]. Specifically, the heat up cycling and corrosion flow tests will provide additional information on the separate effects of water and temperature. 


\subsection{Quality Requirements}

The quality requirements are provided in the LWRS Quality Assurance Program Document (QADP) [4]. Work was performed under controlled conditions using test plans to perform characterization. As some tests were first of the kind and no prior test methods were available, the opportunity was taken during this execution of the tests, to update/redlining the draft test plans for improvement and future repeatability. Work directions were given during a weekly briefing meeting, as well as ad hoc meetings as necessary. Results are recorded in the laboratory note books in accordance with MCP-2875 [5]. Mock-up samples and SiC-CMC sleeve samples were received from the LWRS store located in INL EROB building accompanied by the "Activity sheet" and relevant quality labeling (eg green tag or white tag) (See Appendix A). The samples were registered in the lab C17a register and stored in the locked storage cabinet until use. All samples are well numbered and labeled at all times. Results, sketches and notes are recorded in dedicated LWRS characterization laboratory note books. Specific characterization results are also recorded in the specific qualified researcher's note book. The interpretation and conclusions of all characterization data are reported in technical reports. Inspection/measuring/characterization is done by qualified researchers and calibrated equipments or standards are used. Characterization plans and test plans for LWRS experiments will be placed under configuration control in the INL EDMS in accordance with LWP-1201 upon updating and approval [6].

\section{MATERIALS AND CHARACTERIZATION METHODS}

\subsection{Materials}

\subsubsection{Gamma Irradiation Test 1}

Samples from the preliminary SiC-CMC-Zr-4 hybrid cladding design were based on a chemically bonded braided outer SiC-CMC sleeve to Zircodyne 702. However, the high temperature bonding processing caused the inner Zircodyne 702 to embrittle and therefore not being representative and preventing the rodlets from being used for further testing. A decision was therefore made to continue with the development and testing of a non-bonded hybrid design. Due to the unavailability of final prototypes prior to the end of September 2011, a program decision was taken to proceed by re-using the braided sleeve of the initial prototypes by acid leached removal of the brittle $\mathrm{Zr}-702$ tube. One mini-rodlet tube mock-up sample (Figure 3) was prepared from SiC-CMC sleeves that had been acid leached to remove damaged (oxidized) inner Zircodyne (Zr-702) tubes. The SiC-CMC tubes were slid over a Zircaloy-4 (Zr-4) tube and oxidized $\mathrm{Zr}-4$ end caps were welded to produce the mini tube mock-up (called mini tube 1). The end caps were originally oxidized in an attempt to prevent chemical interactions between the aluminum ATR hardware (rodlet basket) and the Zr-4 end caps. An autogenous orbital weld (GTAW) technique was used to connect the $\mathrm{Zr}-4$ tube to the oxidized endcaps. The weld was performed using argon as a shielding gas but was not performed in a completely inert environment (i.e. in a glove box filled with argon). A second weld was performed using an autogenous laser weld with argon as a shielding gas to attach protective $\mathrm{Zr}-4$ sleeves to the $\mathrm{Zr}$-4 inner tube. The purpose of the $\mathrm{Zr}-4$ protective sleeves is to prevent the ends of the $\mathrm{SiC} \mathrm{SMC} \mathrm{braided} \mathrm{tubes} \mathrm{from} \mathrm{damage} \mathrm{during} \mathrm{high} \mathrm{water} \mathrm{flow} \mathrm{past} \mathrm{the}$ rodlet while in the ATR. The SiC-CMC tube has been handled with gloves and alcohol cleaning of metallic parts took place prior to the assembly of the mini tube. No special handling precautions were taken during the mini tube fabrication therefore bare hands likely touched the metallic parts. No cleaning was conducted after the mini tube fabrication and the mini tube 1 was gamma irradiated as fabricated.

In addition to the one mini-rodlet tube mock-up sample, 5 sets of small samples were prepared with designation 2 to 5 with sample $2 \mathrm{~W}$ given as example as shown in Figure 3. For each sample set, a second sample labeled with a "W" was included. This indicated that this sample were prepared (fabricated) identical to the original number, but was irradiated in an aqueous medium. Sample set 2 is representative of the mini tube sample 1 fabrication method and therefore un-bonded. Sample sets 3 to 5 were prepared using different bonding techniques for initial gamma irradiation evaluation. The samples were prepared 
by the fabrication/development principle investigator (PI) to be similar, although not representative of the LWRS-1 prototypes for development purposes. During fabrication of these development samples, gloves were used when handling the samples, but no sample cleaning took place after fabrication and samples were gamma irradiated as received. The detail of the samples is provided in Table 1. As only non-bonded hybrid tubes is foreseen to be irradiated in ATR, the initial characterization focused mainly on sample 2 and mini tube 1. Although characterization information is provided for the bonded samples as well, no final conclusions can be reached or recommendations made on the path forward, as this was the work scope placed on the author due to ITAR restrictions [2].

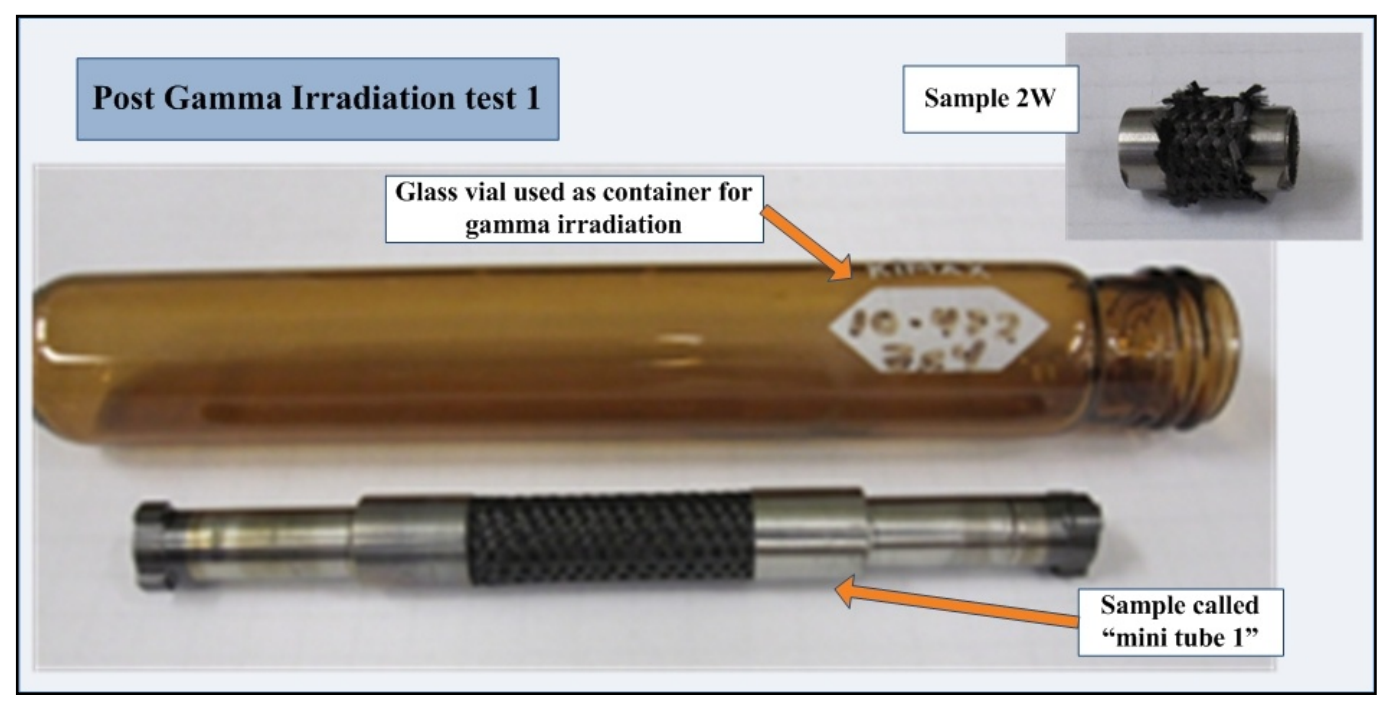

Figure 3. Figure showing mini-rodlet tube mock-up sample (mini tube 1) and glass vial used for gamma irradiation of mini tube 1 . Sample $2 \mathrm{~W}$ and the other samples were placed in similar glass vials.

Table 1. Sample description of Gamma Irradiation Test 1.

\begin{tabular}{|l|l|}
\hline Sample No & Fabrication History Description* \\
\hline 2 & Zircaloy 4 with CMC $(10-482)$ no bonding to Zr-4 tube \\
\hline $2 \mathrm{~W}$ & Zircaloy 4 with CMC $(10-482)$ no bonding to Zr-4 tube-in water \\
\hline 3 & Zircaloy 4 with CMC $(10-482)$ and PIP, bonded with Ceraset $\left(\mathrm{Ar}, 330^{\circ} \mathrm{C}\right)$ \\
\hline $3 \mathrm{~W}$ & Zircaloy 4 with CMC $(10-482)$ and PIP, bonded with Ceraset $\left(\mathrm{Ar}, 330^{\circ} \mathrm{C}\right)$-in water \\
\hline 4 & Zircaloy 4 with CMC $(10-482)$ and PIP \& graphite flakes, bonded with Ceraset $\left(\mathrm{Ar}, 330^{\circ} \mathrm{C}\right)$ \\
\hline $4 \mathrm{~W}$ & Zircaloy 4 with CMC $(10-482)$ and PIP \& graphite flakes, bonded with Ceraset $\left(\mathrm{Ar}, 330^{\circ} \mathrm{C}\right)$-in water \\
\hline 5 & Zircaloy 4 with CMC $(10-482)$ and PIP with carbon, bonded with Ceraset $\left(\mathrm{Ar}, 330^{\circ} \mathrm{C}\right)$ \\
\hline $5 \mathrm{~W}$ & Zircaloy 4 with CMC $(10-482)$ and PIP with carbon, bonded with Ceraset $\left(\mathrm{Ar}, 330^{\circ} \mathrm{C}\right)$-in water \\
\hline 6 & Zircaloy 4 only \\
\hline $6 \mathrm{~W}$ & Zircaloy 4 only-in water \\
\hline Mini tube 1** & Zircaloy 4 with CMC $(10-482)$ no PIP, end sleeves \& end cups welded \\
\hline $\begin{array}{l}\text { Base tube } \\
\text { LWRS-18-1 }\end{array}$ & Original manufactured tube from PSI from first prototypes (Not acid washed $)$ \\
\hline LWRS-67 & Representative Zr-4 sample for chemical analysis prior to gamma irradiation \\
\hline LWRS-68 & Representative Zr-4 sample for chemical analysis prior to gamma irradiation \\
\hline Non-bonded & Bonded \\
\hline
\end{tabular}

*Fabrication History description provided by fabrication/development PI

**Fabricated by the Design Engineer 


\subsubsection{Gamma Irradiation Test 2}

Two SiC-CMC sleeves were used in the gamma irradiation test 2 namely LWRS-1-6-A-1 and LWRS1-6-A-3. Both SiC-CMC tubes were PIP processed and were not acid leached. It was identified by the manufacturing PI and experiment manager that sample LWRS-1-6-A-1 is technically fully representative of the prototype samples which with the exception of small dimensional deviations and number of PIP cycles processed (still in the development stage). It was therefore decided to continue with the gamma irradiation test 2 to gain development knowledge for future decision making prior to ATR reactor insertion. Sleeve sample LWRS-1-6-A-1 was a 2 ply braided SiC-CMC sleeve which was 5 times PIP processed and LWRS-1-6-A-3 was a 1-ply, PIP processed using 5 cycles for comparative purposes. Figures 4 and 5 show the schematic presentation of the sampling plans for the sub-sample identification and the respective characterization on these two SiC-CMC sleeves. Due to the limited Zr-4 tube stock no mini tube was fabricated for the 1 ply SiC-CMC sleeve sample (LWRS-1-6-A-3). Please note that Figures 4 and 5 are schematic drawings only and therefore dimensions are approximate.

As in the case of mini tube 1, the SiC-CMC tube only has been handled with gloves and although the metallic parts were cleaned by alcohol after fabrication, no cleaning of the mini tube was done after assembly of the mini tube and therefore bare hands likely touched the metallic parts. Mini tube 2, LWRS1-6-A-1-3 and LWRS-1-6-A-3-1were gamma irradiated as fabricated. It needs to be noted that the subsample LWRS-1-6- A-1-2 was chemically cleaned prior to placement in the glass vial as to determine if cleaning attributed to different chemical composition of the vial water after gamma irradiation if compared with sub-sample LWRS-1-6- A-1-3.

Table 2. Sample description of Gamma Irradiation Test 2.

\begin{tabular}{|l|l|}
\hline Sample No & Fabrication History Description \\
\hline $\begin{array}{l}\text { 1-6-A-1-1 ** } \\
\text { Mini tube 2 }\end{array}$ & $\begin{array}{l}\text { Mock-up mini tube (Zr-4*** with SiC-CMC no bonding to Zr-4 tube) - in } \\
\text { water }\end{array}$ \\
\hline 1-6-A-1-2 & SiC-CMC only after chemically cleaned prior to glass vial insertion - in water \\
\hline $1-6-A-1-3$ & SiC-CMC only-in water \\
\hline $1-6-A-3-1$ & SiC-CMC only-in water \\
\hline Standard (LWRS-68) & Zr-4 only-in water \\
\hline
\end{tabular}

**Fabricated by the Design Engineer

***SEM-EDS analysis identify it as a Zr-Hf alloy and not Zr-4 (see section 3.2.6.3)

\subsection{Gamma Irradiation Method}

The Co-60 gamma irradiator at the INL is easily accessible and results can be obtained in a relatively short period of time. Therefore, the gamma irradiator can be used as a tool to evaluate potential issues prior to insertion into the ATR, particularly for materials with no prior history of irradiation exposure.

Gamma irradiation was conducted by a Nordion gamma cell 220E gamma irradiator with cobalt-60 source at a dose rate of $7.2 \mathrm{kGy} / \mathrm{hr}$ for 96 hours and 167 hours for the two tests respectively. Selected specimens were contained in synthetic ATR primary coolant system water to test the potential effect of constituent chemicals in the water affecting the experiment samples. The $\mathrm{pH}$ of this water was 5.07 and 5.03 respectively for the two tests. The total irradiation dose was $60 \mathrm{mRad}$ and the irradiation temperature was $50^{\circ} \mathrm{C}$ for Gamma Irradiation test 1 and the total irradiation dose was $104.6 \mathrm{mRad}$ and the irradiation temperature was $50^{\circ} \mathrm{C}$ for Gamma Irradiation test 2 . 


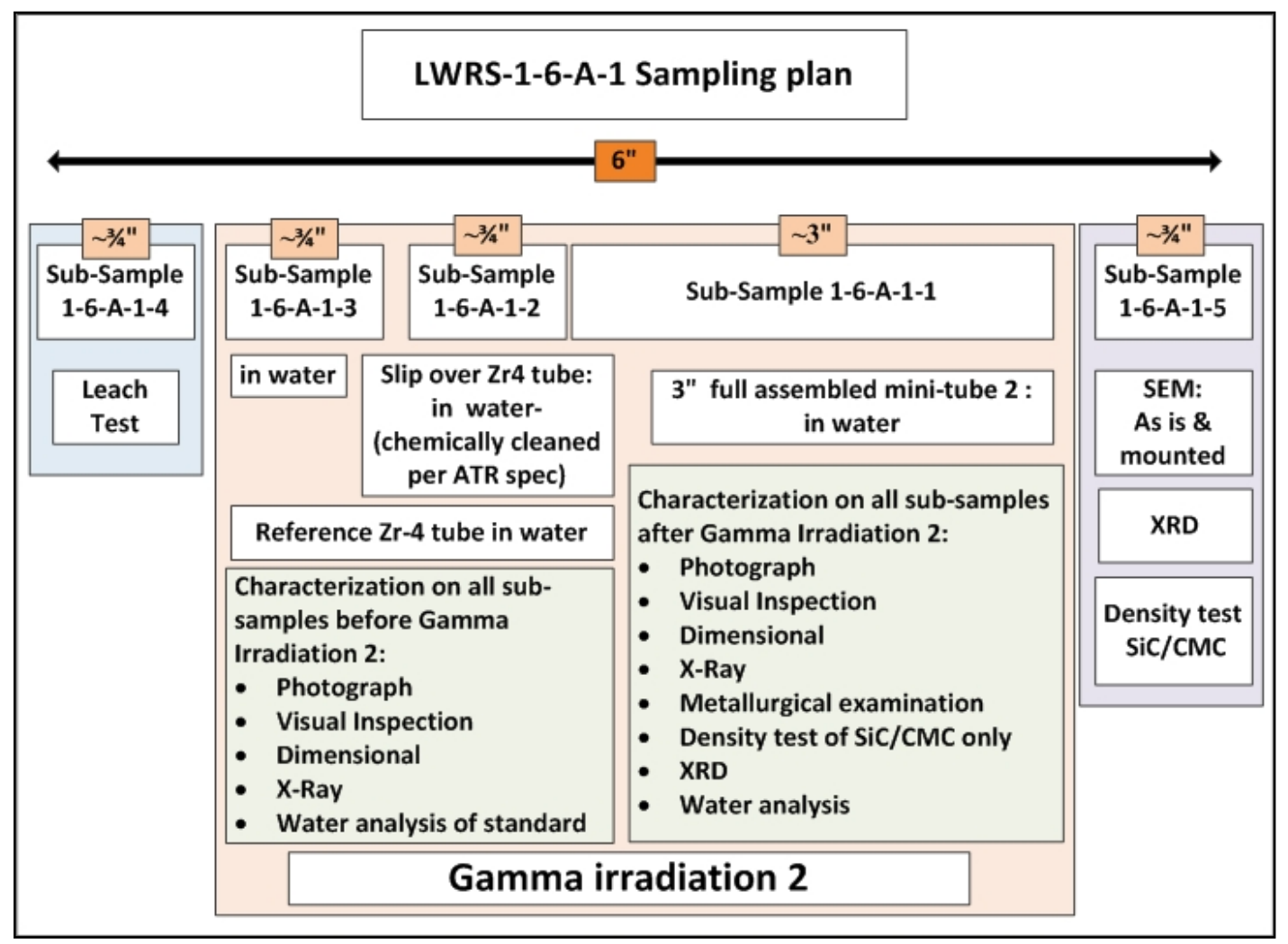

Figure 4. Schematic presentation of the sampling plan (sub-samples) and characterization planned for SiC-CMC sleeve samples LWRS-1-6-A-1.

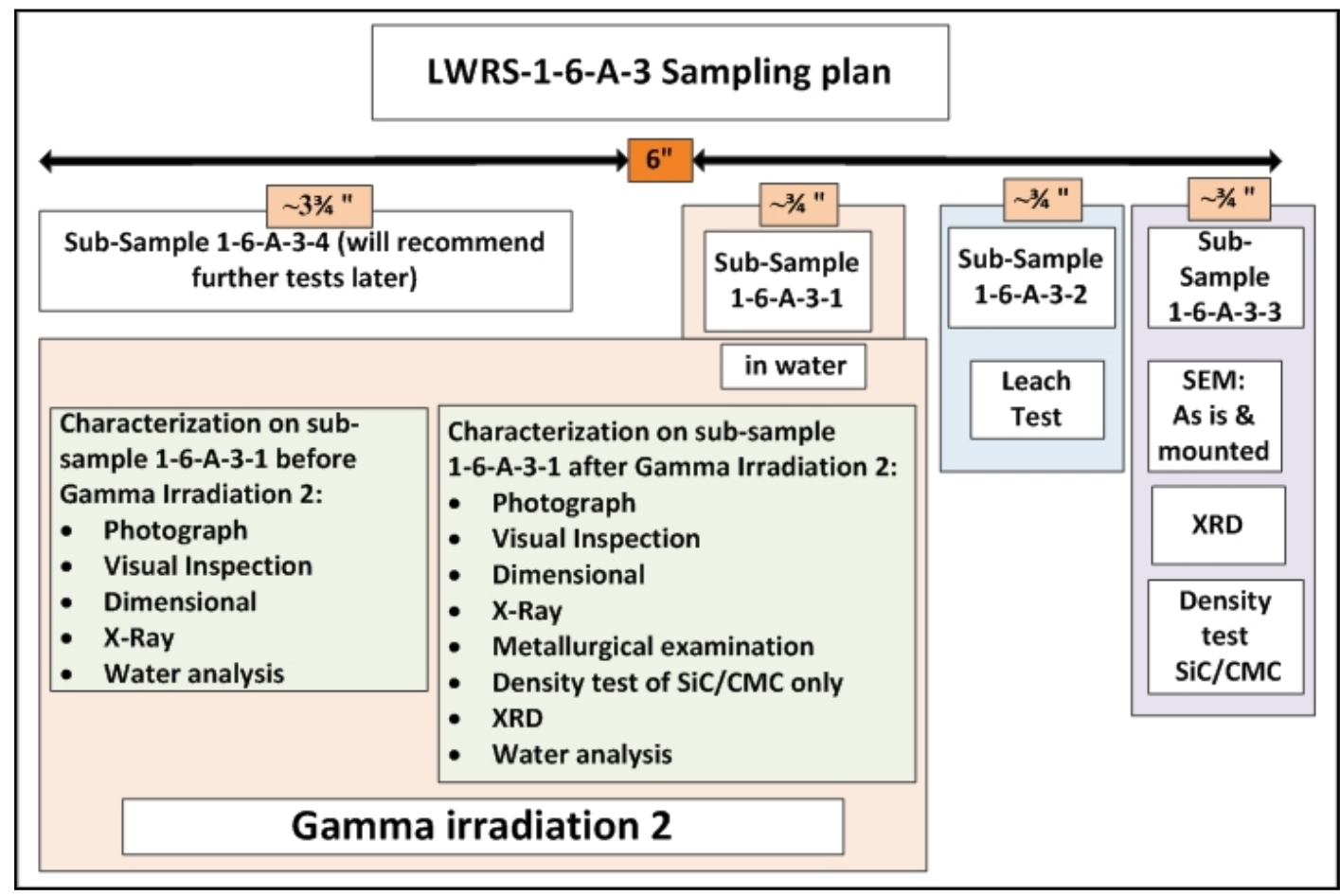

Figure 5. Schematic presentation of the sampling plan (sub-samples) and characterization planned for SiC-CMC sleeve samples LWRS-1-6-A-3. 


\subsection{Characterization Techniques}

The following characterization tests are executed prior to and after gamma irradiation and a justification of each characterization tests is provided below. For additional detail, see the Cold characterization test plan PLN-3927 [2] and in the Gamma Irradiation test plan PLN-3963 [7]. Please note that this report is describing only the results relevant to the gamma irradiation tests and that the preliminary conclusions are based on these results only. These results needs to be integrated with the whole battery of "prototype" tests prescribed in the cold characterization plan. Specifically, the heat up cycling and corrosion flow tests will provide additional information on the separate effects of water and temperature. Control sample tests were not performed for comparison to the gamma irradiation results. Without this information, definitive conclusions about the effect of gamma irradiation on the material properties cannot be determined. Additional tests should be performed with a control sample set to validate the results.

\subsubsection{Visual Examination, Dimensional, and Weight Measurements}

2.3.1.1 Summarized motivation. Visual examination will show possible fraying or defects or discoloration which may give an indication of any chemical reactions with the water during irradiation.

CMC sleeve and $\mathrm{Zr} 4$ tube may expand differently during irradiation due to irradiation structural changes and temperature effects. Dimensional information can be used for stress calculations and possible predictions of fretting behavior.

Weight variation may be an indication of the corrosive nature of both materials in typical ATR water environment (water in capsule was stagnant in gamma experiments).

2.3.1.2 Equipment and calibration. Dimensional and weight variances were determined for the test samples using a calibrated micrometer and balance. The dimensional inspection was completed in accordance with PLN-3961[8] and it focused on two parts namely the SiC/CMC tube and the Zr- 4 tube.

For gamma irradiation test 1 the dimensions were measured with a calibrated INL micrometer (\#713990; calibration expires 3/17/2012) and the weights with a calibrated INL balance (\#725 653; calibration expires 12/7/2011).

For gamma irradiation test 2 the dimensions were measured with a calibrated INL micrometer (\#713990; calibration expires 3/17/2012) and the weights with calibrated INL balances (\#715 461; calibration expires $04 / 04 / 2012$ and \#379862; calibration expires 8/25/2012) for the samples prior to gamma irradiation. The dimensions after gamma irradiation were measured using a caliper \#721466 with calibration due on $1 / 18 / 2012$.

All measurements were completed with equipment in known calibration status.

\subsubsection{X-ray Radiographic Inspection}

2.3.2.1 Summarized motivation. 2D X-ray technique is used to show bonding or surface properties between the two interfaces. This may be beneficial to show any possible fretting, defraying or corrosion activities on the interface. Although 3D Tomography is more ideal, it was not available for INL at the initial stages of this work and only introduced for the radiographic examination after the second gamma irradiation test.

2.3.2.2 Equipment and calibration. 2D Radiographic inspection was completed on the samples in accordance with PLN-3950 [9] using a Kevex model KM16010E-A serial \#29761 source with a Varian PaxScan 2520 detector.

The 3D Computed Tomography X-ray imaging system at the INL Research Center was designed by North Star Imaging of Rogers, MN. Possibly the most important components of the system are the extremely powerful graphical processing unit housed in the image reconstruction computer and the 
proprietary image processing software. Additional system components consist of a Hamamatsu $130 \mathrm{kVp}$ micro focus x-ray unit capable of producing approximately $10 \mu \mathrm{m}$ resolution images, a Varian PaxScan flat panel digital $\mathrm{x}$-ray detector, and a rotational stage.

\subsubsection{Water Chemical Analysis}

2.3.3.1 Summarized motivation. Selected water chemical analysis is done to measure changes due to chemical reaction during irradiation. These results may also give an indication of any leachable chemicals which may enter the ATR coolant water. The leach test [10] is used for assessment of whether or not ATR restricted chemicals [11] will leach into the test water from the specimen at greater than allowable concentrations. Leach tests shall be conducted per SP-10.3.1.13 [12] guidance on materials that will be exposed to the reactor coolant which contain compounds of halides or halogens such as chlorine/chlorides or sulfates in concentrations of individual halide/halogen or sulfate constituents exceeding $250 \mathrm{ppm}$ [11]. As the fabrication method includes a PIP process where chlorinated raw materials are used, the leach test was conducted on representative test pieces of the final fabricated and assembled hybrid tube.

2.3.3.2 Equipment and calibration. Chemical analysis was conducted via a Dionex ICS-3000 Ion Chromatograph with an Auto-sampler on water before and after gamma irradiation. The elements the specimen waters were analyzed for were fluoride, chloride and bromide. Fluoride, chloride, and bromide could instigate corrosion and also have neutron absorption cross sections that are significant; therefore they are undesirable in the specimen water in the setting of nuclear reactor. Chloride is especially undesirable and therefore is limited to a concentration of less than 0.1 parts per million in the primary coolant system chemistry. Example of the calibration standard and measurement on sample $2 \mathrm{~W}$ is attached in Appendix B.

\subsubsection{Metallurgical Examination}

2.3.4.1 Summarized motivation. Metallurgical Examination is necessary to examine the interface properties and again may suggest the initiation of hydrogen embrittlement or any other corrosion and/or abrasive activity. Possible surface metallurgical changes may also be observed due to irradiation and temperature interactions. Hydrogen content will be determined after neutron irradiation.

2.3.4.2 Equipment and calibration. Electron microscopic examination is described in PLN-3964 [13] and is executed using a Quanta 650 FEG SEM with the EDAX Triton package. The calibration is performed by the service engineer with a SIRA S170 Certified Test Specimen. This is a magnification standard that is copied from a NIST standard. 10 cubes on this test specimen is equivalent to $\sim 4.63$ microns. An archived image from the last calibration from this specimen is available. An old NBS standard is then used for an image and is measured against the known values and is also archived in the SEM laboratory. Measurements are well within specification for the instrument which is $+/-3 \%$. The NBS standard number is JY-55-VO.

\subsubsection{Density}

2.3.5.1 Summarized motivation. Density values will provide a metric for changes in porosity which may be later correlated to chemical reactivity and hydrogen embrittlement.

2.3.5.2 Equipment and calibration. Density measurements are described in PLN-3957 [14] and are based on an ASTM (Standard Test Methods of Powder Metallurgy (PM) Materials Containing Less than Two Percent Posity-ASTM B 311-08) method [15] that doesn't require a calibration.

Density measurements for gamma irradiation test 1 were using a Mettler Toledo AG204 DeltaRange balance (INL \#715461) with a valid calibration with expiration date of 04/04/2012 (valid at time of measurements during December 2011). The measurements were completed at room temperature and weighing was executed with a balance with a sensitivity of $0.0001 \mathrm{~g}$ and density values are rounded off to the nearest $0.01 \mathrm{~g} / \mathrm{cm} 3$. Results are recorded in Arnold Erickson's log book \#6, pages 79-77 and 79. 


\subsubsection{X-ray Diffraction (XRD)}

2.3.6.1 Summarized motivation. XRD is completed to determine the actual $\mathrm{SiC}$ phase(s) and possible changes due to irradiation.

2.3.6.2 Equipment and calibration. X-ray diffraction patterns were measured using a BrukerAXS D8-A25 in parallel beam mode at $40 \mathrm{kV}$ and $40 \mathrm{~mA}$. Parallel beam (PB) mode is created by a "Gobel Mirror" in the incident beam and removes sample displacement error that would be very apparent in the traditional Bragg/Brentanno mode because of the round sample. In PB mode the incident copper $\mathrm{k}$ alpha 1 and 2 hits the center of the sample in a narrow band about $13 \mathrm{~mm}$ long. The samples were set in some glazier putty diagonally to expose as much of the surface area. The information collected was matched with Bruker-AXS EVA software version 14.0 with a 2008 ICDD PDF-2 data base. Detection limit for a phase (element or compound) is greater than $5 \mathrm{w} \%$.

Phase identification (search and match on Bruker's "EVA" software) uses Powder Diffraction Files (PDF) purchased from The International Centre for Diffraction Data or ICDD. These files normally report powder samples that contain very little texture also known as preferred orientation. Solid materials often have texture and do not follow the peak height or more recently peak area as reported by the PDF. The peaks themselves occur when diffraction occurs along a crystallographic plane.

A NIST alumina standard 1976 using the A12O3 104 peak the tolerances below in 2Theta need to be met:

- 2theta for Bragg Brentano $(\mathrm{BB})=35.149+/-0.02$

- 2 theta for Parallel Beam (PB) $=35.138+/-0.02$

\section{RESULTS AND DISCUSSION}

\subsection{Gamma Irradiation Test 1}

\subsubsection{Visual Examination}

Figures 6 and 7 show the comparative images for the mini tube (sample 10-472 Zr4) and samples 2 to 5 , prior to and post gamma irradiation respectively. Although the images of the samples before gamma irradiation were taken in the glass vial which obscures the images slightly, the visual examination shows no significant changes due to gamma irradiation. Differences are noted due to the different bonding techniques.

\subsubsection{Dimensional and Weight Measurements}

Dimensional variances were determined for the test samples and are presented in Figure 8 with the detail of these measurements reported in Appendix C. No significant diameter differences were observed of the non-bonded $\mathrm{SiC} / \mathrm{CMC}$ tube samples during gamma irradiation between the samples irradiated in water and without water. Length variances up to $+10 \%$ of samples irradiated was observed for the $\mathrm{SiC} / \mathrm{CMC}$ tube samples in both gamma irradiations with water or without water. The weight variances for both the bonded and non-bonded tube samples were very small with values up to $+0.34 \%$. Significant changes however are noted in length and diameter changes for the three sets of bonded sleeves with variances up to $+21 \%$ in length after gamma irradiation in water. Generally the length variances are higher for the bonded sleeves in water with the exception of sample 5. The development PI will evaluate this trend. The diameter change does not follow the same trend; in this instance sample 3 has a smaller diameter variance in water if compared to the sample without water. At this stage it is not conclusively of the trends observed are due to the irradiation, water of temperature effects. 


\section{Mini tube 1 (Sample number 10-482 Zr-4)}

\section{Before gamma irradiation}

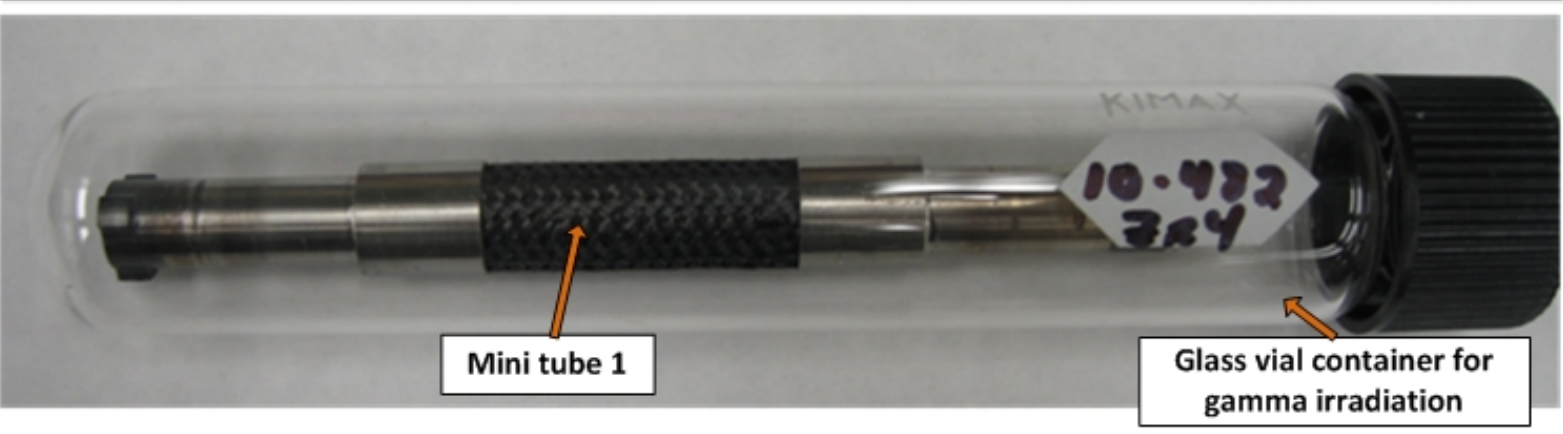

\section{After gamma irradiation}

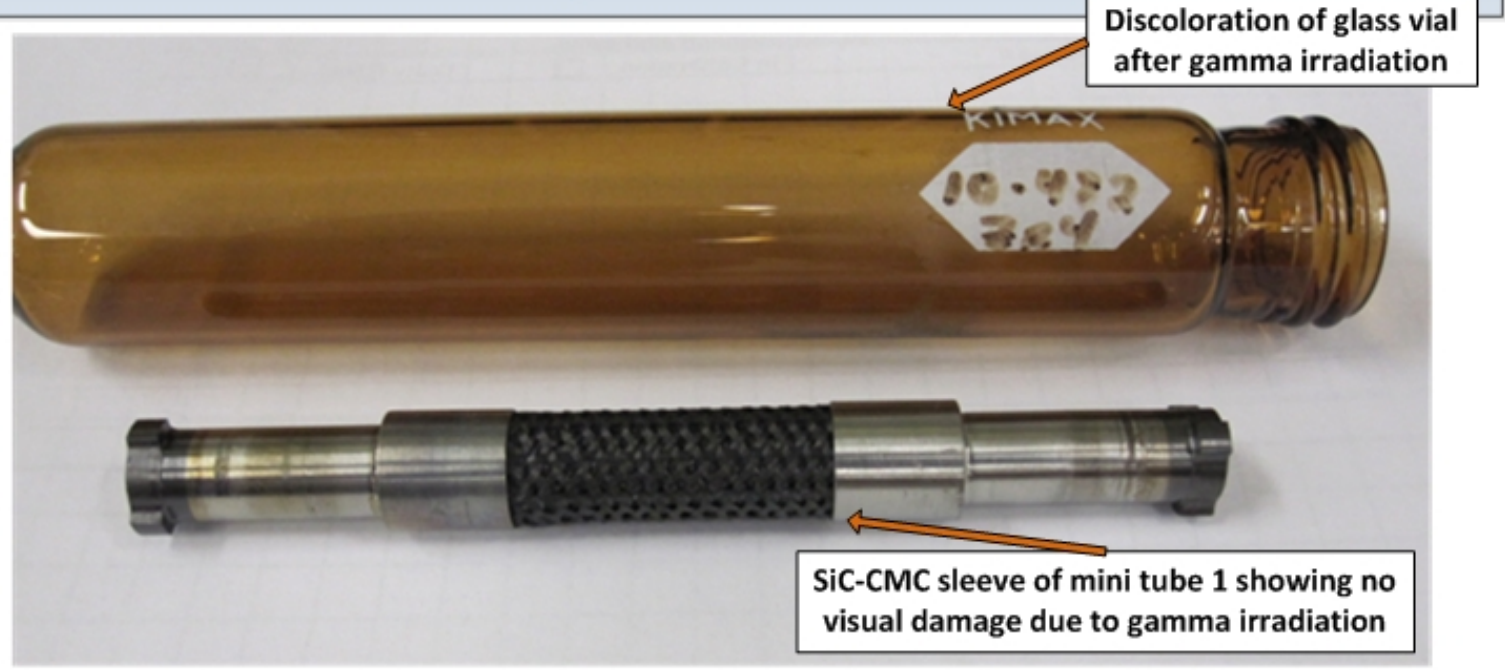

Figure 6. Figure showing comparative images of the mini-tube (sample 10-482 Zr-4). Although the images of the samples prior to gamma irradiation were taken in the glass vial which obscures the image slightly, the visual examination shows no significant changes due to gamma irradiation. 


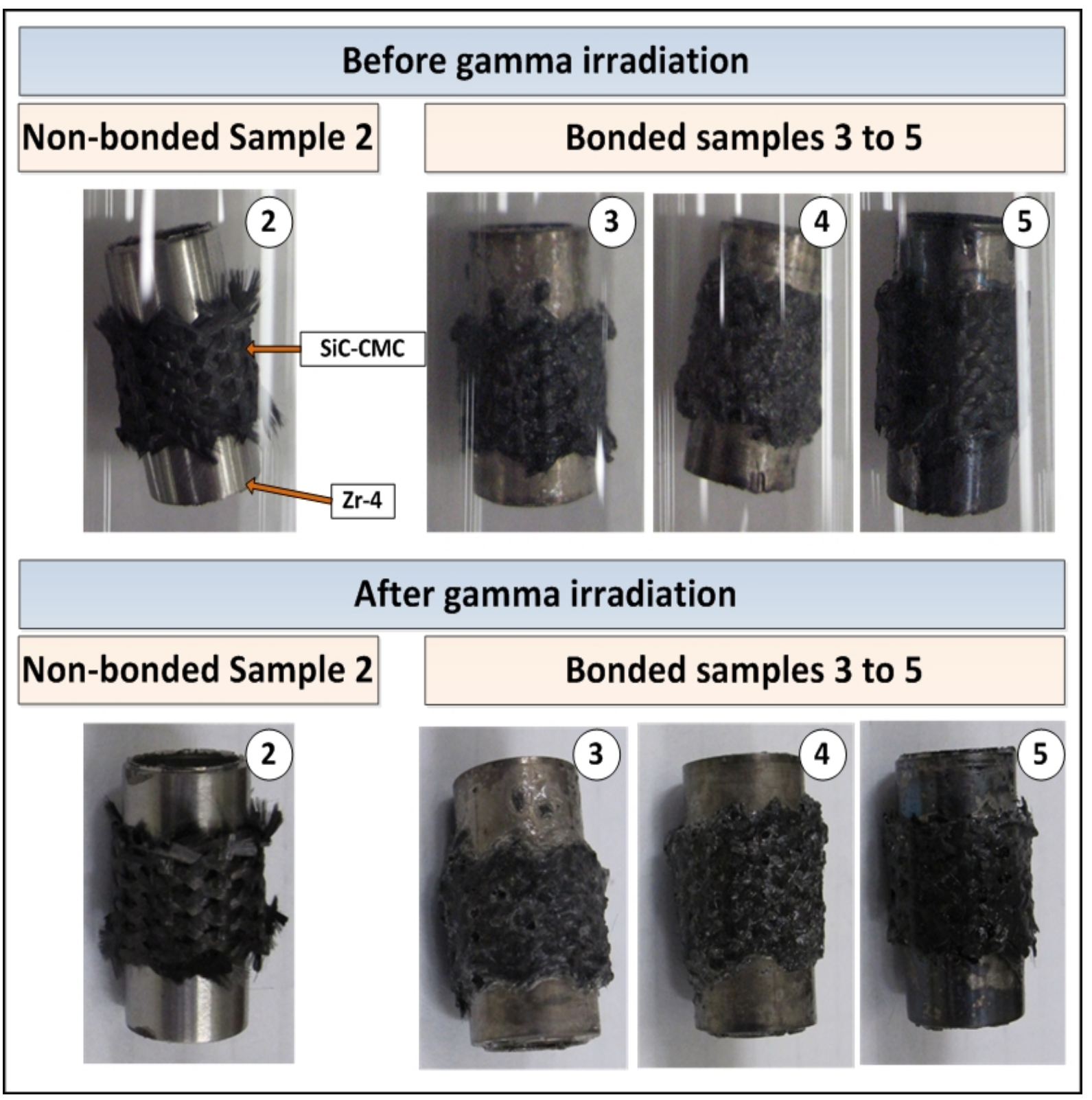

Figure 7. Figure showing comparative images of samples 2 to 5. Although the images of the samples before gamma irradiation were taken in the glass vial which obscures the images slightly, the visual examination shows no significant changes due to gamma irradiation. Differences are noted due to the different bonding techniques. 


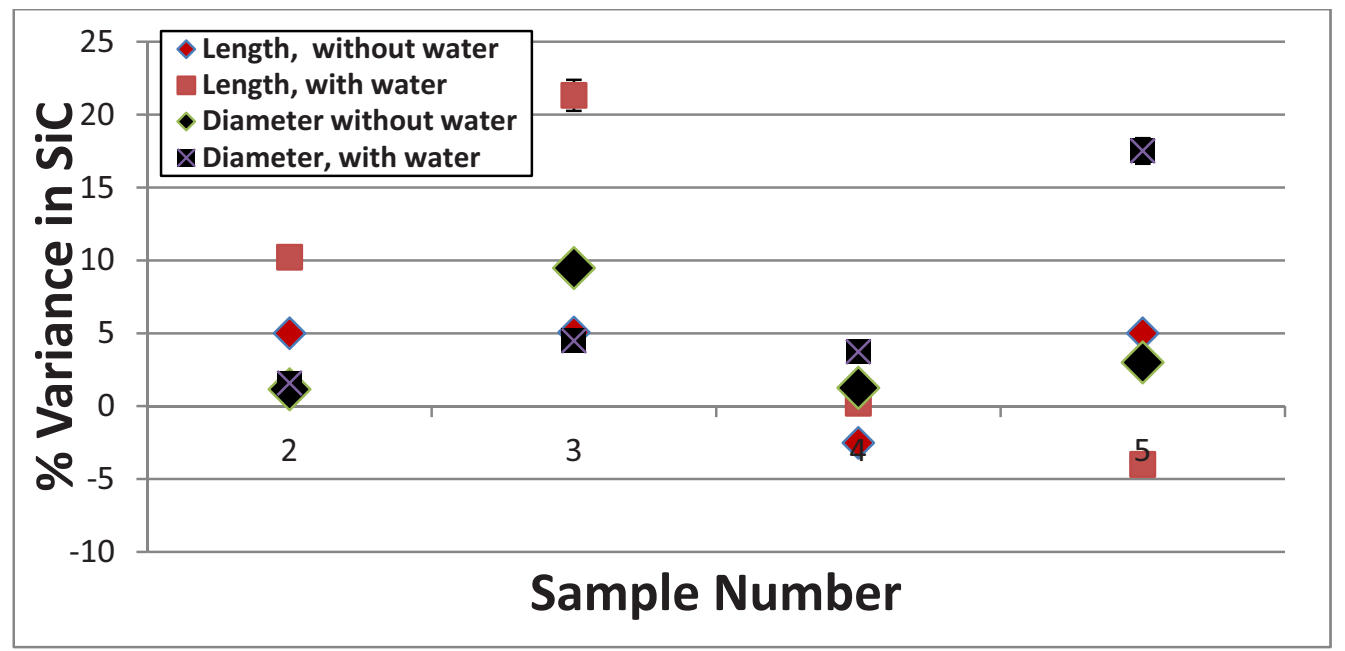

Figure 8. Figure showing the variance in length and diameter of the $\mathrm{SiC} / \mathrm{CMC}$ sleeve due to gamma irradiation.

\subsubsection{2-D X-ray Radiographic Inspection}

2D radiographic inspection was completed only as an initial trial to determine the benefits there-of as a characterization technique. This examination provided information on the gap between the SiC-CMC sleeve and the Zr-4 tube and some elementary detail could be seen also on the braided profiles (Figure 9). No open porosity was identified using this technique. This is not a conclusive finding regarding porosity and is only relevant to the areas examined. No changes were observed when comparing the x-ray maps taken before and after gamma irradiation as shown in Figure 9. The end caps also showed sound weld integrity as x-rayed in the prescribed four rotation directions. Furthermore, no differences between the bonded samples and non-bonded samples could be identified using the 2D x-ray technique (Figure 10). It is recommended that $3 \mathrm{D}$ tomography be utilized for future work.

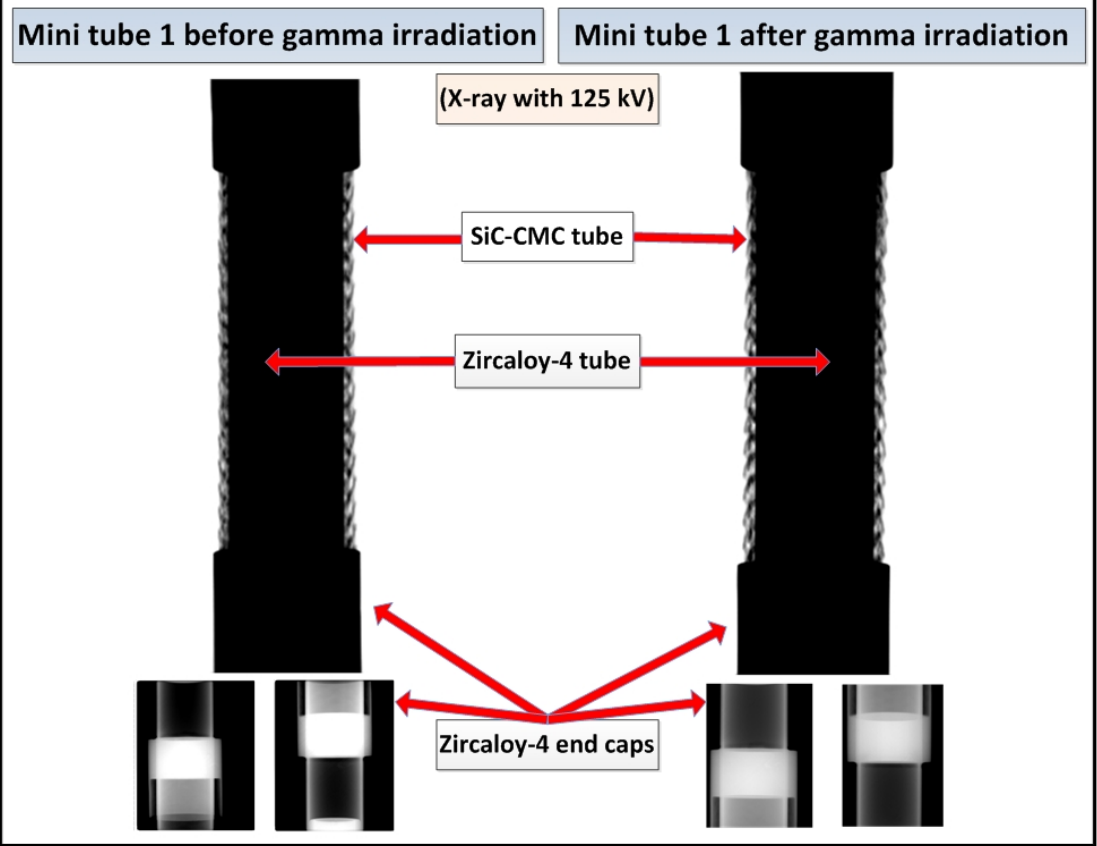

Figure 9. Example of the x-ray radiographic examination completed on the mock-up mini tube used in the first gamma irradiation experiment. 


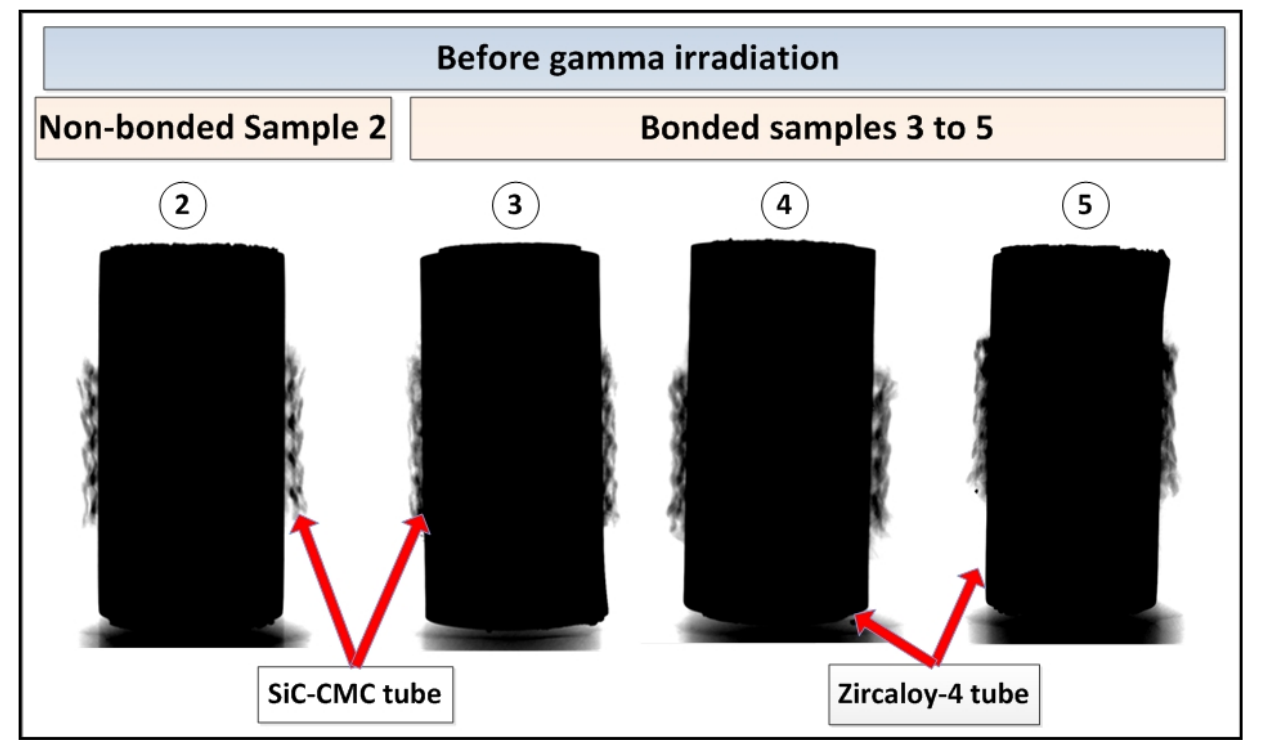

Figure 10. X-ray radiographic micrographs showing the 2D x-ray technique used is not sensitive enough to show visual differences between the non-bonded and bonded samples.

\subsubsection{Chemical Analysis}

3.1.4.1 Leach testing on CMC fibers. The original fibers were tested to ensure lot compliance before the $\mathrm{SiC}$ tubes were braided. Each lot of $\mathrm{SiC}$ fiber was qualified as compliant with the ATR water specifications as shown in Table 3. The specifications are given in SP-10.3.1.13 (referencing SAR-153) [12] as being below $250 \mathrm{ppm}$ individually, or combined $500 \mathrm{ppm}$ of ions.

Table 3. Original SiC-CMC Fiber Sample Results for Ion Chromatography ( $1 \mu \mathrm{g} / \mathrm{mL}$ is equivalent to 1 ppm.)

\begin{tabular}{|l|r|r|r|}
\hline \multicolumn{1}{|c|}{ Sample } & $\boldsymbol{\mu g} \mathbf{F} \backslash \mathbf{m L}$ & $\boldsymbol{\mu g} \mathbf{C l} \backslash \mathbf{m L}$ & $\boldsymbol{\mu g} \mathbf{B r} \backslash \mathbf{m L}$ \\
\hline 57A & $<0.393$ & 10.538 & $<0.024$ \\
\hline 57B & $<0.393$ & 5.559 & $<0.024$ \\
\hline 58A & $<0.393$ & 8.136 & $<0.024$ \\
\hline 58B & $<0.393$ & 4.510 & $<0.024$ \\
\hline 59A & $<0.393$ & 1.516 & $<0.024$ \\
\hline 59B & $<0.393$ & 1.161 & $<0.024$ \\
\hline 60A & $<0.393$ & 0.730 & $<0.024$ \\
\hline 60B & $<0.393$ & $<0.073$ & $<0.024$ \\
\hline 61A & $<0.393$ & 0.146 & $<0.024$ \\
\hline 61B & $<0.393$ & $<0.073$ & $<0.024$ \\
\hline 62A & $<0.393$ & $<0.073$ & $<0.024$ \\
\hline 62B & $<0.393$ & $<0.073$ & $<0.024$ \\
\hline 63A & $<0.393$ & $<0.073$ & $<0.024$ \\
\hline 63B & $<0.393$ & $<0.073$ & $<0.024$ \\
\hline
\end{tabular}


3.1.4.2 Leach testing on SiC-CMC braided sleeve. No leaching was conducted on the reworked sleeves and water chemistry was only measured after gamma irradiation. Leach testing was not performed on these samples because:

- This sleeves were acid etched prior to sample fabrication

- History of this fabrication is not known to the author of this report due to ITAR restrictions

- No duplicate samples were provided by the development/fabrication PI prior to gamma irradiation test

- Limited timeframe available for the insertion in gamma reactor due to the push to irradiate quickly in the ATR subsequently caused that information was required in a very short time frame.

3.1.4.3 Zircaloy-4 tubes. The Zircaloy-4 tubes were received with certification from the vendor. As part of the non-disclosure agreement, no third party chemical analysis was allowed. Attached in Appendix D includes the typical analysis of Zircaloy-4 and Zircodyne-702. Typically detail analysis verification of the $\mathrm{Zr}-4$ tube composition forms not part of the characterization work scope as the verification took place during the receiving inspection stages.

As part of the metallurgical examination of the gamma irradiation parts, representative unirradiated $\mathrm{Zr}-4$ samples were examined as a baseline to determine the surface condition and the main chemical elements using SEM-EDS. The primary elements were identified as $\mathrm{Zr}, \mathrm{Sn}, \mathrm{C}, \mathrm{O}$ and $\mathrm{N}$ as shown in Figure 11. This analysis cannot be used as a quantitative measure, but it confirms only that this material is not a Zircodyne alloy as no $\mathrm{Nb}$ and $\mathrm{Hf}$ was identified. An EDS analysis on the actual mini-tube 1 was also completed and found to be in the typical Zr-4 chemical composition range.

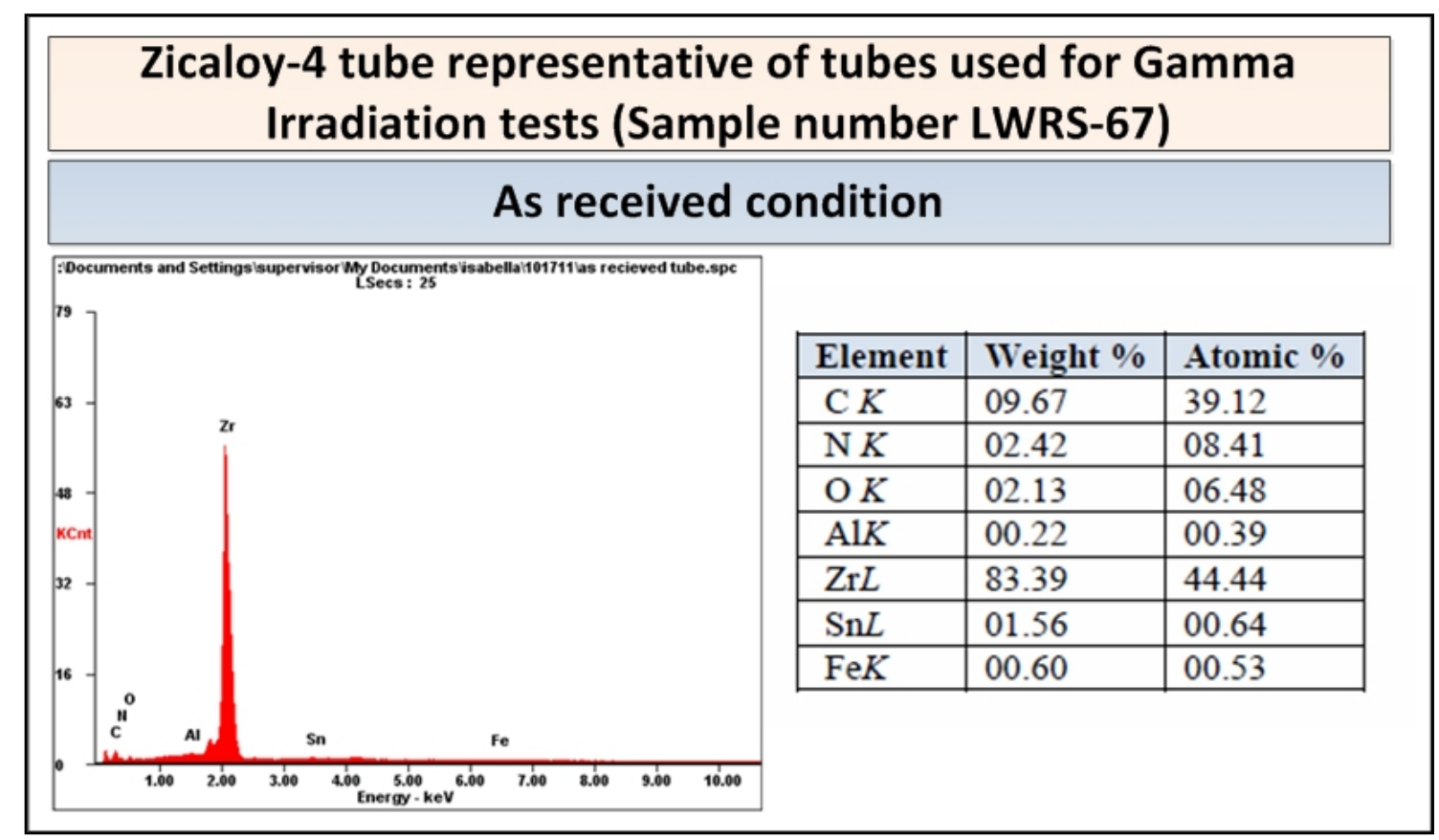

Figure 11. SEM-EDS analysis of the Zr-4 tube used for the gamma irradiation tests (sample number LWRS-67).

3.1.4.4 Experiment water analysis after gamma irradiation. The water analysis results are summarized in Table 4. Figure 12 shows an increase in $\mathrm{Cl}$ and $\mathrm{F}$ due to gamma irradiation. The high $\mathrm{F}$ value for sample $2 \mathrm{~W}$ may be due to the $\mathrm{HF}_{-} \mathrm{HNO}_{3}$ acid leach performed on the $\mathrm{SiC}-\mathrm{CMC}$ sleeve. The other acid leached sleeves were further treated with different bonding processes, therefore preventing the 
release of $\mathrm{F}$. It is interesting to note that even the standard $\mathrm{Zr}-4$ sample (without a SiC-CMC sleeve, sample $6 \mathrm{~W}$ ) showed a $\mathrm{Cl}$ increase which is not fully understood, although it is slightly lower than the hybrid samples. Water analysis results show a significant increase in Si in the bonded samples 3 to 5 and a slight increase in $\mathrm{Al}$ due to gamma irradiation (Figure 13). The main observations from these results are that the bonded samples released both $\mathrm{Si}$ and $\mathrm{Cl}$ (Figures 12 and 13) which is indicative of debonding and/or dilution of the bonding agent. The metallurgical examination confirms this finding (see Section 3.1.5).

Table 4. Water analysis after gamma irradiation test 1 compared to the water analysis before the gamma irradiation test 1 .

\begin{tabular}{|c|c|c|c|c|c|c|c|}
\hline Sample number & F (ppm) & Cl ppm) & $\mathrm{Br}(\mathrm{ppm})$ & $\begin{array}{c}\text { Al dissolved } \\
(\mathbf{p p b})\end{array}$ & $\begin{array}{c}\mathrm{Fe} \\
\text { dissolved } \\
(\mathrm{ppb}) \\
\end{array}$ & $\begin{array}{c}\mathrm{Cu} \\
\text { dissolved } \\
(\mathrm{ppb})\end{array}$ & Si (ppm) \\
\hline ATR Normal range & ST & $<0.05$ & ST & $1.5-4.0$ & $0.5-2.0$ & $0.2-2.0$ & NS \\
\hline ATR Control limit & ST & $<0.1$ & ST & 6.0 & 15 & 15 & NS \\
\hline $\begin{array}{l}\text { Water before gamma } \\
\text { irradiation test } 1 \text { (no } \\
\text { contact with SiC-CMC) }\end{array}$ & $<0.393$ & 0.228 & $<0.024$ & $0.575-0.671$ & NM & NM & 0.093 \\
\hline $\begin{array}{l}2 \mathrm{~W} \\
\text { (after gamma irradiation) }\end{array}$ & 1.578 & 0.861 & $<0.024$ & 2.637 & NM & NM & 3.438 \\
\hline $\begin{array}{l}3 \mathrm{~W} \\
\text { (after gamma irradiation) }\end{array}$ & 0.470 & 1.013 & $<0.024$ & 4.966 & NM & NM & 31.86 \\
\hline $\begin{array}{l}4 \mathrm{~W} \\
\text { (after gamma irradiation) }\end{array}$ & 0.522 & 0.981 & $<0.024$ & 4.471 & NM & NM & 43.22 \\
\hline $\begin{array}{l}5 \mathrm{~W} \\
\text { (after gamma irradiation) }\end{array}$ & 0.685 & 1.182 & $<0.024$ & 4.753 & NM & NM & 44.78 \\
\hline $\begin{array}{l}\text { 6W } \\
\text { (after gamma irradiation) }\end{array}$ & $<0.393$ & 0.836 & $<0.024$ & $\begin{array}{l}<0.158 \\
\mu \mathrm{g} / \mathrm{mL}\end{array}$ & NM & NM & 0.898 \\
\hline
\end{tabular}

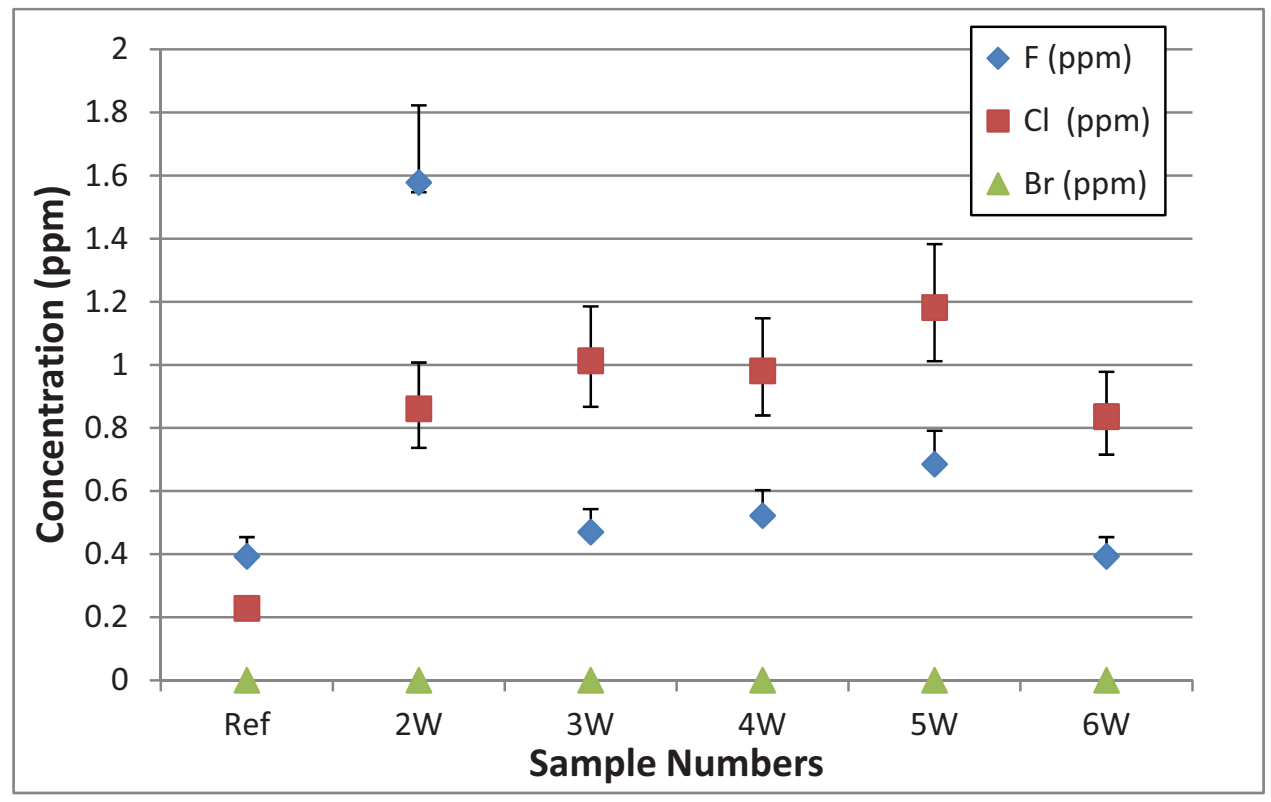

Figure 12. Water analysis results show an increase in $\mathrm{Cl}$ and $\mathrm{F}$ due to the gamma irradiation test. 


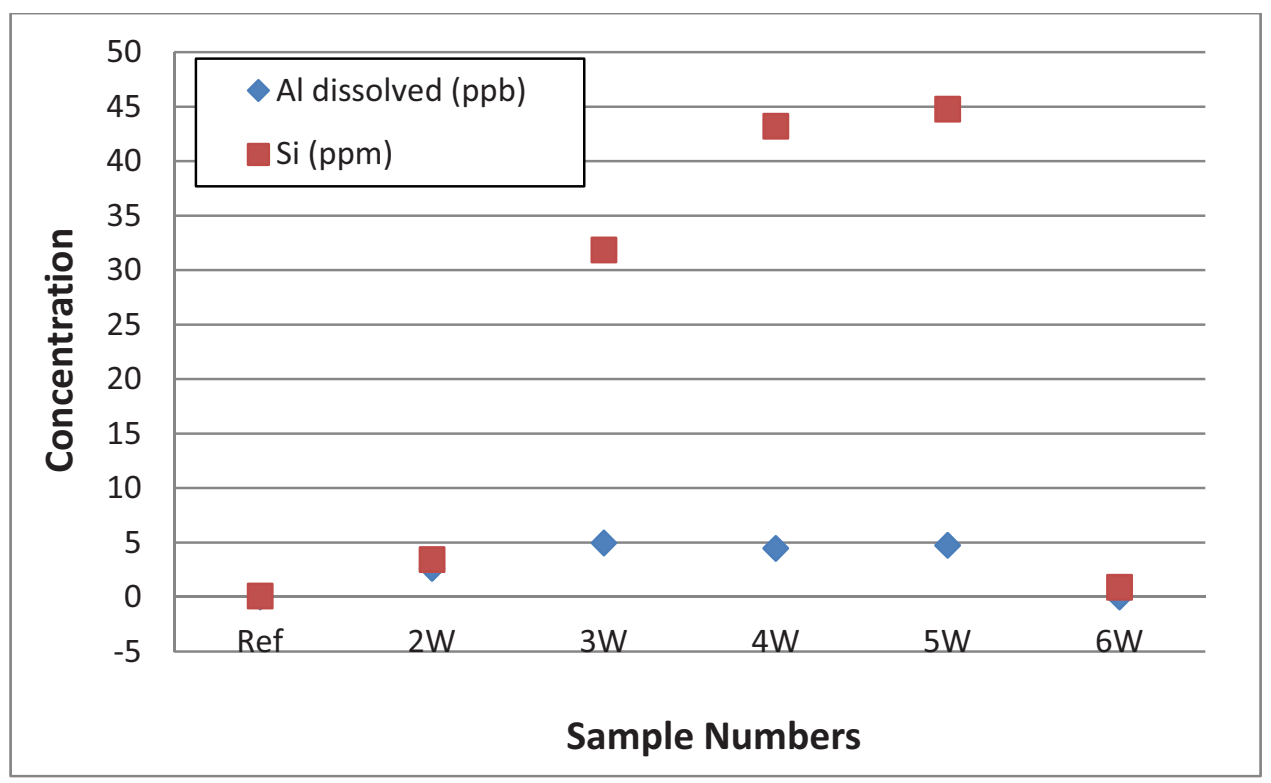

Figure 13. Water analysis results show a significant increase in $\mathrm{Si}$ in the bonded samples 3 to 5 and a slight increase in $\mathrm{Al}$ due to gamma irradiation test (mean \% error $-0.8 \pm 1.3$ and $0.9 \pm 0.3$ for $\mathrm{Al}$ and $\mathrm{Si}$ respectively).

\subsubsection{Metallurgical Examination}

Metallurgical examinations of the mini tube and the samples 2 to 6 were completed in accordance with PLN-3964 [13] using scanning electron microscopic examination and EDS analytical techniques. This examination's main focus was to investigate possible metallurgical changes in both the $\mathrm{Zr}-4$ tubes as well as in the SiC-CMC sleeve due to processing (fabrication) and/or irradiation effects. The interface properties are also examined as this may give indications of possible fretting, corrosion and/or erosion activities which may result in decreased life expectancy of the fuel cladding. Changes to the planned measurement locations were made at the discretion of the Characterization Principle Investigator (PI) and is reported in this section.

3.1.5.1 Non-bonded sleeves (mini tube and samples 2 and $2 W$ ). The metallurgical examination plan of the mini tube is shown in Figure 14 and examinations were performed on the identified positions $1,2 \mathrm{a}$ and $2 \mathrm{~b}$. It was decided to exclude examination of the cross sectional locations 3 and 4 based on the information collected on positions $2 \mathrm{a}$ and $2 \mathrm{~b}$ showing that the mini tube deviates too much from the planned prototypes.

The following main findings were made based on the metallurgical examination of the mini tube and the non-bonded samples 2 and $2 \mathrm{w}$ :

- Longitudinal section of the laser welds show full penetration and no defects (Figure 15).

- PIP matrix material seems to be removed by the $\mathrm{HF}-\mathrm{HNO}_{3}$ leaching, thus the mini-tube is not representative of the real prototypes (Figure 16).

- Although some loose fibers are observed at the Zircaloy-4 sleeve end side, it cannot be concluded that it is due to the gamma irradiation. No other obvious differences were observed between the SiC-CMC structure between the locations $2 \mathrm{a}$ and $2 \mathrm{~b}$ (Figure 16). Only remaining "flakes" of the PIP matrix are visible and the SEM-EDS analysis in two areas shows that the flakes are mainly $\mathrm{Si}, \mathrm{C}$, and $\mathrm{O}$ (Figures 17 and 18).

- Figure 19 shows the pitted surface on the sample 2W Zircaloy-4 tube with no significant chemical reactions (pitting) observed on the surface of sample 2. 
- The SEM metallurgical examination (Figure 20) of two representative samples (LWRS-67 and LWRS-68) of the Zircaloy-4 tubes used for the gamma irradiation experiments show the expected fabrication marks. However, sample LWRS-67 has already a pitted surface as received for analysis (not irradiated) which made the interpretation on the corrosion surfaces observed after gamma irradiation nearly impossible. EDS analysis of the pitted surface revealed no element explaining the corrosion (detail of these EDS analysis is shown in Appendix E). This report does not offer conclusive explanations for the corroded condition of the $\mathrm{Zr}-4$ tube as supplied for characterization, although one reason may be due to uncontrolled storage conditions of the raw material in the development laboratory.

- A thin layer of changed microstructure is observed on the inside of the $\mathrm{Zr}-4$ tube of sample $2 \mathrm{~W}$ (Figure 21). However, a SEM- EDS analysis showed similar chemical composition (Figure 22) and the SEM-EDS technique are not sensitive enough to quantify small changes. The micrograph in Figure 21 also show indications of a rougher inner surface of the Zr-4, however, this is not quantified. This thin layer was however not observed in the sample 2 which was not irradiated in water. For future work EBSD and TEM are recommended. No significant differences were observed if the outside diameter microstructures of the two samples are compared (Figure 23).

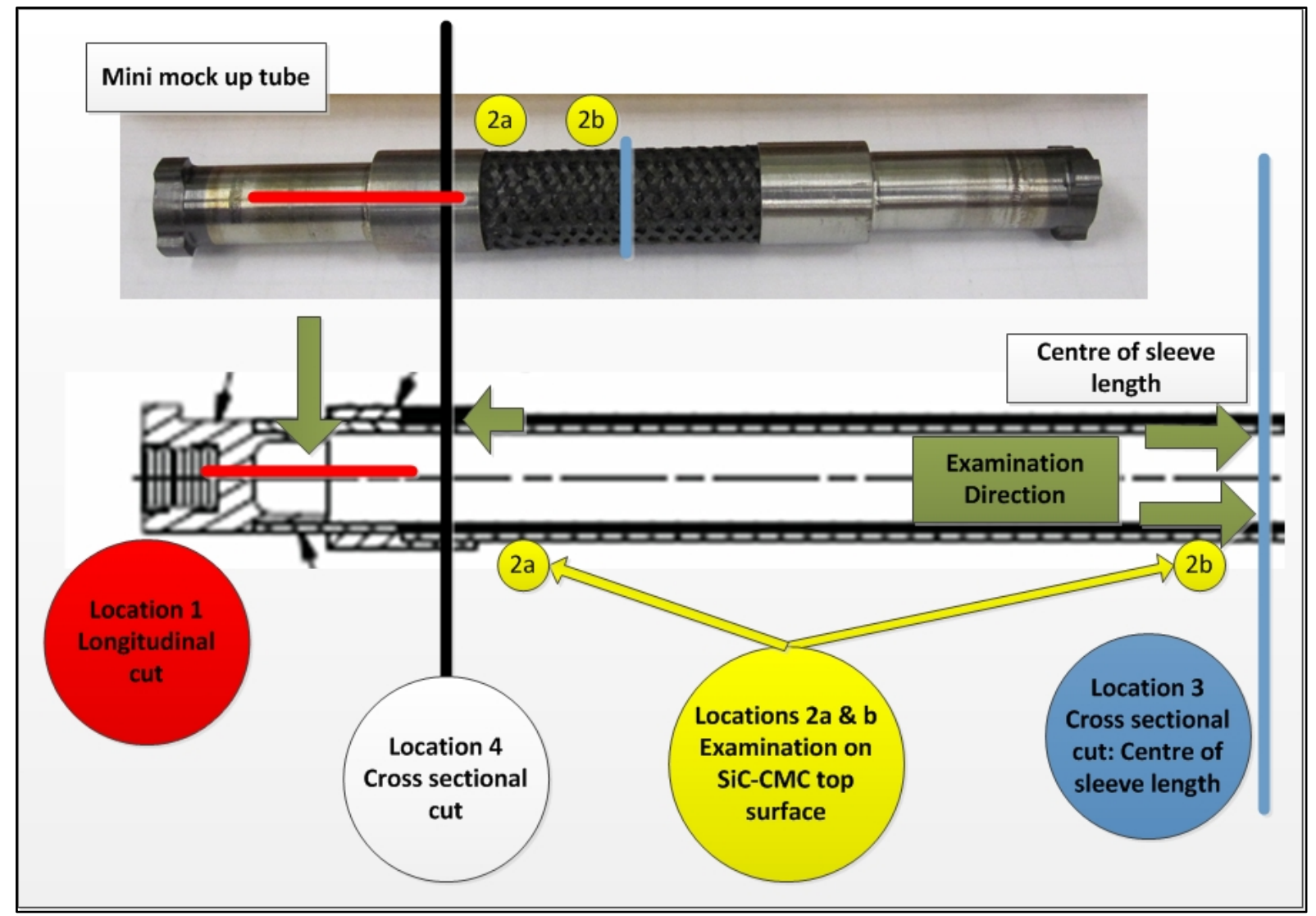

Figure 14. Planned sub-sample locations identification for the metallurgical examination of the mini tube (sample 10-472 Zr-4). 


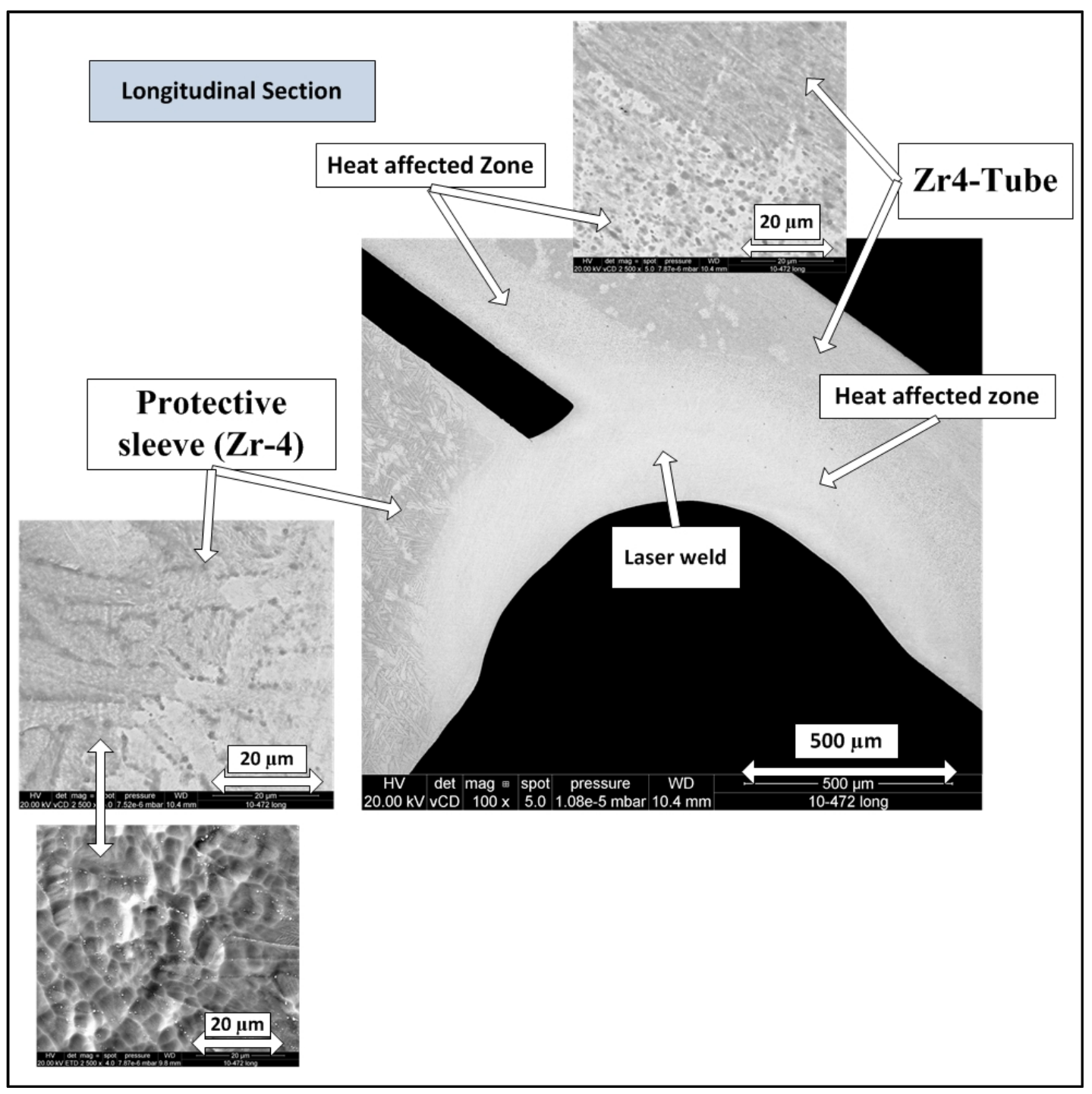

Figure 15. SEM micrographs showing the metallurgical examination of the longitudinal cut (location 1) through the welds of mini tube (sample 10-472 Zr-4). Full weld penetration is noted with no defects visible. 


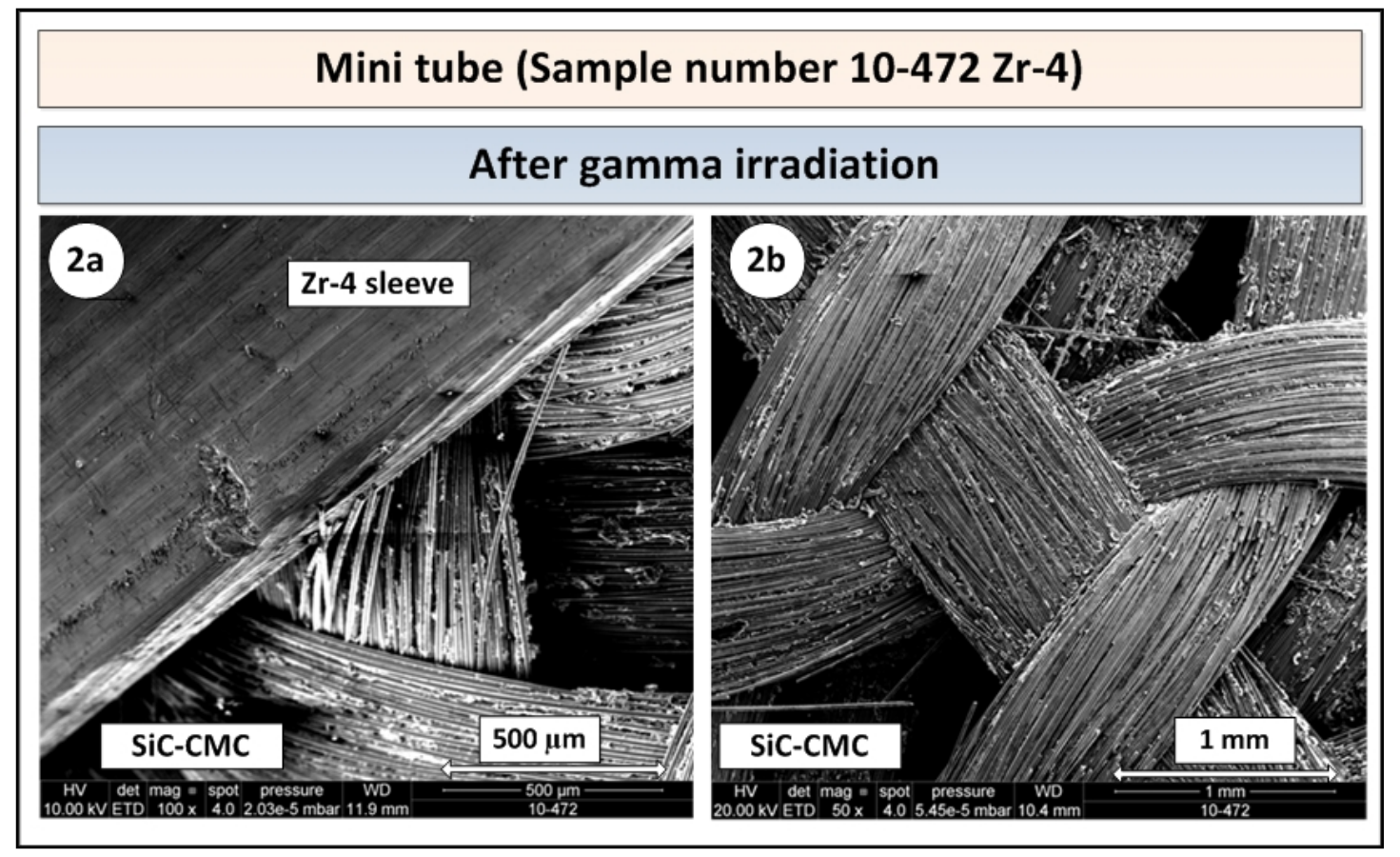

Figure 16. SEM metallurgical examination of the mini tube (sample 10-472 Zr-4) at locations $2 \mathrm{a}$ and $2 \mathrm{~b}$ after gamma irradiation. PIP matrix seems to be removed by the $\mathrm{HF}-\mathrm{HNO}_{3}$ leaching, thus the mini-tube 1 is not representative of the real prototypes.

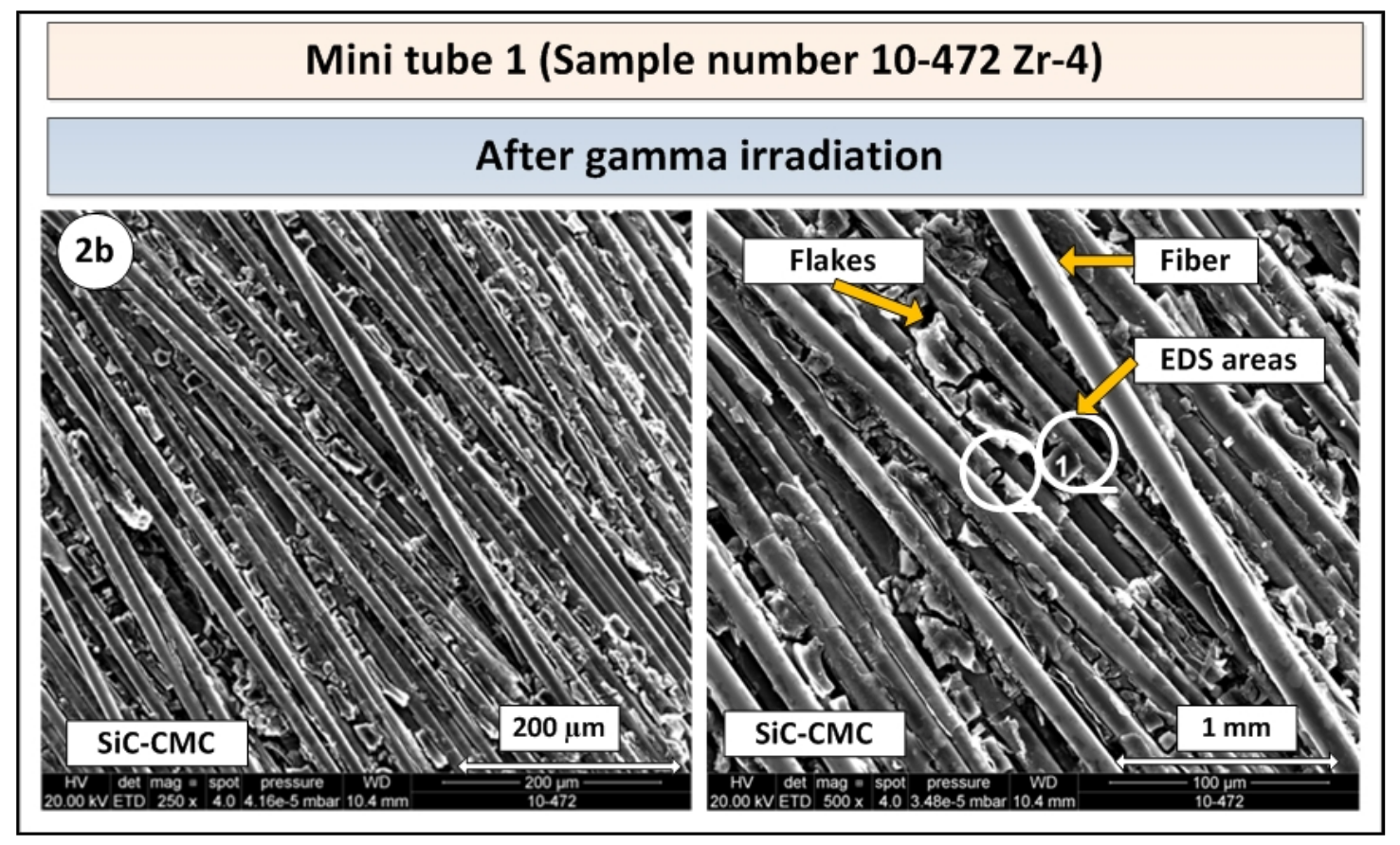

Figure 17. SEM metallurgical examination of the mini tube (sample 10-472 $\mathrm{Zr}-4$ ) at position $2 \mathrm{~b}$ after gamma irradiation shows only "flakes" of the PIP matrix remains after $\mathrm{HF}-\mathrm{HNO}_{3}$ leaching. 


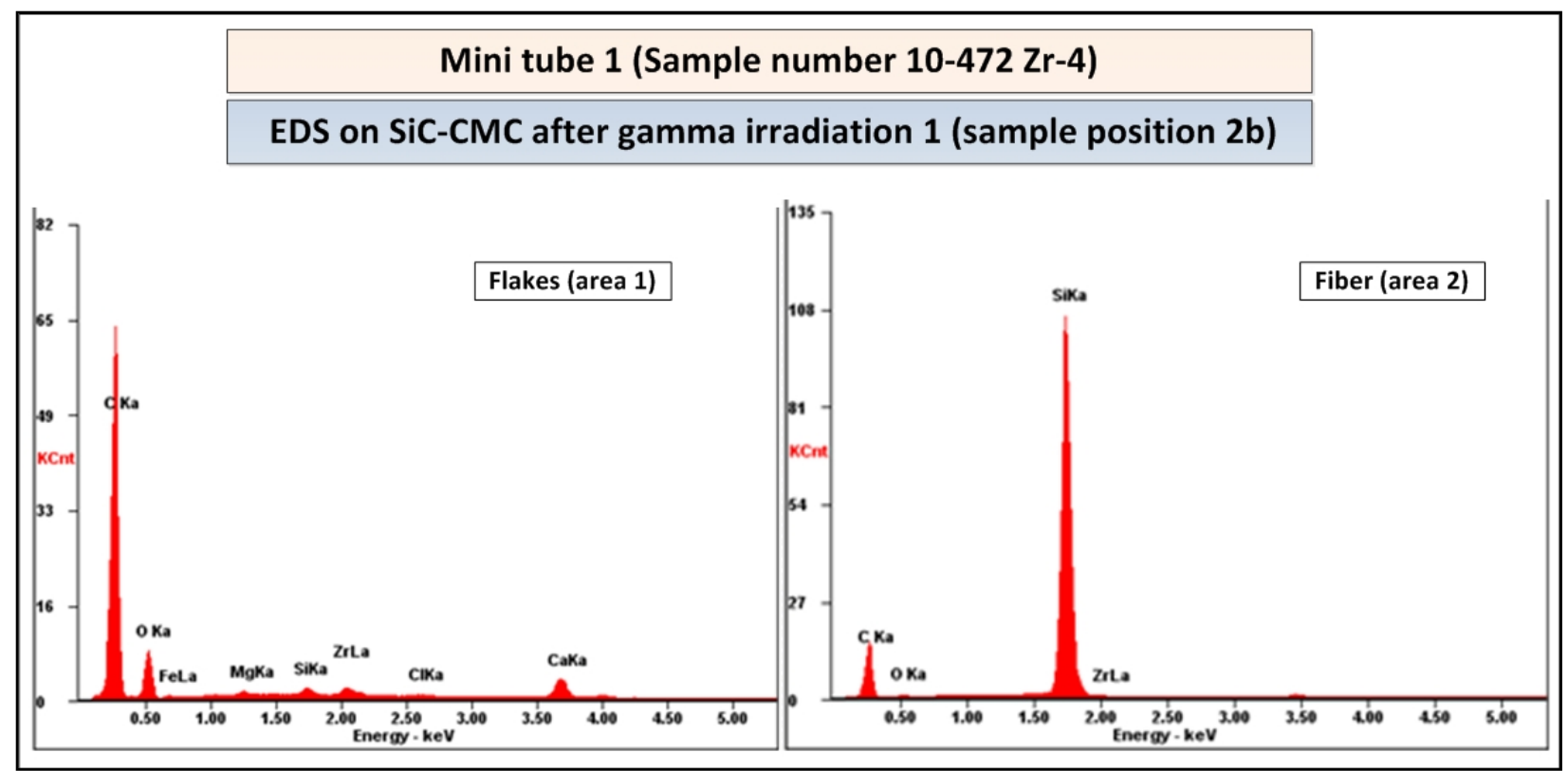

Figure 18. SEM-EDS analysis in the two areas shown in Figure 17, shows that the flakes are mainly Si, C, and $\mathrm{O}$.

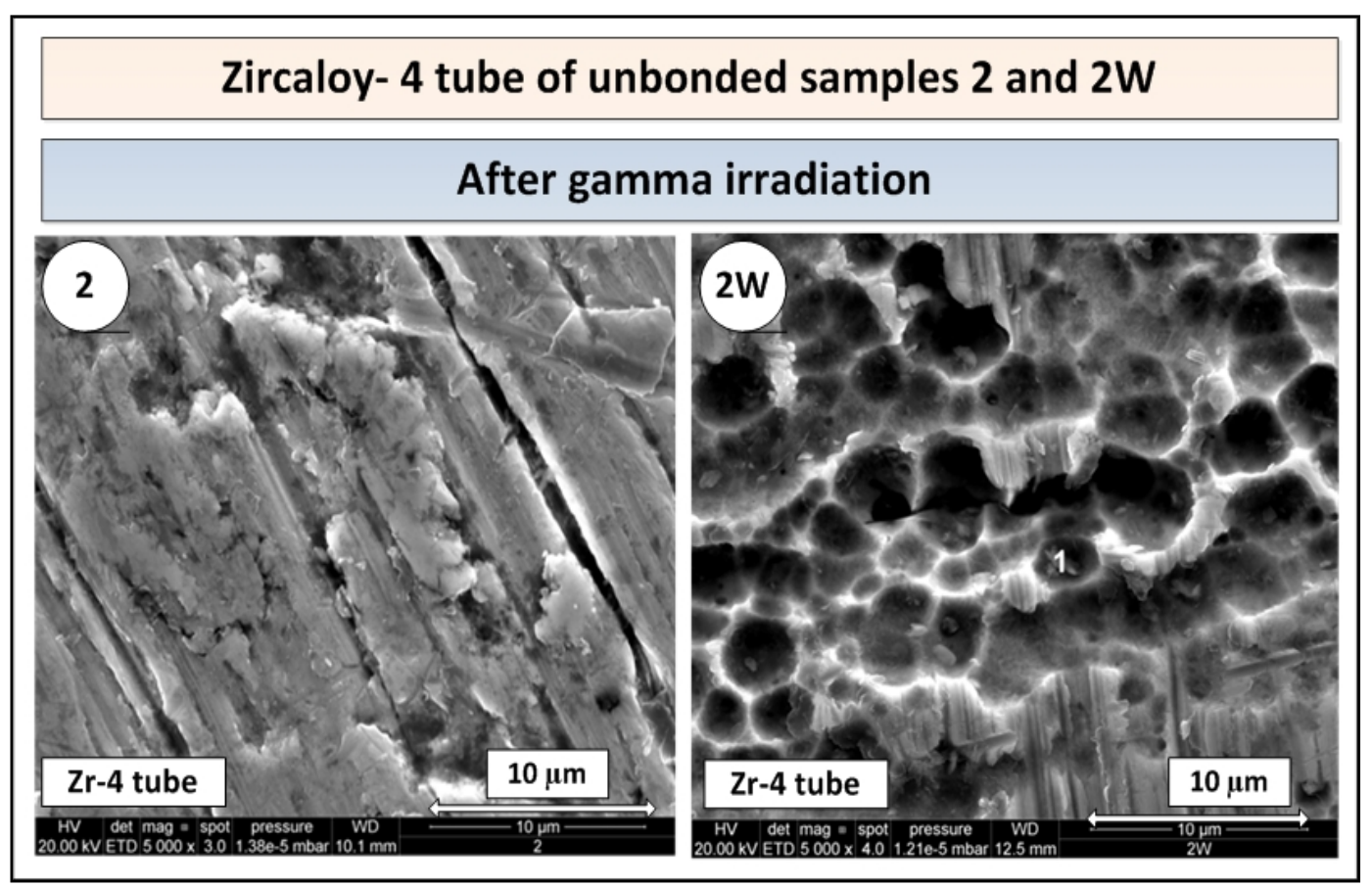

Figure 19. SEM metallurgical examination of the Zircaloy 4 tubes for samples 2 and $2 \mathrm{~W}$. No significant chemical reactions (pitting) are observed on the surface of sample 2, but pitting is observed in sample $2 \mathrm{~W}$ surface. 


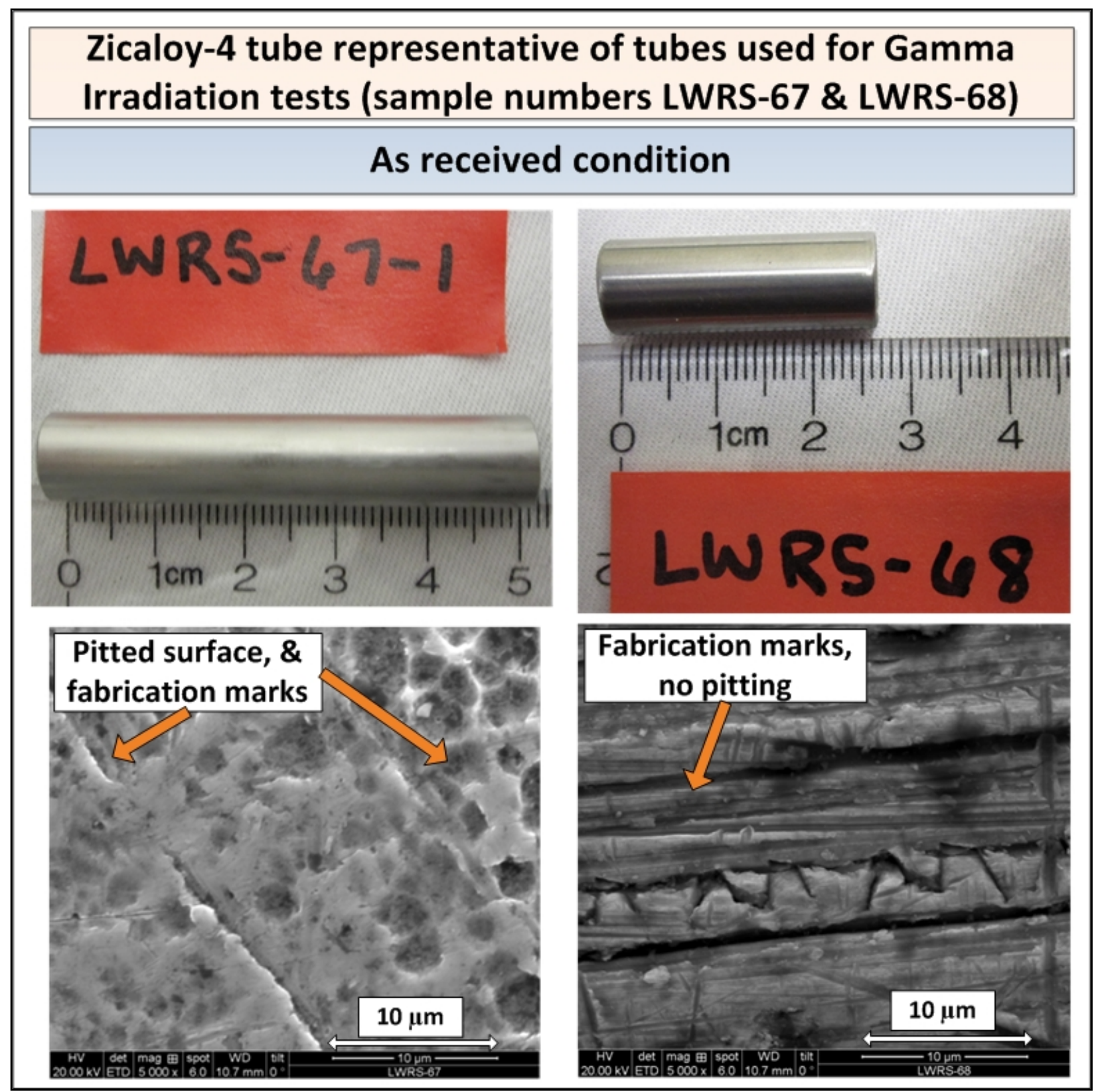

Figure 20. SEM metallurgical examination of two representative samples of the Zircaloy-4 tubes used for the gamma irradiation experiments. Fabrication marks are observed on both samples as expected but sample LWRS-67 has already a pitted surface which made the interpretation on the corrosion surfaces observed after gamma irradiation nearly impossible. 


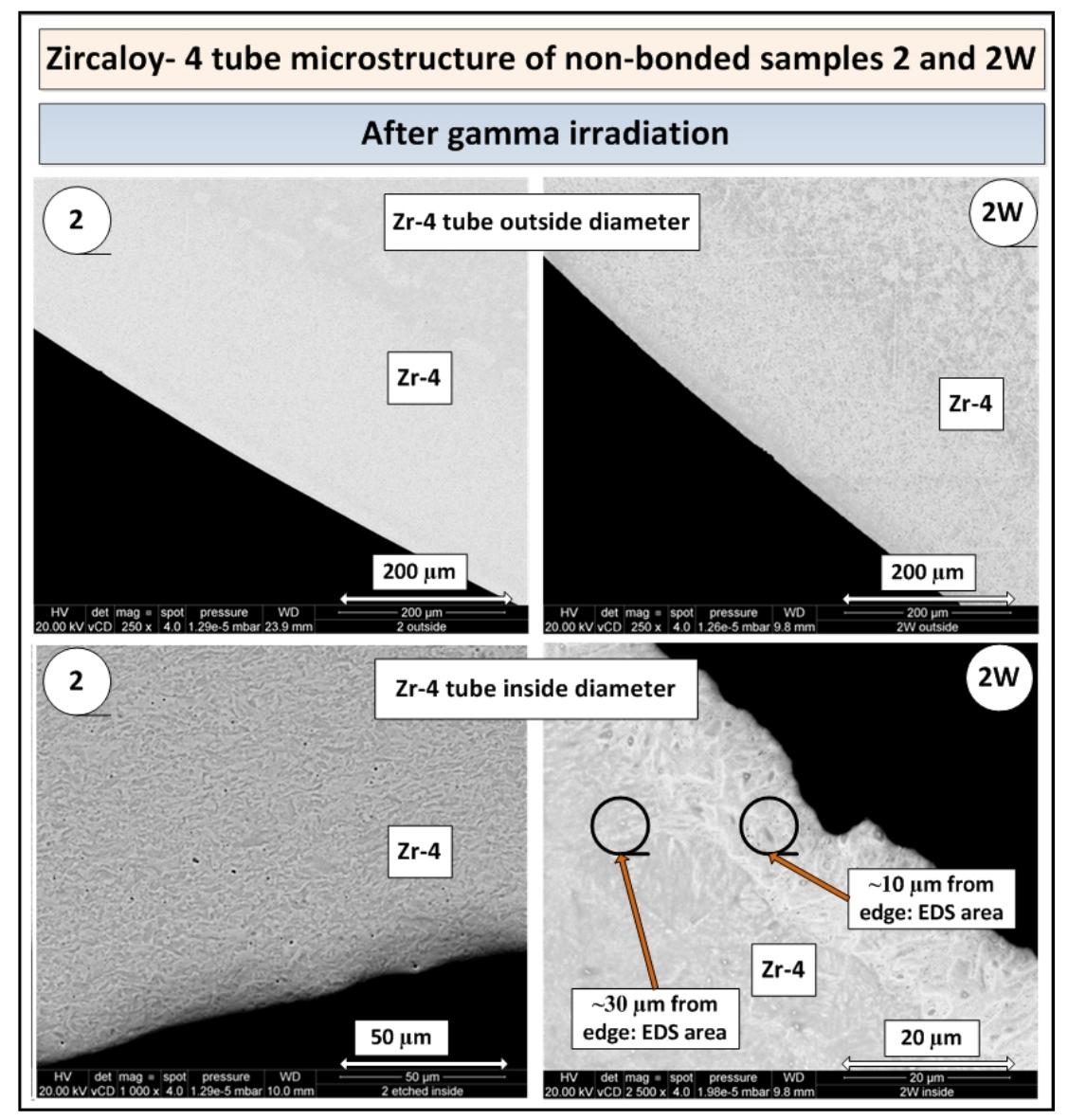

Figure 21. SEM metallurgical examination of samples 2 and $2 \mathrm{~W}$ comparing the inner and outer diameters of the Zircaloy-4 tubes used for the gamma irradiation experiments. A thin layer of changed microstructure are observed in the inside of the $\mathrm{Zr}-4$ tube of sample $2 \mathrm{~W}$ are observed.

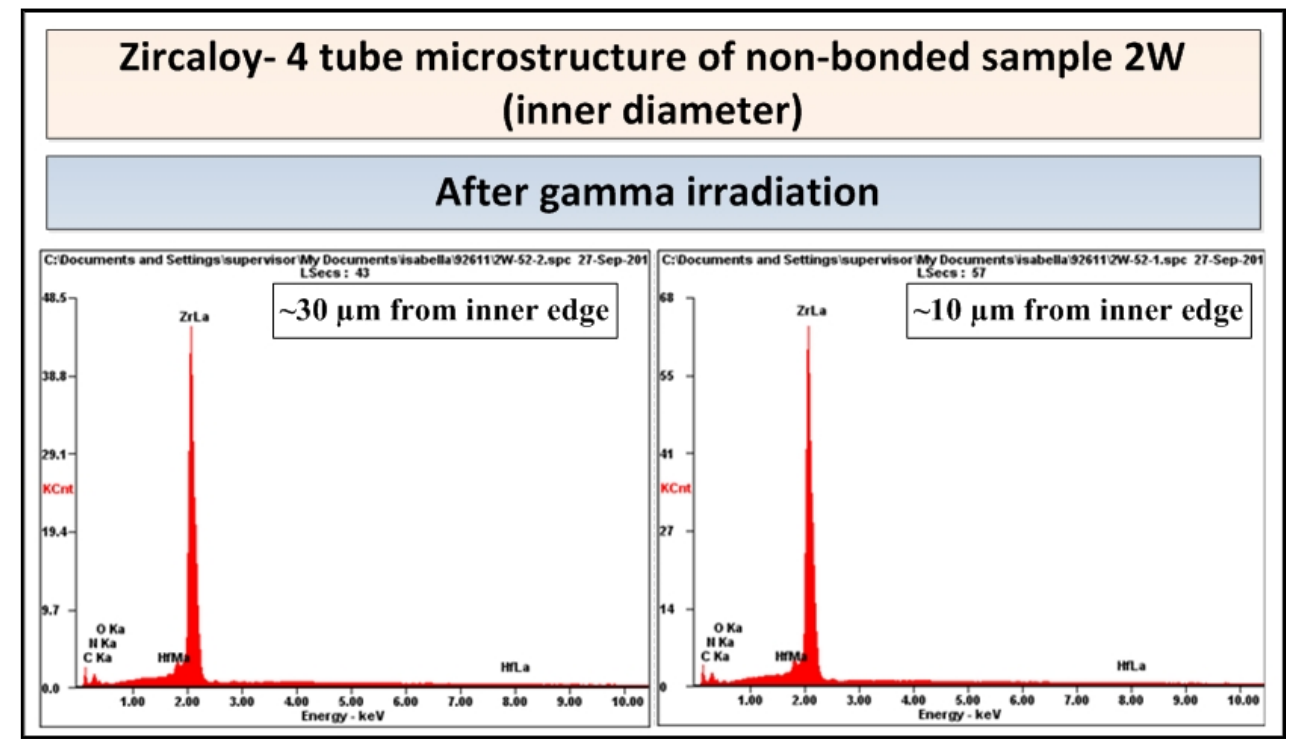

Figure 22. SEM-EDS analysis on the inner diameter of the $\mathrm{Zr}-4$ tube of sample $2 \mathrm{~W}$ show no difference in the chemical composition in areas at the inner edge and approximately $30 \mu \mathrm{m}$ away from inside edge. Possible changes in oxide content cannot be quantified with the SEM-EDS technique. 
3.1.5.2 Bonded sleeves (Samples 3 to 5 and $3 W$ to $5 W$ ). As indicated previously, the main focus of the characterization was on the non-bonded $\mathrm{SiC}-\mathrm{CMC}$ hybrid samples and only basic metallurgical examination was done on the bonded SiC-CMC hybrid samples.

The metallurgical examination of all the bonded samples shows similar metallurgical features with typical examples shown in Figure 21. All the bonded samples showed significant breakage (flaking) and pitting at the bonding interface. Flaking could explain the increased $\mathrm{Si}$ and $\mathrm{Cl}$ content in water after gamma irradiation test 1 .

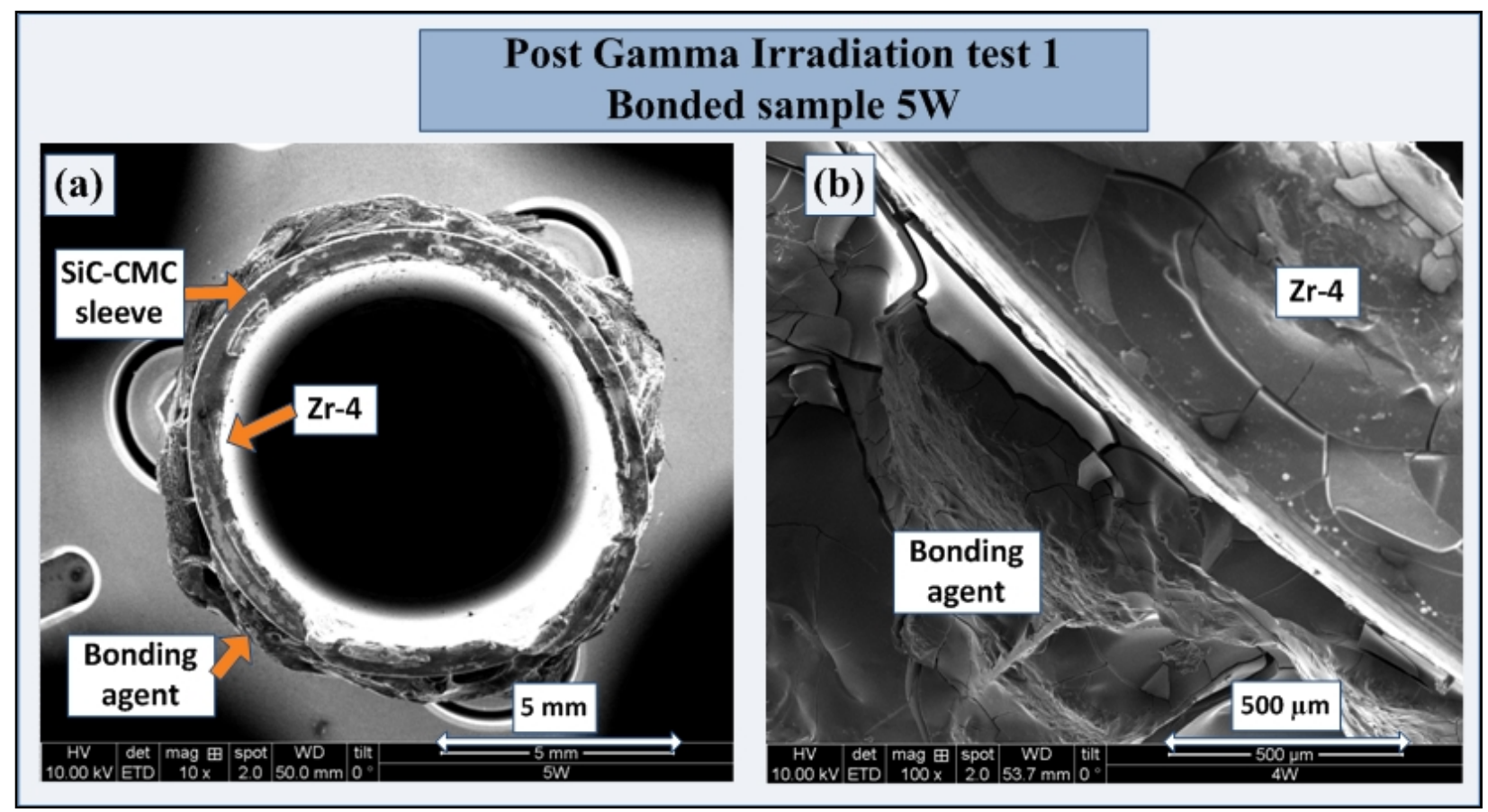

Figure 23. SEM micrographs showing typical breakages, pitting and flaking on the $\mathrm{Zr}-4$ and SiC-CMC bonding surface. All bonded samples ( 3 to 5 ) showed similar features irrespective if there was water present or not.

\subsubsection{Density}

During the visual and microscopic examination it was found that the $\mathrm{SiC} / \mathrm{CMC}$ sleeves were very porous and that $\mathrm{SiC}-\mathrm{CMC}$ matrix was no longer present, leaving only the braided SiC fibers. As indicated previously, samples 3 to 5 had the SiC-CMC sleeve bonded to the Zr-4 tube, making it impossible to measure the density of the sleeve separately without altering the assembly and possibly the composition of the SiC-CMC sleeve. Therefore only the density of the SiC-CMC of samples 2 and $2 \mathrm{~W}$ are reported in this report and is 2.75 and $2.53 \mathrm{~g} / \mathrm{cm}^{3}$ respectively (detail measurements in Appendix F). Although it is noted the density of the sleeve irradiated in water showed a lower density if compared to the one irradiated in the absence of water, no final conclusion on the significance can be made due to the statistical insignificance of the sample. Unfortunately in this case, the densities were only determined after the gamma irradiation operation and therefore possible changes due to gamma irradiation and/or corrosion cannot be recorded for this experiment. The main purpose of these tests was to verify the testing procedures and to establish if these results may be meaningful for gamma irradiated samples.

\subsubsection{X-Ray Diffraction}

As indicated before the analysis focused on the non-bonded samples and a typical XRD pattern is shown in Figure 24. These results show no phase/compound differences between the three samples. .All 
samples are compromised of the cubic 3C (beta) SiC phase as indicated by the black arrows in Figure 24 . A small amount of the hexagonal (alpha) $\mathrm{SiC}$ is also identified as shown by the grey arrow. This small amount of alpha $\mathrm{SiC}$ also existed in the original fabricated sample (LWRS-18-1). Slight peak broadening are visible for the gamma irradiated material which is an indication of particulate size (or grain size) changes. At this stage it is not possible to determine if temperature or irradiation is the cause for these observed changes. The XRD patterns for the bonded samples is shown in Appendix G and showed very different results compared with the non-bonded samples. These patterns and needs further interpretation which does not form part of this report.

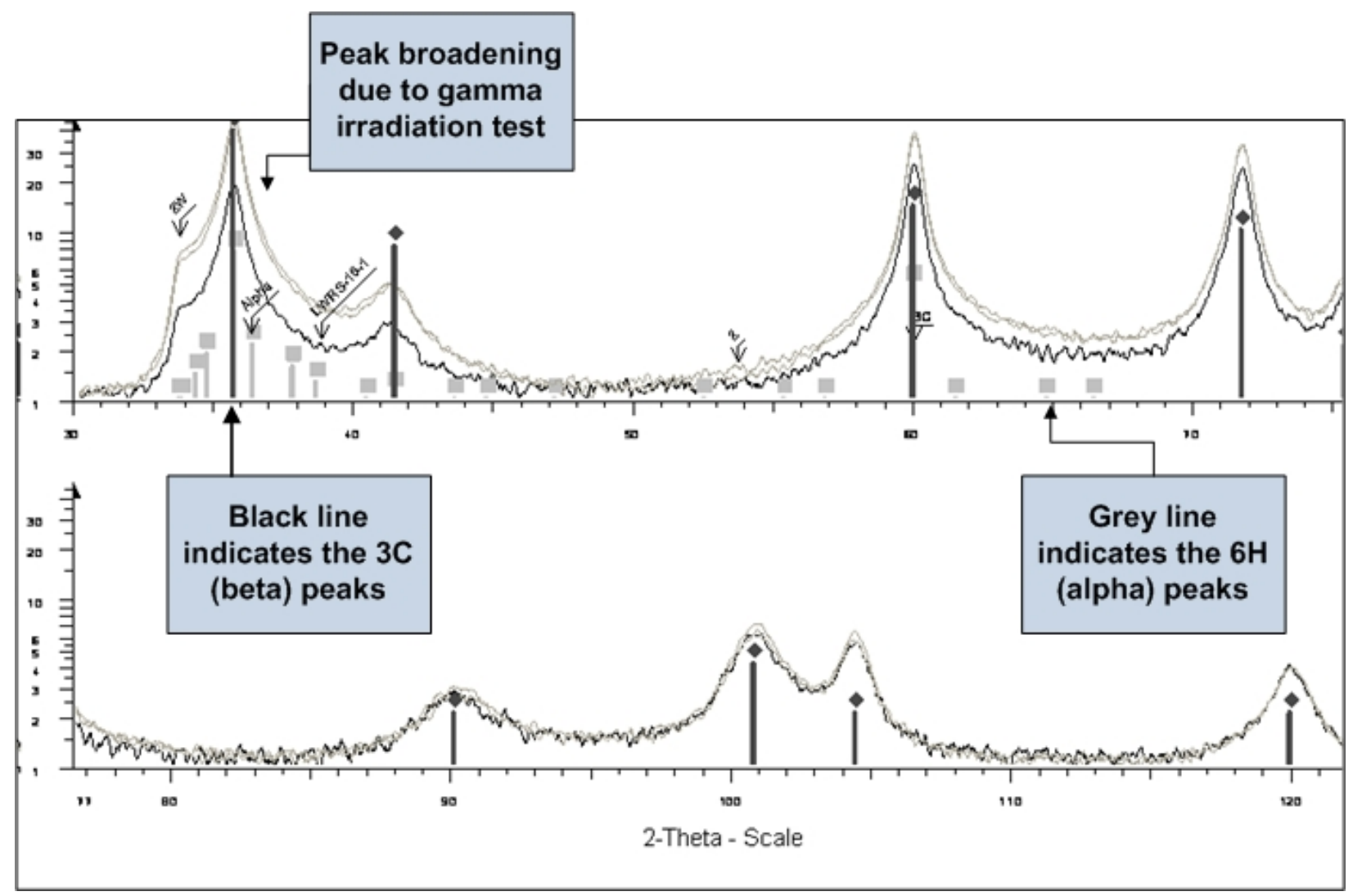

Figure 24. Combined figure of the XRD patterns of the original SiC-CMC sleeve without acid washing (LWRS-18-1) and the non-bonded samples (2 and 2W).

\subsection{Gamma Irradiation Test 2}

\subsubsection{Visual Examination}

Two SiC-CMC sleeves, LWRS-1-6- A-1 and LWRS-1-6- A-3 (Figure 25), were released by INL quality for development testing purposes only (white release tags shown in Appendix A). The masking tape labeling by the supplier, PSI, was not acceptable and communicated as such for correction with next deliveries. It is advised by the fabrication PI and experimental manager that the LWRS-1-6- A-1 SiCCMC sleeve were technically representative of the prototypes which was due for delivery, with only diameter dimensional deviations, and therefore this sleeve was used for the fabrication of the gamma irradiation mock-up mini-tube. It was decided to proceed with the gamma irradiation test as it is argued to be representative of the sleeves to be used in for reactor insertion. Sleeve LWRS-1-6- A-3 is included in this investigation, as the development team would collect valuable information in comparing the gamma irradiation stability of a 1 ply braided tube when compared to the representative 2 ply braided sleeve (LWRS-1-6- A-1). Figure 26 shows the sub-samples ready for gamma irradiation reactor insertion. It 
needs to be noted that the sub-sample LWRS-1-6- A-1-2 was chemically cleaned prior to placement in the glass vial as to determine if cleaning attributed to different chemical composition of the vial water after gamma irradiation if compared with sub-sample LWRS-1-6- A-1-3. Figure 27 shows the discoloration of the glass vials after the gamma irradiation test similar to previously observed with the gamma irradiation 1 sample set. Additionally, the water of subsample LWRS-1- 6-A-1-3 appears "milky" after gamma irradiation whilst the other four samples appear clear. The reason for the "milky" appearance is not known yet. The visual examination shows no significant changes for samples that were gamma irradiated when comparing the before and after photo's with the exception of the white discoloration on sample LWRS-1- 6-A-1-3 (Figure 28).

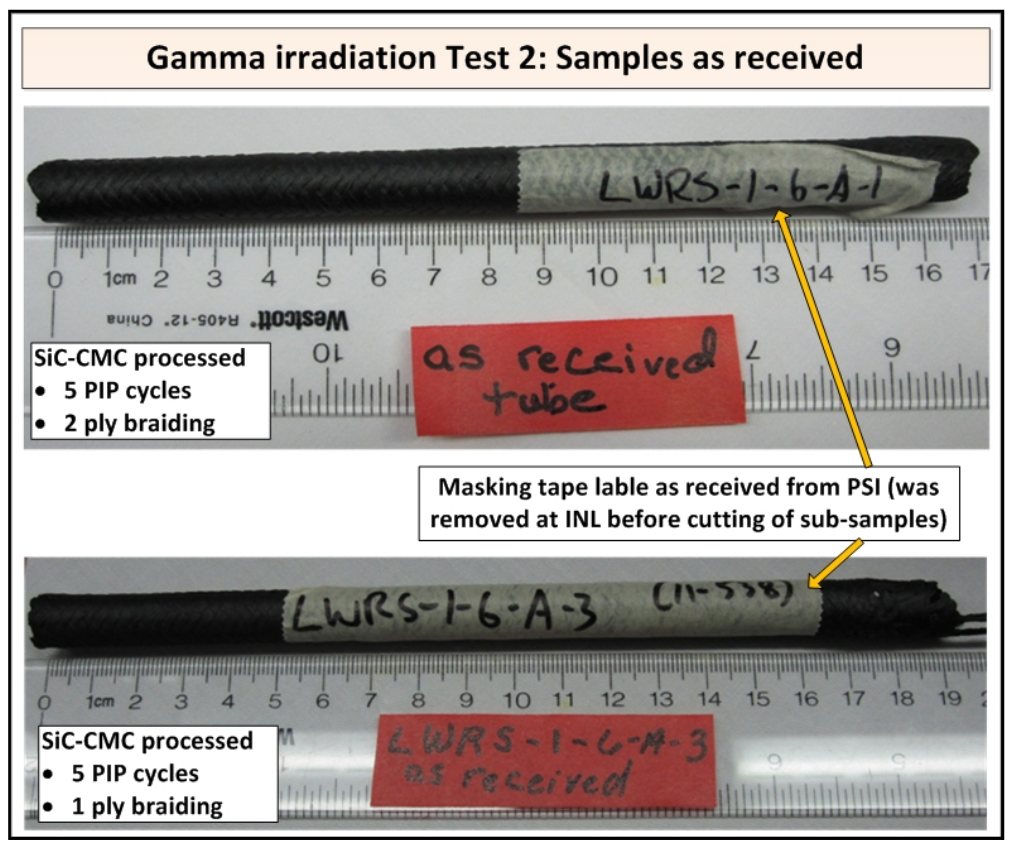

Figure 25. Visual examination of samples LWRS-1-6- A-1 and LWRS-1-6- A-3 showing the masking tape labeling as received form PSI. This is a deviation from the delivery requirements and is communicated to the supplier PSI by the experiment manager

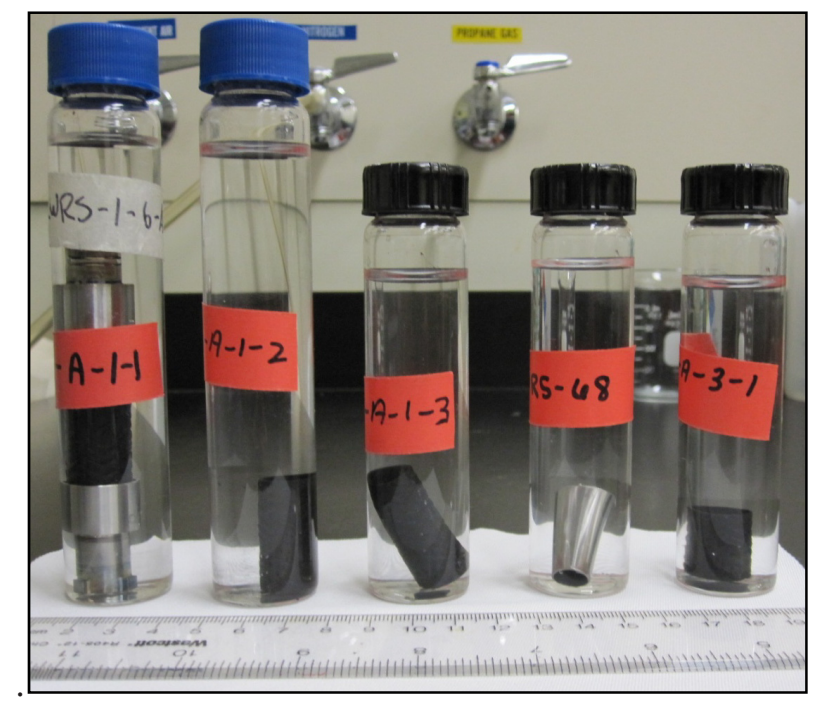

Figure 26. Samples prepared for insertion for the gamma irradiation test 2. 


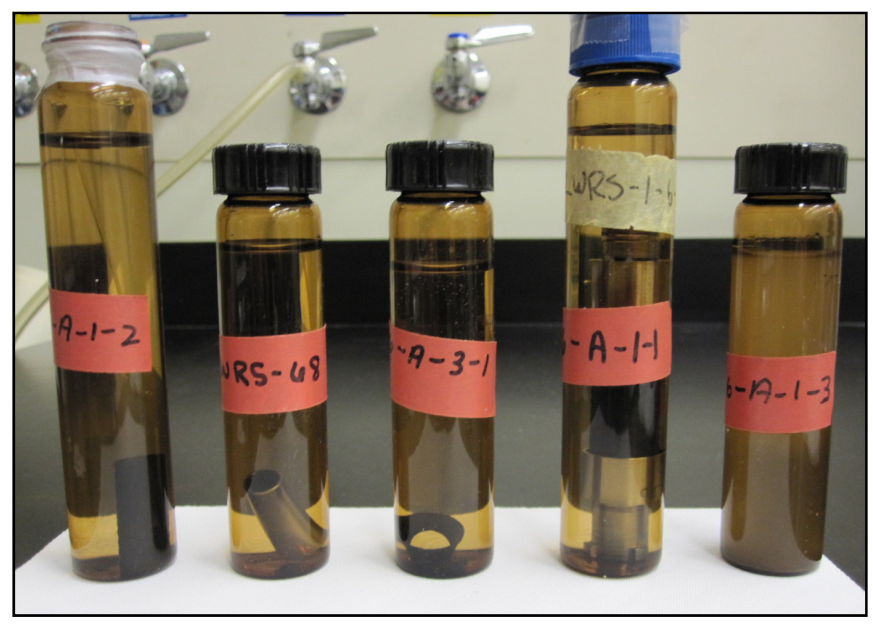

Figure 27. Photograph showing the samples in glass vials after the gamma irradiation cycle. Samples in glass vials after discoloration of the glass vials are again observed as in the case with the gamma irradiation test 1. Additionally, the water of subsample LWRS-1- 6-A-1-3 appears "milky" after gamma irradiation whilst the other four samples appear clear.

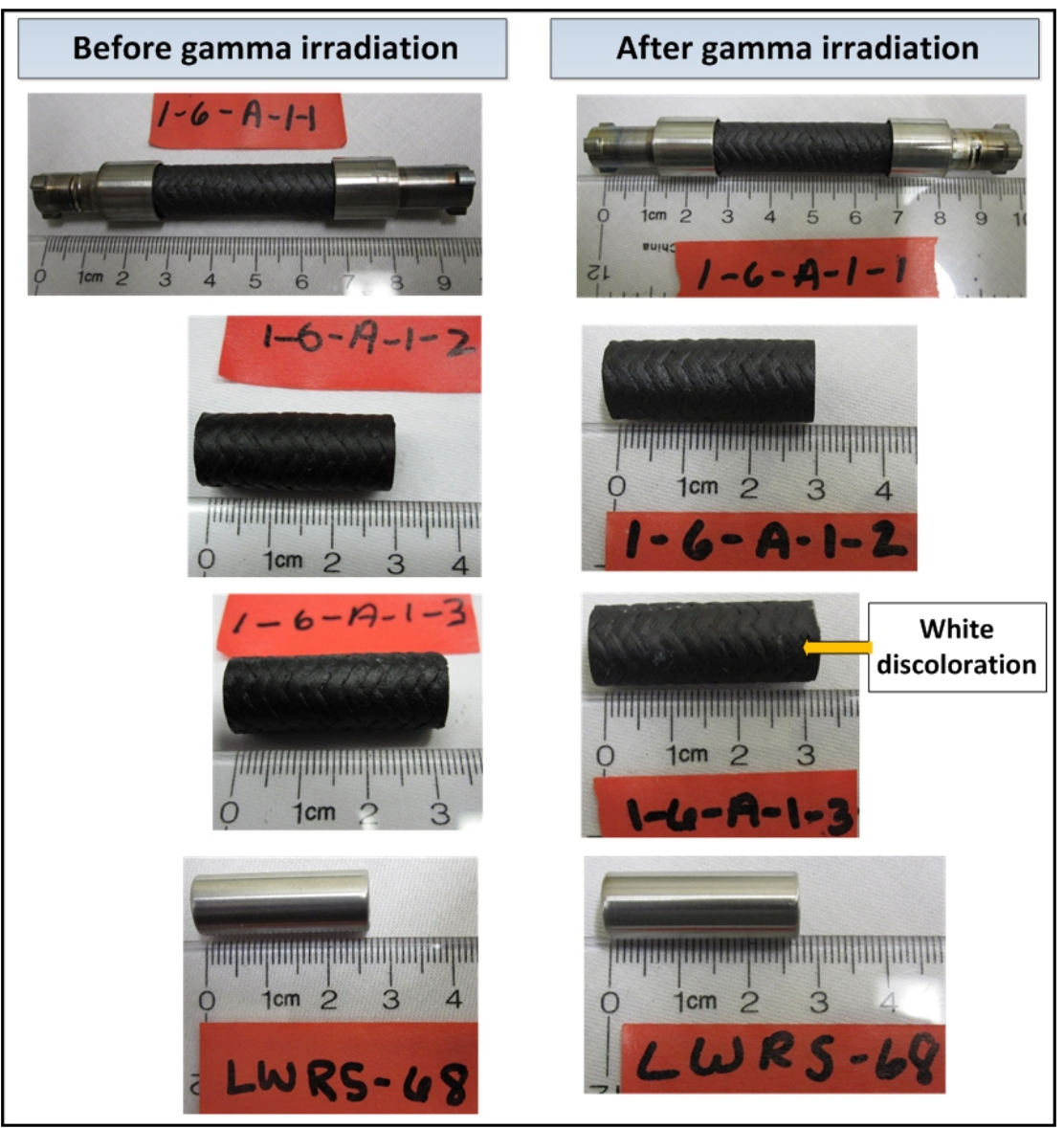

Figure 28. Photograph showing the comparative visual examination for the samples before and after gamma irradiation. No significant visual differences are observed, except for the white discoloration on sample 1-6-A-1-3, which is also the sample showing the "milky" appearance of the water after gamma irradiation. 


\subsubsection{Dimensional and Weight Measurements}

Dimensional and weight variances were determined for the test samples and the dimensional results are presented in Figure 29 with the detail of the measurements reported in Appendix H. The measurement summary is shown in Figure 29 as a \% variance from measurements after and before gamma irradiation. A weight loss of smaller than 5\% is observed for these three samples. Length and diameter variances of smaller than 3\% are measured. However sample LWRS-1-6-A-1-3 shows a very slight increase in both diameter and length after exposed to gamma irradiation. It is however important to note that the measurement error may be significant due to different measuring systems used namely metric for the measurements before and empirical measurements after gamma irradiation. It is found that statistically it is not possible to make final conclusions based on these measurements.

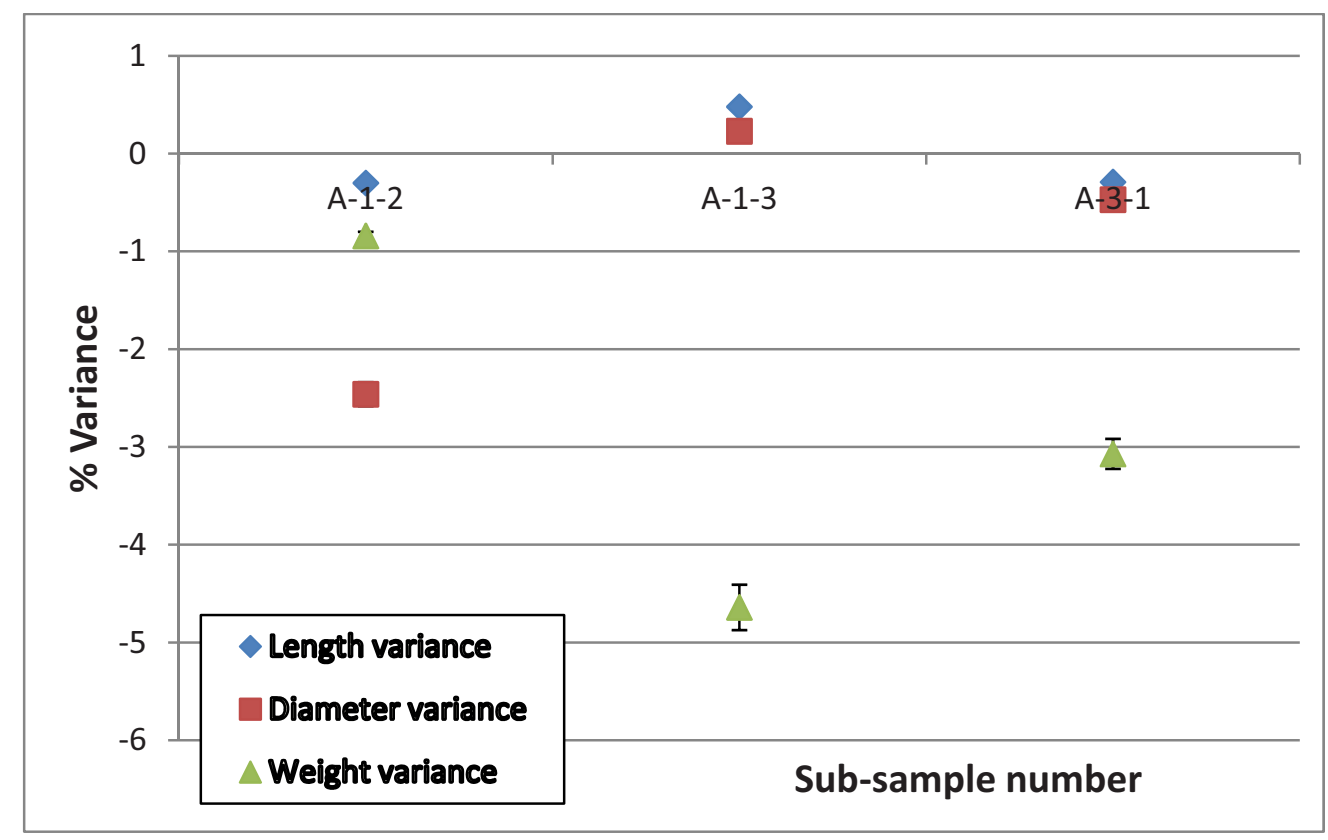

Figure 29. Graphical presentation of the dimension- and weight variances due to the gamma irradiation test (standard measurement error of 5\%).

\subsubsection{Radiographic Inspection}

Although the recommendation from the first gamma irradiation test was to evaluate 3D tomography as a non destructive inspection technique prior to gamma irradiation, the equipment was out of commission at the time of testing, therefore only $2 \mathrm{D} x$-rays were taken prior to gamma irradiation. Fortunately the advantages of the $3 \mathrm{D}$ tomography examination were demonstrated with the inspection after gamma irradiation. Figures 30 and 31 show the detail of the weave patterns as well as the inner surface condition of the SiC-CMC sleeves. The detail of the gap between the SiC-CMC sleeve and the $\mathrm{Zr}-4$ tube can be measured at any distance interval during the $3 \mathrm{D}$ tomography images. No defraying or open porosity is observed in any of the samples after gamma irradiation. It is noted that the inner surface of the one ply braided SiC-CMC sleeve was visually rougher when compared with the 2 ply sleeve. These will needs to be verified in future batches. Additionally it is not known if this is due to the effects of gamma irradiation or due to the fabrication processes. 


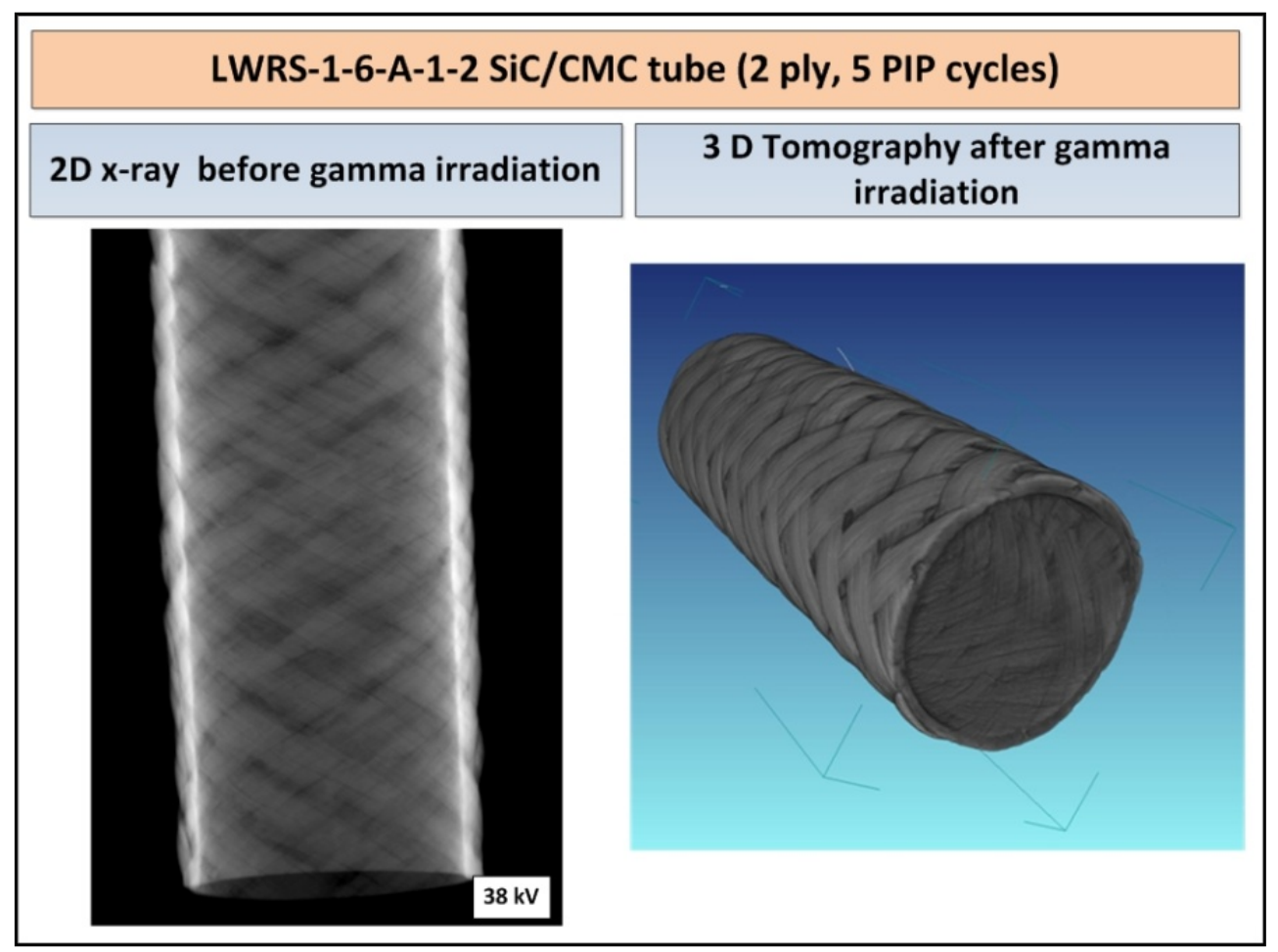

Figure 30 . Advantages of the $3 \mathrm{D}$ tomographic inspection in comparison of the $2 \mathrm{D} \mathrm{x}$-ray technique are demonstrated by these photos.

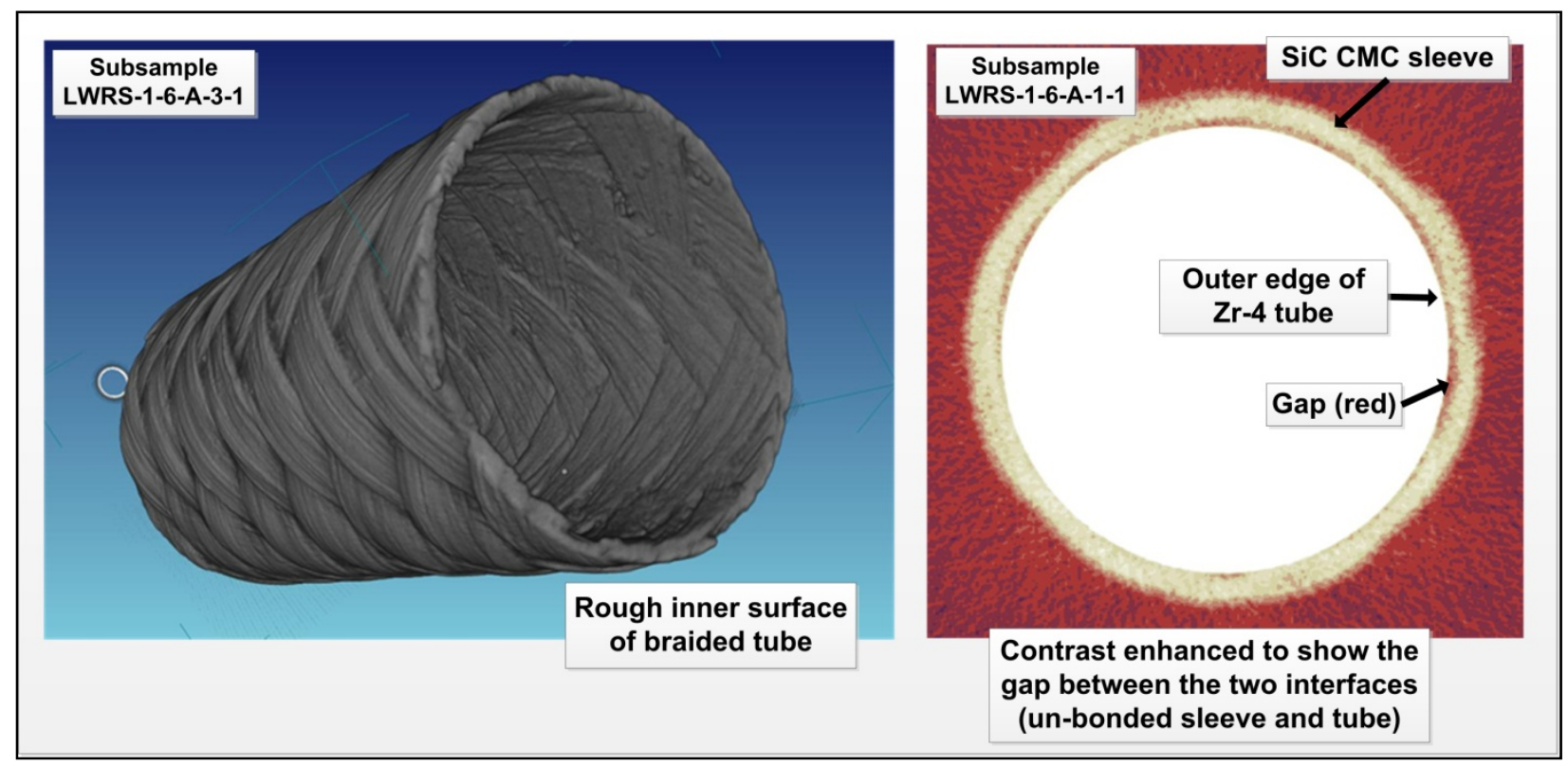

Figure 31. Surface condition and details of the gap between the interfaces in a non-bonded sleeve and Zr-4 tube.

\subsubsection{Density}

The density was measured on two representative sub-samples namely LWRS-1-6-A-1-5 and LWRS1-6-A-3-3. Density measurements after gamma irradiation of sub-samples LWRS-1-6-A-1-2, LWRS-1-6- 
A-1-3 and LWRS-1-6-A-3-1 are also measured as shown in Table 5 with the detail measurements in Appendix I. No significant differences are observed when comparing these density values.

Table 5. Density measurements of representative samples before and after gamma irradiation test 2 .

\begin{tabular}{|c|c|c|c|c|}
\hline Sample number & $\begin{array}{c}\text { Density before Gamma } \\
\text { Irradiation }\left(\mathbf{g} / \mathbf{c m}^{\mathbf{3}}\right)\end{array}$ & STD & $\begin{array}{c}\text { Density after Gamma } \\
\text { Irradiation } \mathbf{( g / \mathbf { c m } ^ { 3 } )}\end{array}$ & STD \\
\hline LWRS-1-6-A-1-5 & 2.66 & 0.003 & N/A & N/A \\
\hline LWRS-1-6-A-3-3 & 2.60 & 0.003 & N/A & N/A \\
\hline LWRS-1-6-A-1-2 & N/A & N/A & 2.68 & 0.005 \\
\hline LWRS-1-6-A-3-1 & N/A & N/A & 2.67 & 0.004 \\
\hline LWRS-1-6-A-1-3 & N/A & N/A & 2.63 & 0.007 \\
\hline
\end{tabular}

\subsubsection{X-Ray Diffraction}

Figure 32 shows the comparative XRD patterns of the gamma irradiated SiC-CMC sleeve (LWRS-16-A-3-3) with the sleeves as received (LWRS-1-6-A-3-1) and show no significant changes in the 2 theta angles. These results show no phase/compound differences between the samples. All samples are compromised of the cubic 3C (beta) SiC phase as indicated by the black arrows in Figures 32 and 33. A slight peak broadening is however observed in the two gamma irradiated samples. Broadening/narrowing of peaks is generally associated with grain or particulate size changes and is also temperature dependant. At this stage with the small data set, it is not conclusive if temperature or irradiation is the main cause of these changes.

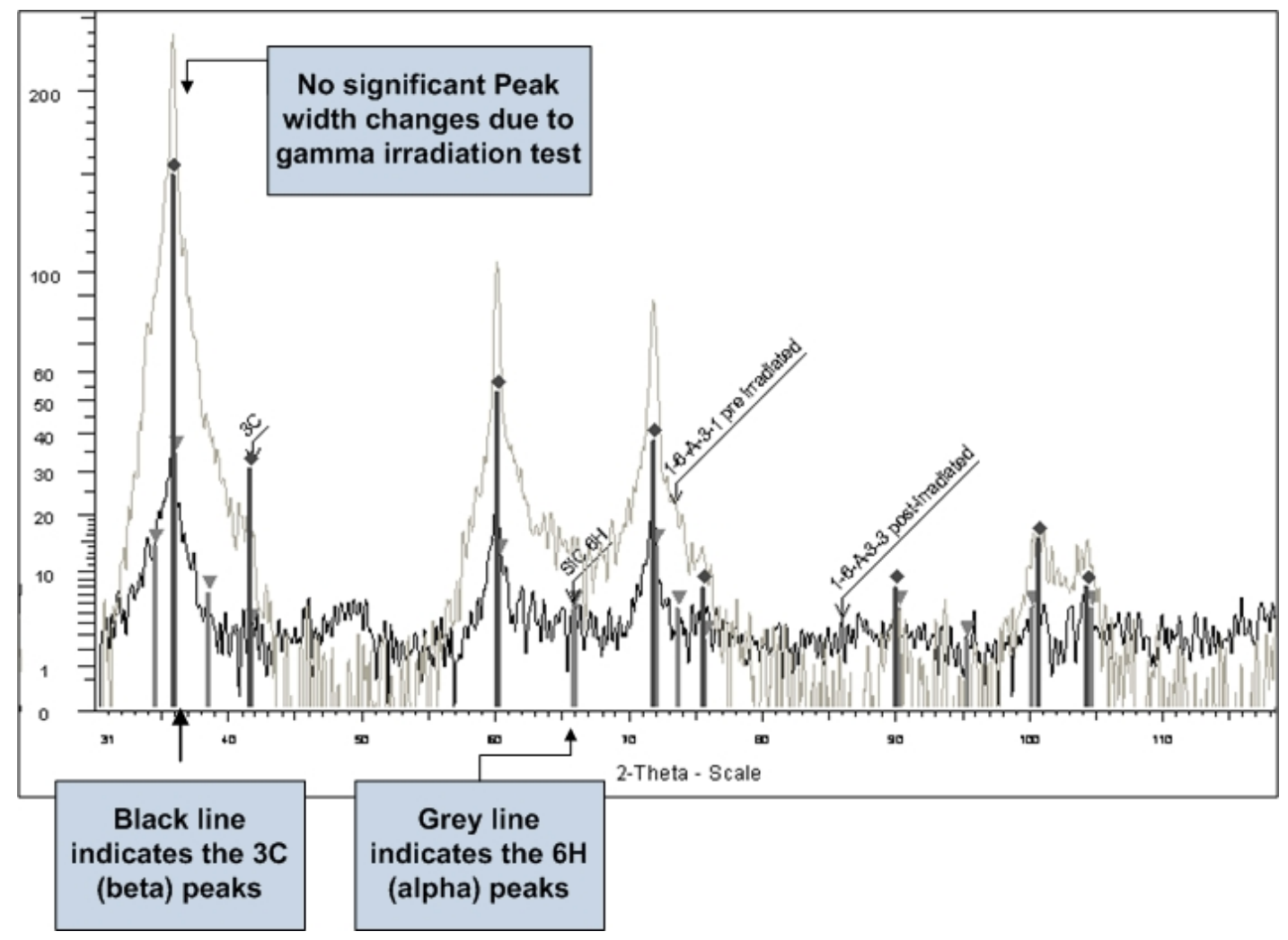

Figure 32. Comparative XRD patterns of the gamma irradiated SiC-CMC sleeve (LWRS-1-6-A-3-3) with the sleeves as received (LWRS-1-6-A-3-1) showing now significant changes in the 2 theta angles or peak width due to the gamma irradiation test. Only $3 \mathrm{C} \mathrm{SiC}$ is observed. 


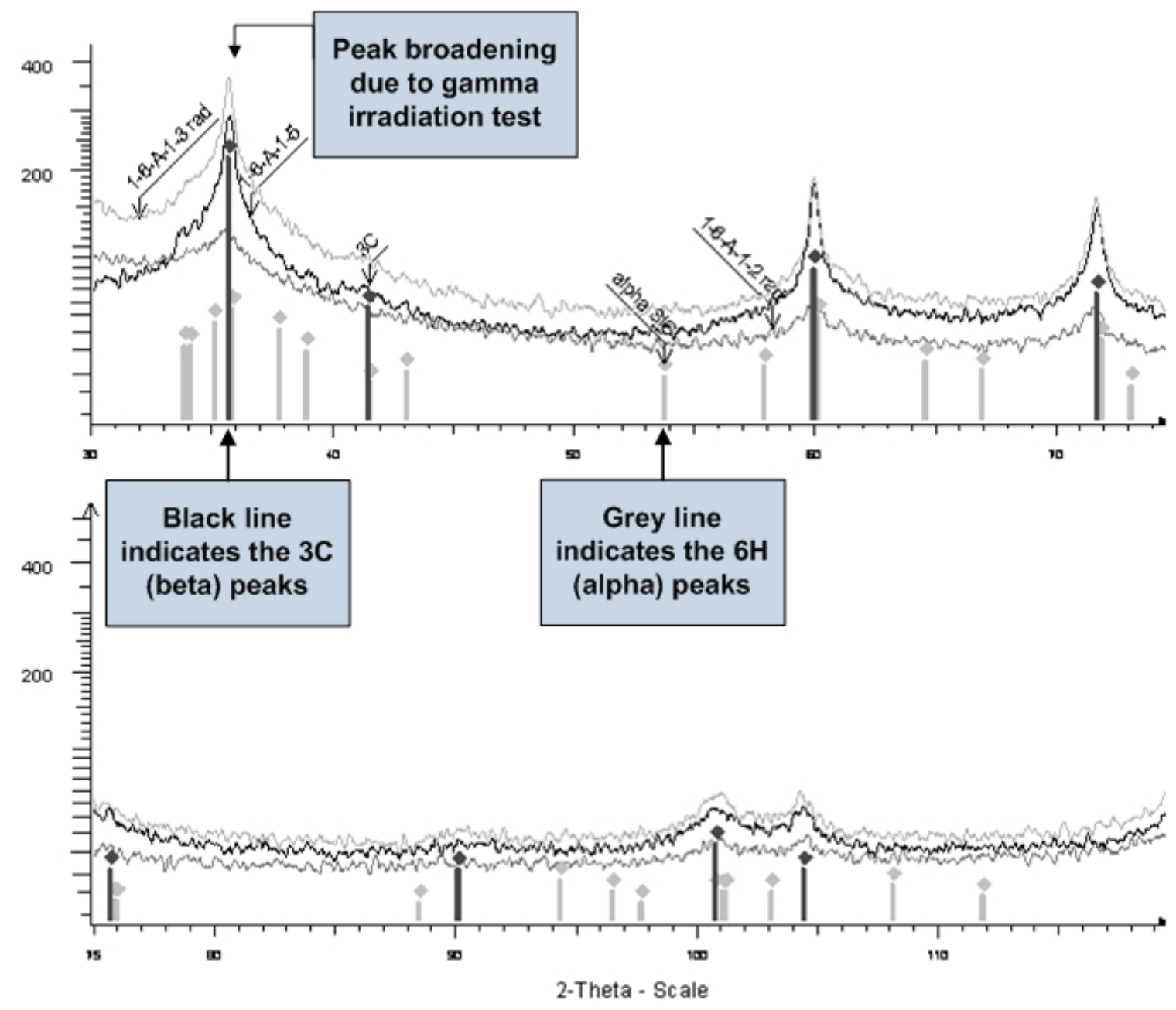

Figure 33. Comparative XRD patterns of the gamma irradiated SiC-CMC sleeve (LWRS-1-6-A-1-3, LWRS-1-6-A-1-2) with the sleeves as received (LWRS-1-6-A-1-5) showing now significant changes in the 2 theta angles although indications of slight peak broadening are observed in the two samples after the gamma irradiation test.

\subsubsection{Chemical Analysis}

3.2.6.1 Leach testing on CMC fibers. The SiC-CMC sleeves used for this gamma irradiation test 2 were manufactured from the same CMC fibers as reported in Section 3.1.4.1.

3.2.6.2 Leach testing on SiC/CMC braided sleeve. Although the chloride concentration increased from $0.228 \mathrm{ppm}$ to $20 \mathrm{ppm}$ for the LWRS-1-6-A-1-4 sample, it is still within the specification of $<250 \mathrm{ppm}$ (Table 6). It is also interesting that the bromide content of the LWRS 1-6 A 3-2 sample showed a detectable quantity when compared to LWRS 1-6 A 1-4. These results suggest that more $\mathrm{Cl}$ and $\mathrm{Si}$ are leached out by the 2 ply SiC-CMC sleeve if compared with the 1 ply braided sleeve. However, this needs to be verified with a larger number of samples for a better statistical soundness. 
Table 6. Leach test water analysis on representative samples prior to gamma irradiation test 2.

\begin{tabular}{|c|c|c|c|c|c|c|c|}
\hline Sample Number & F (ppm) & $\mathrm{Cl}$ (ppm) & Br (ppm) & $\begin{array}{c}\text { Al } \\
\text { Dissolved } \\
\text { (ppb) } \\
\end{array}$ & $\begin{array}{c}\text { Fe } \\
\text { Dissolved } \\
(\text { ppb) }\end{array}$ & $\begin{array}{c}\text { Cu } \\
\text { Dissolve } \\
\text { d (ppb) }\end{array}$ & Si (ppm) \\
\hline ATR Normal range & ST & $<0.05$ & ST & $1.5-4.0$ & $0.5-2.0$ & $0.2-2.0$ & $\mathrm{NS}$ \\
\hline ATR Control limit & ST & $<0.1$ & ST & 6.0 & 15 & 15 & NS \\
\hline $\begin{array}{l}\text { Water before gamma } \\
\text { irradiation test } 2\end{array}$ & $\begin{array}{c}\text { Not } \\
\text { detected }\end{array}$ & 0.228 & $\begin{array}{c}\text { Not } \\
\text { detected }\end{array}$ & $\begin{array}{c}<0.158 \\
\text { ppm }\end{array}$ & NM & NM & $<0.093$ \\
\hline LWRS 1-6 A 1-4 & $\begin{array}{c}\text { Not } \\
\text { detected }\end{array}$ & 20.008 & $\begin{array}{c}\text { Not } \\
\text { detected }\end{array}$ & $<0.158$ & NM & NM & 77.100 \\
\hline LWRS 1-6 A 3-2 & $\begin{array}{c}\text { Not } \\
\text { detected }\end{array}$ & 1.213 & 0.455 & $<0.158$ & NM & NM & 46.950 \\
\hline
\end{tabular}

3.2.6.3 Zircaloy-4 tubes. As indicated in section 3.1.4.3, no independent chemical analysis is collected on Zr-4 tube material, only the qualitatively SEM-EDX analysis. The SEM-EDS analysis indicated the presence of $\mathrm{Hf}$ and therefore it revealed that this tube is not $\mathrm{Zr}-4$. This is further confirmed by the diameter dimensions that is not typically those of the $\mathrm{Zr}-4$ tubes in stock. As these tests were for development purposes, the fact that another $\mathrm{Zr}$-alloy tube was used does not invalidate the preliminary tests, but it highlighted a shortfall in the raw material storage and traceability quality aspects. This has been addressed since.

3.2.6.4 Experiment water analysis after gamma irradiation. The water analysis for the gamma irradiation test 2 experiment is shown in Table 7 (detail in Appendix J) and Figure 34. The water results of most samples show an increase in the $\mathrm{Cl}$ and $\mathrm{Si}$ content. Additionally, the mini-tube water (LWRS-1-6-A-1-1) showed also an increase in F content of $\sim 11 \mathrm{ppm}$. The duplicate sleeve samples LWRS-1-6-A-1-2 showed a decrease in $\mathrm{Cl}$ content which may be due to the cleaning action that took place prior to the insertion in the vial prior to reactor insertion. The dissolved Al measurements showed very low concentrations which is below the ATR normal range.

Table 7. Water analysis after gamma irradiation test 2 compared to the water analysis before the gamma irradiation test 2.

\begin{tabular}{|c|c|c|c|c|c|c|c|}
\hline Sample Number & $\begin{array}{c}\mathbf{F} \\
(\mathrm{ppm})\end{array}$ & $\begin{array}{c}\mathrm{Cl} \\
(\mathrm{ppm})\end{array}$ & $\begin{array}{c}\mathrm{Br} \\
(\mathrm{ppm})\end{array}$ & $\begin{array}{l}\text { Al Dissolved } \\
\text { (ppb) }\end{array}$ & $\begin{array}{c}\text { Fe Dissolved } \\
\text { (ppb) }\end{array}$ & $\begin{array}{c}\text { Cu Dissolved } \\
\text { (ppb) }\end{array}$ & $\mathrm{Si}$ (ppm) \\
\hline ATR Normal range & ST & $<0.05$ & ST & $1.5-4.0$ & $0.5-2.0$ & $0.2-2.0$ & NS \\
\hline ATR Control limit & ST & $<0.1$ & $\mathrm{ST}$ & 6.0 & 15 & 15 & NS \\
\hline $\begin{array}{l}\text { Water before gamma } \\
\text { irradiation test } 2\end{array}$ & ND & 0.228 & ND & $<0.158 \mathrm{ppm}$ & NM & NM & $<0.093$ \\
\hline LWRS -1-6-A-1-1 & 10.702 & 5.547 & ND & 0.695 & NM & $\mathrm{NM}$ & 42.000 \\
\hline LWRS-1-6-A-1-2 & $<0.403$ & 0.189 & ND & 0.408 & NM & NM & 34.850 \\
\hline LWRS 1-6-A-1-3 & ND & 3.324 & ND & $<0.158 \mathrm{ppm}$ & NM & NM & 21.720 \\
\hline LWRS 1-6-A-3-1 & ND & 1.039 & ND & $<0.158 \mathrm{ppm}$ & NM & NM & 15.905 \\
\hline LWRS-68 & ND & 0.789 & ND & $<0.158 \mathrm{ppm}$ & $\mathrm{NM}$ & $\mathrm{NM}$ & 0.530 \\
\hline
\end{tabular}




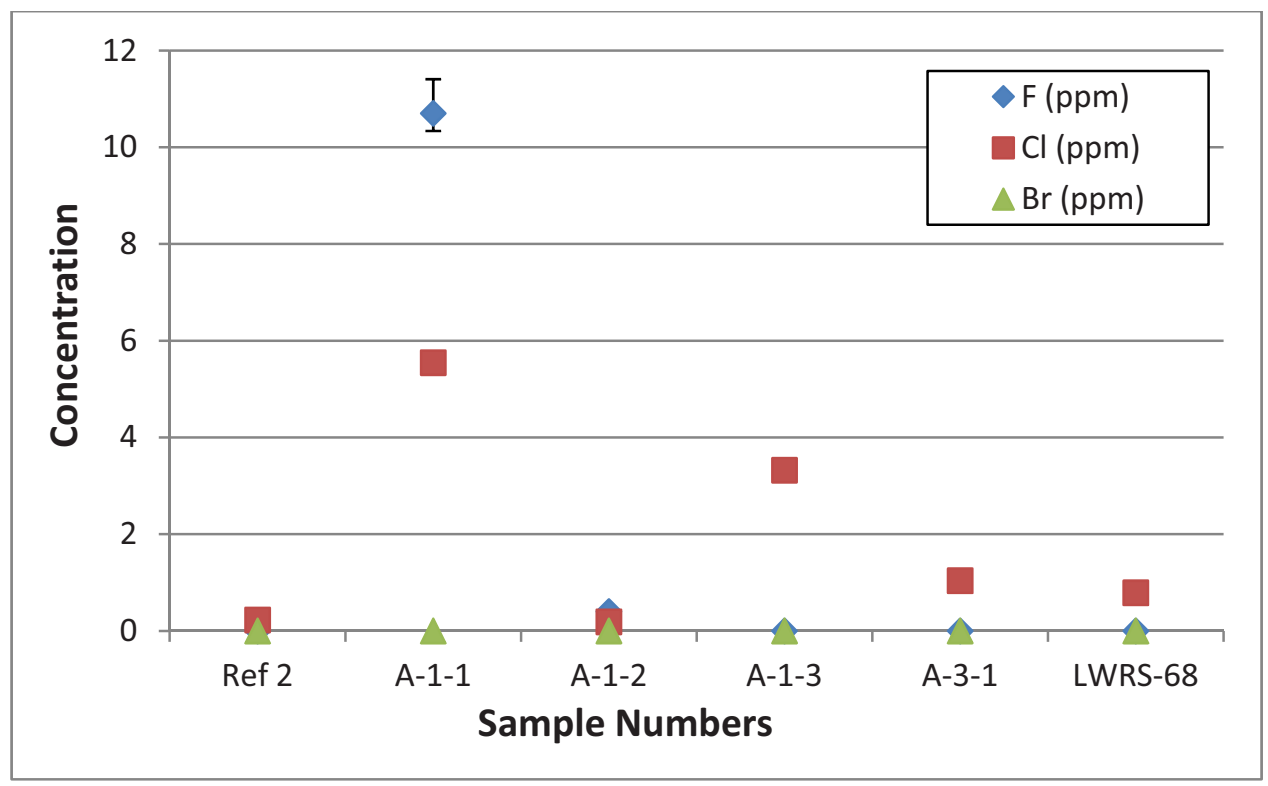

Figure 34. Figure showing the water analysis before and after gamma irradiation test 2 and is showing the increased $\mathrm{F}$ and $\mathrm{Si}$ content of the mini tube 2 sample (A-1-1) if compared with the rest of the gamma irradiated samples. The decreased $\mathrm{F}$ and $\mathrm{Cl}$ content of the cleaned sample A-1-2 are clearly visible.

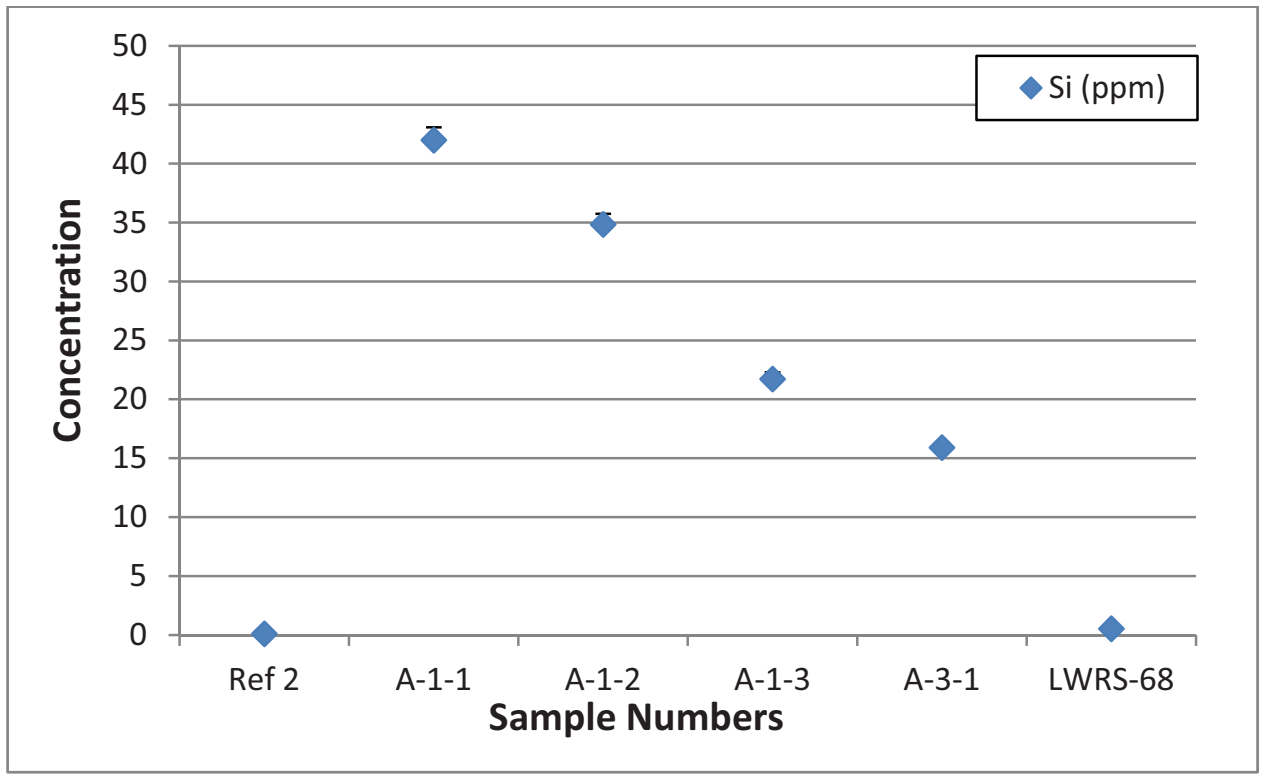

Figure 35. Figure showing the increased Si content of all SiC-CMC sleeve samples. The highest release was measured for the mini tube 2 sample (A-1-1) if compared with the rest of the gamma irradiated samples.

\subsubsection{Metallurgical Examination}

Metallurgical examinations of the mini tube (LWRS-1-6-A-1-1) and the respective sleeve samples shown in section 2.1.2 were examined in accordance with PLN-3964 using scanning electron microscopic examination and EDX analytical techniques. This examination's main focus was to investigate possible metallurgical changes in both the $\mathrm{Zr}-4$ tubes as well as in the SiC-CMC sleeve due to processing (fabrication) and/or irradiation effects. The interface properties will also be examined as this may give 
indications of possible fretting, corrosion and/or erosion activities which may result in decreased life expectancy. Changes to the planned sample locations were done to the discretion of the Characterization Principle Investigator (PI) and is reported in this section.

The micrographs in Figure 36 show the microstructure of the representative SiC-CMC sleeve subsamples of LWRS-1-6-A-1. More cracks in the SiC matrix material are observed due to the gamma irradiation treatment and some of the SiC material broke off. Specifically sample LWRS-1-6-A-1-2 showed the most spalling after irradiation. The SiC matrix material (samples LWRS-1-6-A-1-2 and LWRS-1-6-A-1-3) has a more cracked and "flaky" appearance after gamma irradiation if compared with the unirradiated material (sample LWRS-1-6-A-1-5). Figure 37 shows the microstructure of the mini tube 2 (LWRS-1-6-A-1-1) and showed similar cracked matrix behavior due to gamma irradiation. Evidence of bulky material removal is also seen as shown in Figure 37. The 1 ply SiC-CMC sleeve (LWRS-1-6-A-31) exhibits also matrix material removal during the irradiation process as shown in Figure 38.

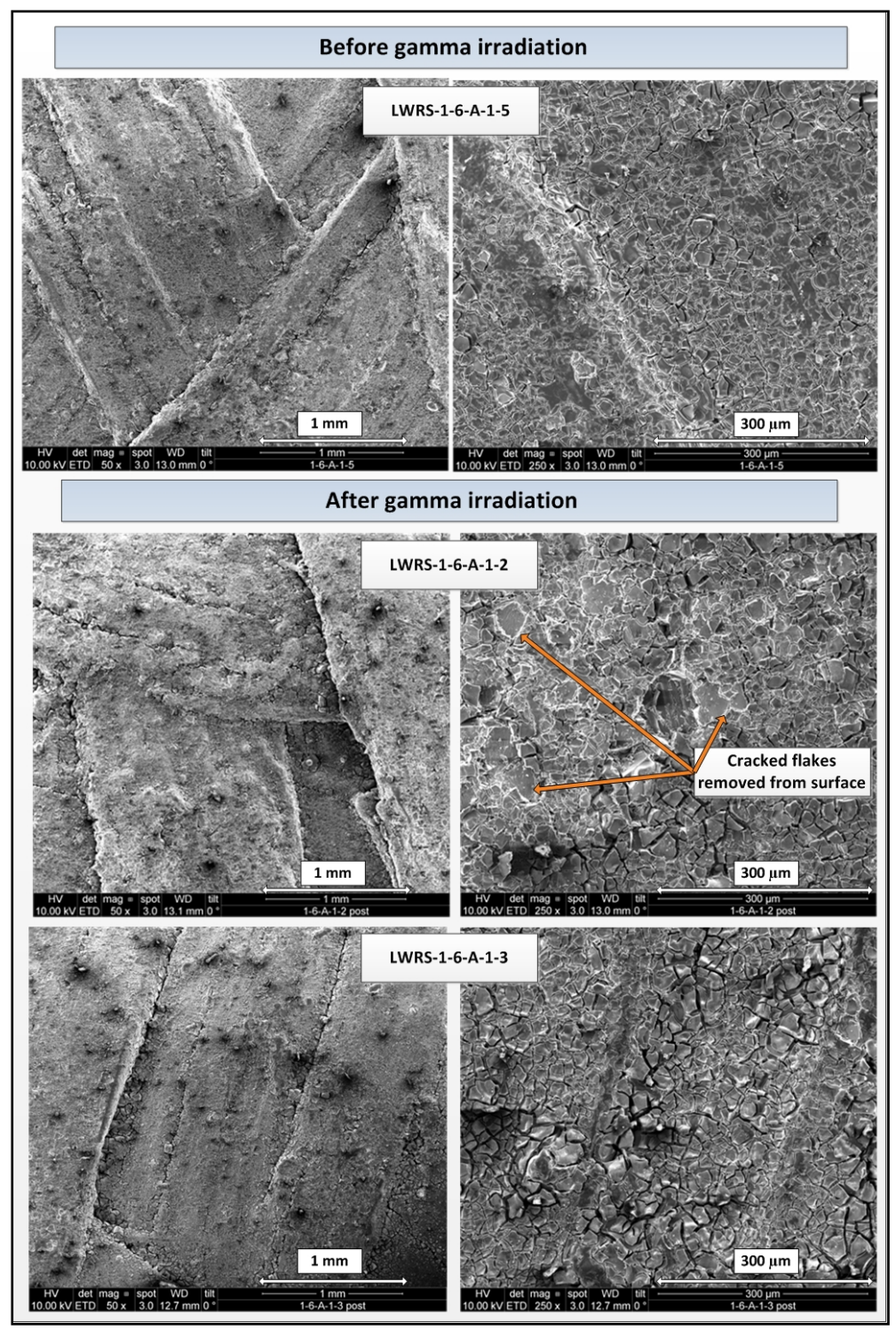

Figure 36. Micrographs showing the microstructure of the representative SiC-CMC sleeve subsamples of LWRS-1-6-A-1. More cracks in the SiC matrix material are observed after the gamma irradiation treatment and some of the SiC material broke off from especially sample LWRS-1-6-A-1-2 after the irradiation test. 


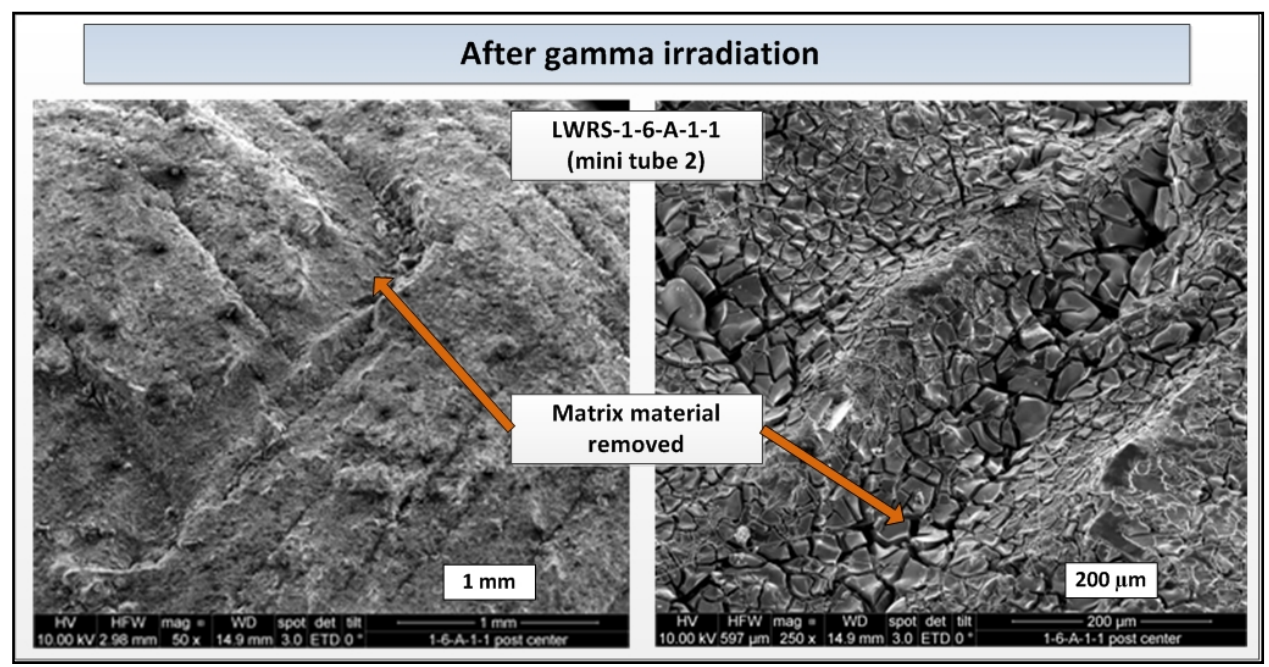

Figure 37. Micrographs showing the microstructure of the representative SiC-CMC sleeve subsamples of LWRS-1-6-A-3. The SiC matrix is removed during the gamma irradiation process.



Figure 38. Micrographs showing the microstructure of the representative SiC-CMC sleeve subsamples of LWRS-1-6-A-3. The SiC matrix is "eroded" during the gamma irradiation process. 


\section{LESSONS LEARNED}

The lessons learned by doing these two gamma irradiation tests are not only applicable to technical knowledge, but also to the methods and process controls. Main lessons learned are summarized below:

- Control of the samples was difficult as no designated laboratory was available for the full duration of the first experiment and only during the very last of the post irradiation characterization, a laboratory was made available.

- Method development:

- The standardization of measurement techniques and equipment caused an unknown measuring error and caused difficulty in the integration of results.

- The actual execution of the leach test needs more attention as the repeatability of the volume and the addition of water needs to be updated in the procedure as current process can be interpreted differently.

- Quality:

- Chemical composition sample labeling and follow-up caused initially delays and re-testing (possibly symptom of lack of control and methods )

- The cleaning and handling precautions are not standardize and needs more attention during the actual fabrication of samples and execution of experiments. All work requests, test plans, instruction documents needed to be reviewed and updated to include this. This needs to receive attention in pre-job briefings as well.

- Fabrication controls and requirements needs to be recorded to ensure that full traceability exist in raw material etc.

- $\quad$ Zr-4 raw material storage and traceability need attention and detail descriptions and record keeping of the samples provided for characterization needs to be provided to the characterization PI for review and inclusion in future characterization reports.

- Importance of pre-experiment characterization is demonstrated by the first gamma irradiation test. As an example the density values that could not be compared and fully used. Additionally the microstructural examination prior to experiment would have shown that the $\mathrm{SiC}$ matrix material is basically fully removed and then the experiment could have been re-evaluated.

- Control sample tests were not performed for comparison to the gamma irradiation results. Without this information, definitive conclusions about the effect of gamma irradiation on the material properties cannot be determined. Additional tests should be performed with a control sample set to validate the results.

\section{CONCLUSIONS}

Both two gamma irradiation tests provided valuable information for development purposes which can be summarized as follows.

\subsection{Gamma Irradiation Test 1}

- The various bonding agents used for gamma irradiation test 1 resulted in an increased $\mathrm{Cl}-, \mathrm{F}-$ and $\mathrm{Si}$ concentrations soluble in the water during irradiation with the $\mathrm{Cl}$ content exceeding the ATR control limit. It should be noted here that a leach test water results on the raw $\mathrm{SiC}$-fibers, already showed already the leaching of $\mathrm{Cl}$, although below the specification limit. It is this reasonable to argue that the increased $\mathrm{Cl}$-content is mainly due to the bonding agents. 
- The metallurgical examination of the bonded samples further also shows that cracking and degrading of the bonded layer and $\mathrm{SiC}$ matrix material occurred which may be the reason for the increased Cl-, F- and Si concentrations found.

- The high F- content in the water after gamma irradiation for the non-bonded SiC-CMC sleeve may possibly be explained as a remainder of the HF acid used for the leaching of the compromised Zircodyne tubes.

- As the SiC-CMC sleeve was not representative of the developed product due to the acid leaching, valid information on the $\mathrm{SiC}$ matrix material was lost in this initial gamma irradiation experiment.

- Full interpretation on the surface condition of the $\mathrm{Zr}$-4 tube after gamma irradiation could also not be made, as the control on the original raw stock used for these assemblies, were not monitored and was most probably already pitted prior to sample assembly. The tube material used for this experiment was however confirmed using EDX analysis, as Zr-4 and not Zircodyne.

- The metallurgical investigation revealed that the welding was defect free and no significant microstructural changes were observed in the $\mathrm{Zr}-4$ due to gamma irradiation. (Please note that this conclusion is based only on SEM analysis as no nanostructure analysis (TEM) was completed on these samples).

- The XRD analysis after gamma irradiation shows predominantly $\beta$-SiC with a trace of $\alpha$-SiC. No conclusion could be made if the presence of $\alpha-\mathrm{SiC}$ is solely due to the gamma irradiation, although it is not expected to be the cause.

- It was found that the $2 \mathrm{D}$ x-ray radiographic inspection provided no significant information as comparative purposes to evaluate the effect of gamma irradiation.

\subsection{Gamma Irradiation Test 2}

- The advantages of pre-gamma irradiation characterization are fully demonstrated by the battery of characterization test results in this report, but specifically the density and XRD values. It can be concluded that no significant differences exists between the 2 ply and 1 ply SiC-CMC sleeves both prior and after gamma irradiation. Additionally, no change in density could be conclusively determined due to gamma irradiation. The XRD patterns showed that no $\alpha$-SiC was present in either prior or after the irradiation.

- The advantages of 3D tomography were demonstrated during this experiment by showing:

- Gaps between the SiC-CMC sleeve and Zr-4 tube at any distance alongside the tube

- Inner and outer surface morphology can be evaluated

- Open porosity can be identified

- Braided weave patterns can be observed

- Leach test analysis prior to gamma irradiation revealed that more $\mathrm{Cl}$ (20 times) and $\mathrm{Si}$ (3 times) are released for the 2 ply braided SiC-CMC sleeves if compared with the 1 ply sleeve. This observation continued with the water analysis after gamma irradiation with the $\mathrm{Cl}$ content for the 1 ply be generally lower than for the 2 ply sleeve samples. The exclusion to this generalization is that the pre-cleaned sample of the 2 ply $\mathrm{SiC}-\mathrm{CMC}$ sleeve had the overall lowest $\mathrm{Cl}$ releases during gamma irradiation.

- $\quad$ Significant higher $\mathrm{Cl}, \mathrm{F}$ and $\mathrm{Si}$ releases from the mini tube suggest possible contamination during the fabrication steps, although the possible sources thereof is not speculated in this report.

- The SEM microstructural examination of the 2 ply samples shows that more cracks and flakes are visible in the $\mathrm{SiC}$ matrix material after the gamma irradiation treatment and even some of the $\mathrm{SiC}$ matrix flakes broke off from the pre-cleaned 2 ply sample LWRS-1-6-A-1-2 after gamma irradiation 
in water. SiC matrix material removal was evident on both the mini tube 2 and the 1 ply sample die to irradiation.

\section{RECOMMENDATIONS}

These two preliminary gamma irradiation tests provided relevant technical information for the improvement of the SiC-CMC sleeve design of the prototypes. It is recommended that the gamma irradiation experiment results be used as an input for design selections and neutron reactor insertion.

It is further recommended that the future gamma irradiation experiments include EBSD, FTIR and TEM examinations to provide insight in possible changes on nano level.

Updates and modifications to the various test plans are needed based on the lessons learned during the execution of the tests/characterization techniques. These needs to be in place prior to the gamma irradiation experiment of the actual prototypes.

As these samples were processed using different number of PIP cycles, it is recommended that the gamma irradiation test prior to reactor insertion be executed $n$ samples of fully representative processing cycles and therefore be fully be classified as "prototype" samples.

These results needs to be integrated with the whole battery of "prototype" tests prescribed in the cold characterization plan. Specifically, the heat up cycling and corrosion flow tests will provide additional information on the separate effects of water and temperature.

\section{REFERENCES}

[1] LWRS Fuel Development Plan

[2] PLN-3927 Cold Characterization Plan for LWRS-1 hybrid SiC-CMC/Zircalloy-4 fuel experiment

[3] PLN-3971 Project Execution Plan for the Light Water Reactor Sustainability (LWRS) Advanced LWR Nuclear Fuel Development Pathway experiments in the ATR

[4] INL/MIS-10-19844 Light Water Reactor Sustainability Program Quality Assurance Program Description Document

[5] MCP-2875

[6] LWP-1201 "Document Change Configuration Management"

[7] PLN-3963 Gamma Irradiation test plan

[8] PLN-3961 Visual and Dimensional inspection test plan

[9] PLN-3950 X-Ray tomography test plan

[10] PLN-3960 Leach test plan

[11] SAR-153, Chapter 10, Section 10.1.7.3.3, "Containment of Materials"

[12] SP-10.3.1.13 (referencing SAR-153)

[13] PLN-3964 Metallurgical examination of LWRS-1 hybrid tube and welded end caps test plan

[14] PLN-3957 Density test plan

[15] ASTM B 311-08, "Standard Test Method for: "Density of Powder Metallurgy (PM) Materials Containing Less than Two Percent Porosity." 


\section{Appendix A}

\section{Quality Labels of the SiC-CMC Sleeves and Mock-Up Mini Tubes Used for Gamma Irradiation Tests 1 and 2}

NCR Tag No. $460343 \operatorname{Tag} 1$ Date $10 / 18 / 11$

NCR Item: $\angle W R S-1-6-A-2 \div \angle W R S-1-6-A-3$

Expiration Date: $\quad 9 / 30 / 2012$

Limitations/Conditions: The S.C/CAC Tubes Shall be Used

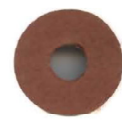

Only for Prototype ¿ Design Development Testing

NCR Tag No. $46346-\operatorname{Tag} * 1$ Date $10 / 20 / 11$

NCR Item: ATR LVBS "I"Hole "Mock-4p"Capoule

Expiration Date:

$9 / 30 / 2012$

Limitations/Conditions: Reference NCR
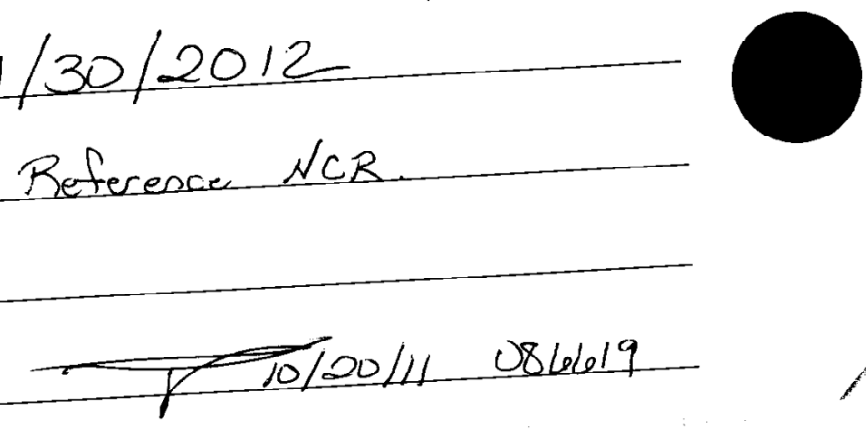


\section{Appendix B}

\section{Ion Chromatography Spectra Showing Spectrum of Calibration Standard and Sample $2 \mathrm{~W}$ as an Example}

Below are two Ion Chromatography spectra, Figure B-1 showing the spectrum of a calibration standard and Figure B-2 showing the spectrum of a sample denoted as 2W. As can be seen in Figure B-2, there are some minor fluoride and chloride peaks, but no bromide peaks, as compared to Figure B-1 (which is the calibration standard for these elements).

\begin{tabular}{|c|c|c|c|c|c|c|}
\hline No. & $\begin{array}{c}\text { Time } \\
\min \end{array}$ & Peak Name & Type & $\begin{array}{c}\text { Area } \\
\mu \mathrm{S}^{*} \min \end{array}$ & $\begin{array}{c}\text { Height } \\
\mu \mathrm{S}\end{array}$ & $\begin{array}{c}\text { Amount } \\
\mathrm{ppm}\end{array}$ \\
\hline 1 & 3.11 & Fluoride & $\mathrm{BMB}^{*}$ & 2.479 & 25.203 & n.a. \\
\hline 2 & 4.36 & Chloride & $\mathrm{BMB}^{*}$ & 1.533 & 14.198 & n.a. \\
\hline 3 & 7.09 & Bromide & $\mathrm{BMB}$ & 0.640 & 3.758 & n.a. \\
\hline \multicolumn{2}{|c|}{ TOTAL: } & 4.65 & 43.16 & 0.00 \\
\hline
\end{tabular}

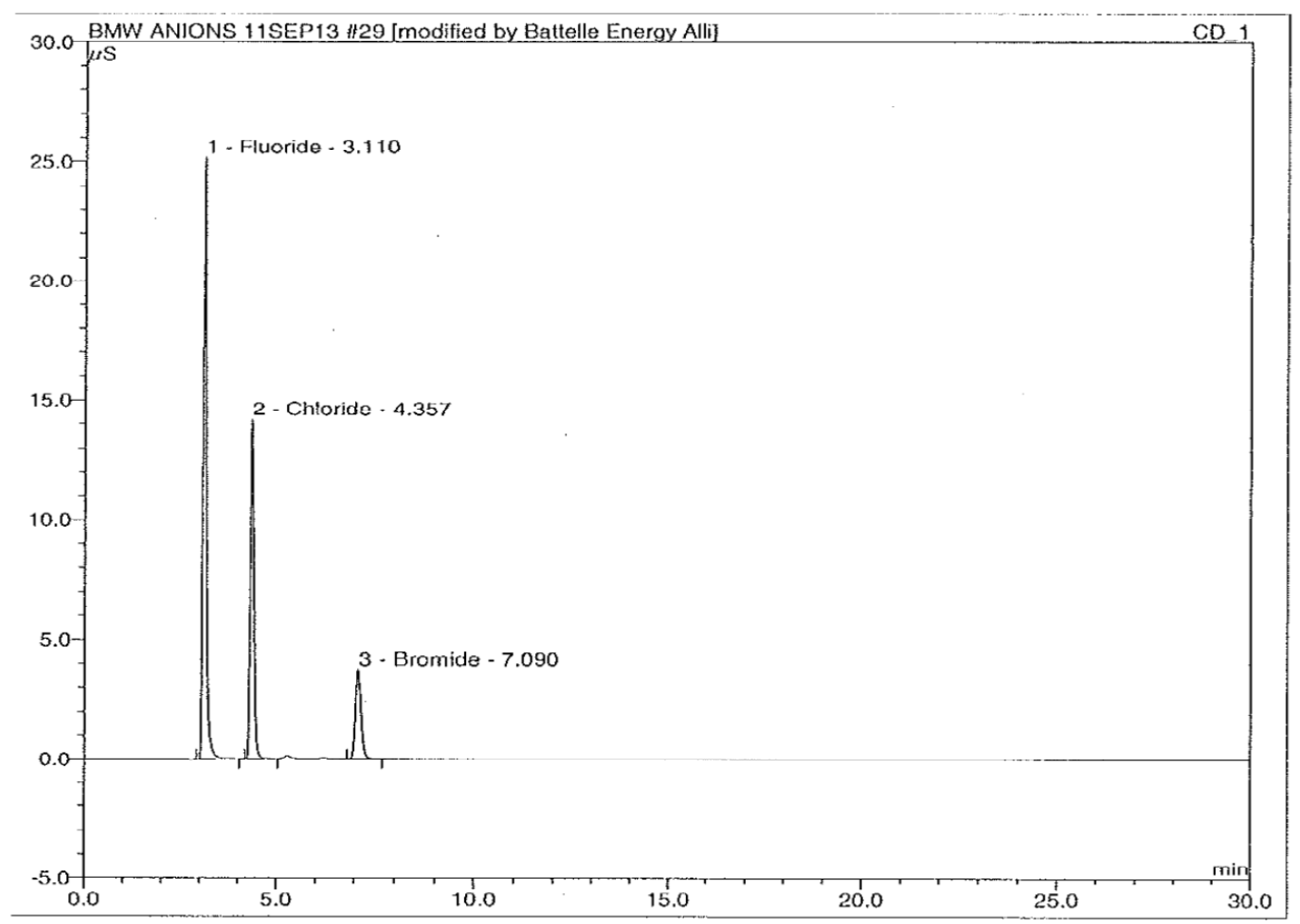

Figure B-1. Calibration Standard for Ion Chromatography Spectrum. 


\begin{tabular}{|c|c|c|c|c|c|c|}
\hline No. & $\begin{array}{c}\text { Time } \\
\mathrm{min}\end{array}$ & Peak Name & Type & $\begin{array}{c}\text { Area } \\
\mu \mathrm{S}^{*} \mathrm{~min}\end{array}$ & $\begin{array}{c}\text { Height } \\
\mu \mathrm{S}\end{array}$ & $\begin{array}{c}\text { Amount } \\
\mathrm{ppm}\end{array}$ \\
\hline 1 & 3.11 & Fluoride & $\mathrm{BM}^{*}$ & 0.523 & 6.340 & n.a. \\
\hline 2 & 4.36 & Chloride & $\mathrm{BMB}^{*}$ & 0.133 & 1.302 & n.a. \\
\hline \multicolumn{2}{|c|}{ TOTAL: } & 0.66 & 7.64 & 0.00 \\
\hline
\end{tabular}

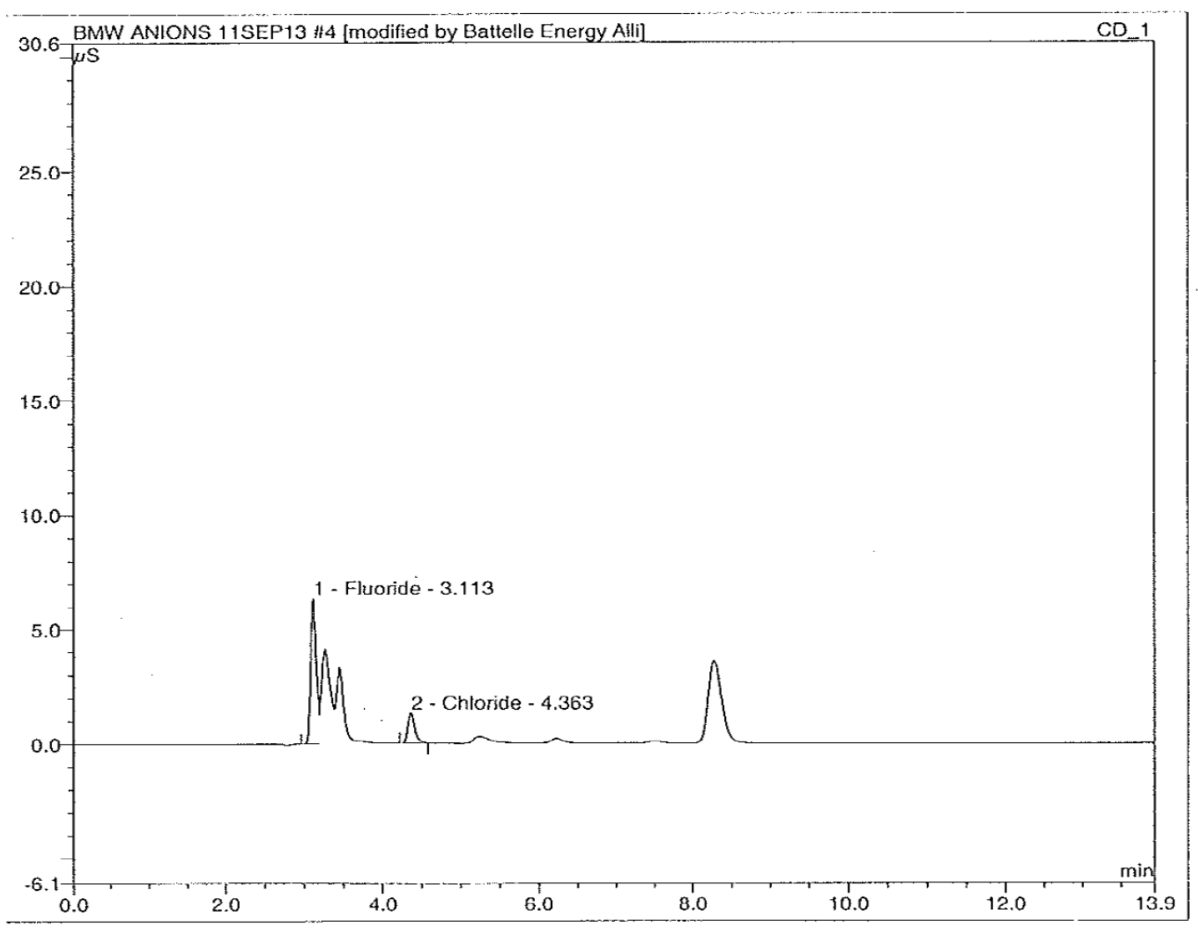

Figure B-2. Sample 2W Ion Chromatography Spectrum. 


\section{Appendix C}

\section{Detail of Dimensional and Weight Measurements of Gamma Irradiation Test 1 Samples}

Table C-1. Gamma irradiation test 1: SiC dimensional measurements prior and after gamma irradiation.

\begin{tabular}{|c|c|c|c|c|c|c|}
\hline \multirow[b]{2}{*}{$\begin{array}{c}\text { Sample } \\
\text { No. }\end{array}$} & $\begin{array}{c}\text { Before Gamma } \\
\text { Irradiation }\end{array}$ & $\begin{array}{c}\text { After Gamma } \\
\text { Irradiation }\end{array}$ & \multirow{2}{*}{$\begin{array}{c}\text { Variance } \\
\text { in } \mathrm{SiC} \\
\text { length } \\
(\%)\end{array}$} & $\begin{array}{c}\text { Prior Gamma } \\
\text { Irradiation } \\
\end{array}$ & $\begin{array}{c}\text { After Gamma } \\
\text { Irradiation } \\
\end{array}$ & \multirow{2}{*}{$\begin{array}{c}\text { Variance } \\
\text { in } \mathrm{SiC} \\
\text { Diameter } \\
(\%)\end{array}$} \\
\hline & $\begin{array}{c}\text { Length } \mathrm{SiC} \\
(\mathrm{mm})\end{array}$ & $\begin{array}{c}\text { Length SiC } \\
(\mathrm{mm})\end{array}$ & & $\begin{array}{c}\text { Diameter SiC } \\
(\mathrm{mm})\end{array}$ & $\begin{array}{c}\text { Diameter SiC } \\
(\mathbf{m m})\end{array}$ & \\
\hline 2 & 7.99 & 8.39 & 5.01 & 11.05 & 11.18 & 1.16 \\
\hline $2 \mathrm{~W}$ & 9.09 & 10.02 & 10.23 & 11.12 & 11.3 & 1.59 \\
\hline 3 & 9.09 & 9.55 & 5.06 & 11.65 & 12.87 & 9.48 \\
\hline $3 \mathrm{~W}$ & 9.35 & 11.34 & 21.33 & 10.86 & 11.37 & 4.49 \\
\hline 4 & 10.98 & 10.7 & -2.51 & 11.77 & 11.92 & 1.26 \\
\hline $4 \mathrm{~W}$ & 9.39 & 9.41 & 0.21 & 11.34 & 11.78 & 3.74 \\
\hline 5 & 9.99 & 10.49 & 5.01 & 11.27 & 11.62 & 3.01 \\
\hline $5 \mathrm{~W}$ & 9.28 & 8.91 & -3.99 & 9.46 & 11.47 & 17.52 \\
\hline
\end{tabular}

Table C-2. Gamma irradiation test 1: Zr-4 tube dimensional measurements prior and after gamma irradiation.

\begin{tabular}{|c|c|c|c|c|c|c|}
\hline \multirow[b]{2}{*}{$\begin{array}{c}\text { Sample } \\
\text { No. }\end{array}$} & \multirow{2}{*}{$\begin{array}{c}\text { Before Gamma } \\
\text { Irradiation }\end{array}$} & \multirow{2}{*}{$\begin{array}{c}\text { After Gamma } \\
\text { Irradiation } \\
\begin{array}{c}\text { Length } \mathrm{Zr}-4 \\
(\mathbf{m m})\end{array} \\
\end{array}$} & \multirow{2}{*}{$\begin{array}{c}\text { Variance } \\
\text { in } \mathrm{Zr}-4 \\
\text { length } \\
(\%) \\
\end{array}$} & \multirow{2}{*}{$\begin{array}{c}\begin{array}{c}\text { Prior Gamma } \\
\text { Irradiation }\end{array} \\
\text { Diameter } \\
\mathrm{Zr}-4(\mathrm{~mm}) \\
\end{array}$} & \multirow{2}{*}{$\begin{array}{c}\text { After Gamma } \\
\text { Irradiation } \\
\begin{array}{c}\text { Diameter } \mathrm{Zr}- \\
4(\mathrm{~mm})\end{array} \\
\end{array}$} & \multirow{2}{*}{$\begin{array}{c}\text { Variance } \\
\text { in } \mathrm{Zr}-4 \\
\text { Diameter } \\
(\%)\end{array}$} \\
\hline & & & & & & \\
\hline 2 & 19.09 & $\begin{array}{r}19.1 \\
\end{array}$ & 0.05 & 9.46 & 9.46 & 0.00 \\
\hline $2 \mathrm{~W}$ & 19.1 & 19.22 & 0.63 & 9.59 & 9.61 & 0.21 \\
\hline 3 & 19.34 & 19.31 & -0.16 & 9.65 & 9.63 & -0.21 \\
\hline $3 \mathrm{~W}$ & 20 & 20.11 & 0.55 & 9.49 & 9.48 & -0.11 \\
\hline 4 & 19.85 & 19.95 & 0.50 & 9.74 & 9.6 & -1.44 \\
\hline $4 \mathrm{~W}$ & 19.38 & 19.52 & 0.72 & 9.59 & 9.46 & -1.36 \\
\hline 5 & 19.75 & 19.85 & 0.51 & 9.77 & 9.74 & -0.31 \\
\hline $5 \mathrm{~W}$ & 19.59 & 19.72 & 0.66 & 11.4 & 9.47 & -16.93 \\
\hline 6 & 20.37 & 20.4 & 0.15 & 9.54 & 9.5 & -0.42 \\
\hline $6 \mathrm{~W}$ & 19.21 & 19.24 & 0.16 & 9.56 & 9.55 & -0.10 \\
\hline
\end{tabular}


Table C-3. Weight measurements of total assembly.

\begin{tabular}{|l|r|r|r|}
\hline $\begin{array}{c}\text { Sample } \\
\text { Number }\end{array}$ & $\begin{array}{c}\text { Weight (g) } \\
\text { Before gamma } \\
\text { Irradiation }\end{array}$ & $\begin{array}{c}\text { Weight (g) } \\
\text { After Gamma } \\
\text { Irradiation }\end{array}$ & \multicolumn{2}{c|}{$\begin{array}{c}\text { Variance in } \\
\text { Weight } \\
(\%)\end{array}$} \\
\hline 2 & 2.16 & 2.16 & -0.05 \\
\hline $2 \mathrm{~W}$ & 3.31 & 3.32 & 0.30 \\
\hline 3 & 3.50 & 3.50 & 0.23 \\
\hline $3 \mathrm{~W}$ & 2.27 & 2.28 & 0.22 \\
\hline 4 & 3.65 & 3.66 & 0.38 \\
\hline $4 \mathrm{~W}$ & 2.38 & 2.37 & -0.04 \\
\hline 5 & 2.36 & 2.37 & 0.42 \\
\hline $5 \mathrm{~W}$ & 2.33 & 2.33 & 0.09 \\
\hline 6 & 3.28 & 3.28 & -0.03 \\
\hline $6 \mathrm{~W}$ & 3.10 & 3.10 & 0.00 \\
\hline
\end{tabular}




\section{Appendix D}

\section{Typical Elemental Composition of Zicaloy-4 and Zircodyne 702 Alloys}

Table D-1. Composition of Zircaloy Alloys. COMPOSITION (WEIGHT PERCENT)

\begin{tabular}{|l|l|l|l|}
\hline Name & Zircaloy-2 & Zircaloy-4 & Zr-2.5Nb \\
\hline UNS Grade & R60802 & R60804 & R60904 \\
\hline Tin & $1.20-1.70$ & $1.20-1.70$ & -- \\
\hline Iron & $0.07-0.20$ & $0.18-0.24$ & --- \\
\hline Chromium & $0.05-0.15$ & $0.07-0.13$ & --- \\
\hline Nickel & $0.03-0.08$ & -- & -- \\
\hline Niobium & --- & -- & $2.40-2.80$ \\
\hline Oxygen & Per P.O. & Per P.O. & Per P.O. \\
\hline Iron + Chromium + Nickel & $0.18-0.38$ & --- & --- \\
\hline Iron + Chromium & --- & $0.28-0.37$ & --- \\
\hline
\end{tabular}

MAXIMUM IMPURITIES, WEIGHT \%

\begin{tabular}{|l|l|l|l|}
\hline Name & Zircaloy-2 & Zircaloy-4 & Zr-2.5Nb \\
\hline Aluminum & 0.0075 & 0.0075 & 0.0075 \\
\hline Boron & 0.00005 & 0.00005 & 0.00005 \\
\hline Cadmium & 0.00005 & 0.00005 & 0.00005 \\
\hline Carbon & 0.027 & 0.027 & 0.027 \\
\hline Chromium & --- & -- & 0.010 \\
\hline Cobalt & 0.0020 & 0.0020 & 0.0020 \\
\hline Copper & 0.0050 & 0.0050 & 0.0050 \\
\hline Hafnium & 0.010 & 0.010 & 0.005 \\
\hline Hydrogen & 0.0025 & 0.0025 & 0.0010 \\
\hline Iron & -- & -- & 0.150 \\
\hline Magnesium & 0.0020 & 0.0020 & 0.0020 \\
\hline Manganese & 0.0050 & 0.0050 & 0.0050 \\
\hline Molybdenum & 0.0050 & 0.0050 & 0.0050 \\
\hline Nickel & -- & 0.0070 & 0.0070 \\
\hline Nitrogen & 0.0080 & 0.0080 & 0.0065 \\
\hline Phosphorus & -- & -- & 0.0020 \\
\hline Silicon & 0.0120 & 0.0120 & 0.010 \\
\hline Tin & -- & -- & 0.0050 \\
\hline Tungsten & 0.010 & 0.010 & 0.005 \\
\hline Titanium & 0.0050 & 0.0050 & 0.0050 \\
\hline Uranium (total) & 0.00035 & 0.00035 & 0.00035 \\
\hline & & & \\
\hline
\end{tabular}


Table D-2. Chemical Composition of Zircadyne Alloys.

\begin{tabular}{|l|l|l|}
\hline \multicolumn{2}{|l|}{ Table 1. Chemical Compositlons of Zlicadyne Alloys } \\
\hline Grade & Zr 702 & Zr 705 \\
\hline UNS Designation & R60702 & R60705 \\
\hline & & \\
\hline Element & Weight \% & Weight \% \\
\hline Zirconium + Hafnium, min & 99.2 & 95.5 \\
\hline Hafnium, max & 4.5 & 4.5 \\
\hline Iron + Chromium, max & 0.20 & 0.20 \\
\hline Tin & - & - \\
\hline Hydrogen, max & 0.005 & 0.005 \\
\hline Nitrogen, max & 0.025 & 0.025 \\
\hline Carbon, max & 0.05 & 0.05 \\
\hline Niobium (Columbium) & - & $2.0-3.0$ \\
\hline Oxygen, max & 0.16 & 0.18 \\
\hline
\end{tabular}




\section{Appendix E}

\section{SEM-EDS Analysis of Various Areas of Zr-4 Tube Samples (LWRS-67 and LWRS-68) in the As-Received Conditions}

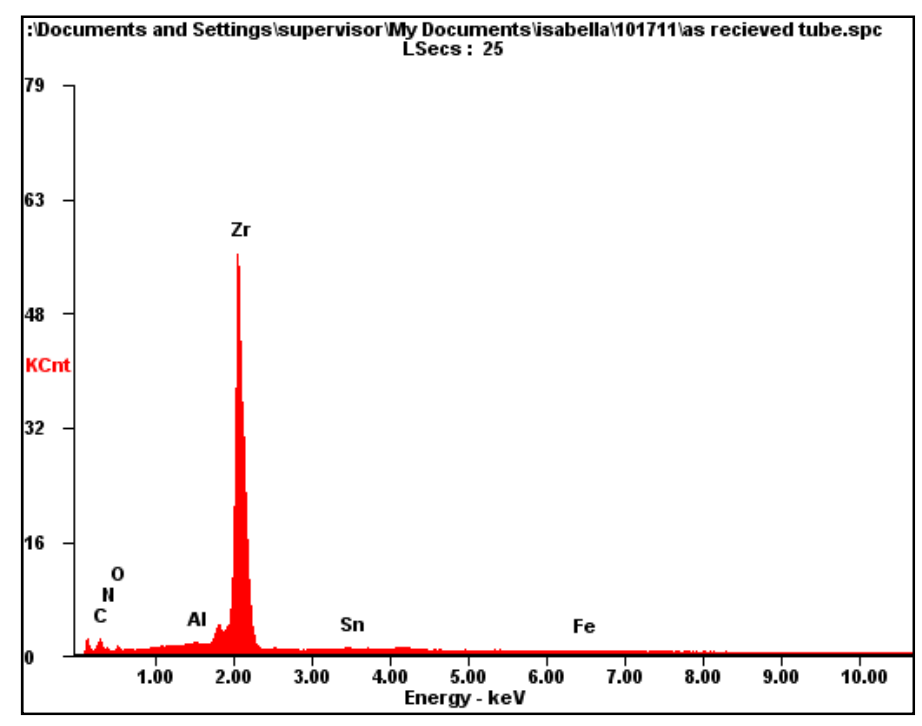

\begin{tabular}{||l|c|c||}
\hline Element & $\boldsymbol{W t} \%$ & $\boldsymbol{A t} \%$ \\
\hline $\boldsymbol{C} \boldsymbol{K}$ & 14.00 & 49.02 \\
\hline $\boldsymbol{N} \boldsymbol{K}$ & 03.18 & 09.56 \\
\hline $\boldsymbol{O} \boldsymbol{K}$ & 01.58 & 04.14 \\
\hline $\boldsymbol{Z r L}$ & 79.56 & 36.69 \\
\hline $\boldsymbol{S n L}$ & 01.68 & 00.60 \\
\hline
\end{tabular}

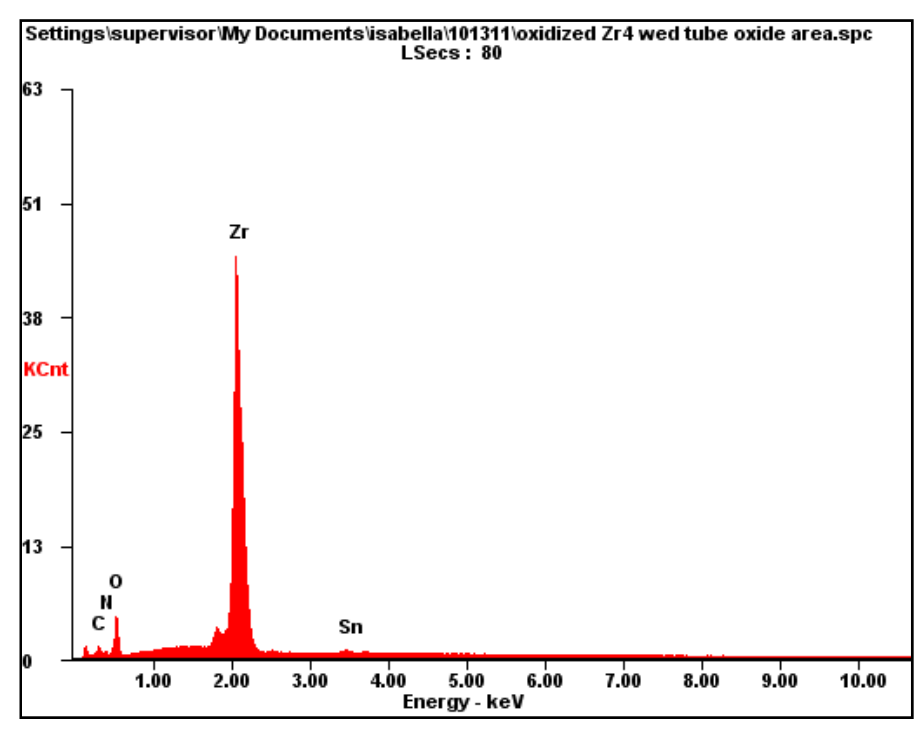

\begin{tabular}{||l|c|c||}
\hline Element & $\boldsymbol{W t} \%$ & $\boldsymbol{A t} \%$ \\
\hline $\boldsymbol{C K}$ & 04.91 & 16.83 \\
\hline $\boldsymbol{N} \boldsymbol{K}$ & 03.01 & 08.85 \\
\hline $\boldsymbol{O} \boldsymbol{K}$ & 15.53 & 39.95 \\
\hline $\boldsymbol{Z r L}$ & 75.03 & 33.84 \\
\hline $\boldsymbol{S n L}$ & 01.51 & 00.52 \\
\hline \hline
\end{tabular}




\section{Appendix F}

\section{Detail of Density Measurements: Gamma Irradiation Test 1}

\begin{tabular}{|c|c|c|c|c|c|c|c|c|c|c|}
\hline \multicolumn{2}{|c|}{ Measured 10-31-2011 } & & & & & & & & & \\
\hline \multicolumn{11}{|c|}{ Theo-dens means the accepted density of $\mathrm{SiC}$, the column to the right is Density /Theo-dens in percent } \\
\hline 1 & $10 / 31 / 2011$ & & Mass & Water & & & & & & \\
\hline & \# & Mass Dry & Immersed & Density & & & Density & $\begin{array}{l}\text { Theo- } \\
\text { dens }\end{array}$ & $\%$ & \\
\hline & $2 \mathrm{~W}$-tube & 0.2147 & 0.1134 & 0.9978 & 0.1013 & 0.2142 & 2.11 & 3.9976 & 52.90 & 1 \\
\hline & 2-tube & 0.2096 & 0.1336 & 0.9978 & 0.0760 & 0.2091 & 2.75 & 3.9976 & 68.84 & 2 \\
\hline & LWRS-18-1 & 0.2341 & 0.1503 & 0.9978 & 0.0838 & 0.2336 & 2.79 & 3.9976 & 69.73 & 3 \\
\hline & Check & 1.0000 & 0.5000 & 0.9978 & 0.5000 & 0.9978 & 2.00 & 3.9976 & 49.92 & 4 \\
\hline 2 & $10 / 31 / 2011$ & & Mass & Water & & & & & & \\
\hline & \# & Mass Dry & Immersed & Density & & & Density & $\begin{array}{l}\text { Theo- } \\
\text { dens }\end{array}$ & $\%$ & \\
\hline & $2 \mathrm{~W}$-tube & 0.2147 & 0.1337 & 0.9978 & 0.0810 & 0.2142 & 2.64 & 3.9976 & 66.16 & 1 \\
\hline & 2-tube & 0.2096 & 0.1329 & 0.9978 & 0.0767 & 0.2091 & 2.73 & 3.9976 & 68.21 & 2 \\
\hline & LWRS-18-1 & 0.2341 & 0.1499 & 0.9978 & 0.0842 & 0.2336 & 2.77 & 3.9976 & 69.40 & 3 \\
\hline & Check & 1.0000 & 0.5000 & 0.9978 & 0.5000 & 0.9978 & 2.00 & 3.9976 & 49.92 & 4 \\
\hline \multicolumn{11}{|c|}{ Measured 10-31-2012 } \\
\hline \multicolumn{11}{|c|}{ Theo-dens means the accepted density of $\mathrm{SiC}$, the column to the right is Density /Theo-dens in percent } \\
\hline 3 & $11 / 1 / 2011$ & & Mass & Water & & & & & & \\
\hline & \# & Mass Dry & Immersed & Density & & & Density & $\begin{array}{c}\text { Theo- } \\
\text { dens }\end{array}$ & $\%$ & \\
\hline & $2 \mathrm{~W}$-tube & 1.0097 & 0.5185 & 0.9978 & 0.4913 & 1.0075 & 2.05 & 3.9976 & 51.30 & 2.906977 \\
\hline & 2-tube & 1.2477 & 0.6361 & 0.9978 & 0.6116 & 1.2450 & 2.04 & 3.9976 & 50.92 & 2.965116 \\
\hline & LWRS-18-2 & 1.4858 & 0.7538 & 0.9978 & 0.7320 & 1.4825 & 2.03 & 3.9976 & 50.66 & 3.023256 \\
\hline & Check & 1.7238 & 0.8714 & 0.9978 & 0.8524 & 1.7200 & 2.02 & 3.9976 & 50.48 & 3.081395 \\
\hline & & & & & & & & & & 3.139535 \\
\hline & & & & & & & & & & 3.197674 \\
\hline & & & & & & & & & & 3.255814 \\
\hline 4 & $10 / 31 / 2011$ & & Mass & Water & & & & & & \\
\hline & \# & Mass Dry & Immersed & Density & & & Density & $\begin{array}{c}\text { Theo- } \\
\text { dens }\end{array}$ & $\%$ & \\
\hline & $2 \mathrm{~W}$-tube & 0.2147 & 0.1346 & 0.9978 & 0.0801 & 0.2142 & 2.67 & 3.9976 & 66.90 & 1 \\
\hline & 2-tube & 0.2096 & 0.1343 & 0.9978 & 0.0753 & 0.2091 & 2.78 & 3.9976 & 69.48 & 2 \\
\hline & LWRS-18-1 & 0.2341 & 0.1494 & 0.9978 & 0.0847 & 0.2336 & 2.76 & 3.9976 & 68.99 & 3 \\
\hline & Check & 1.0000 & 0.5000 & 0.9978 & 0.5000 & 0.9978 & 2.00 & 3.9976 & 49.92 & 4 \\
\hline
\end{tabular}




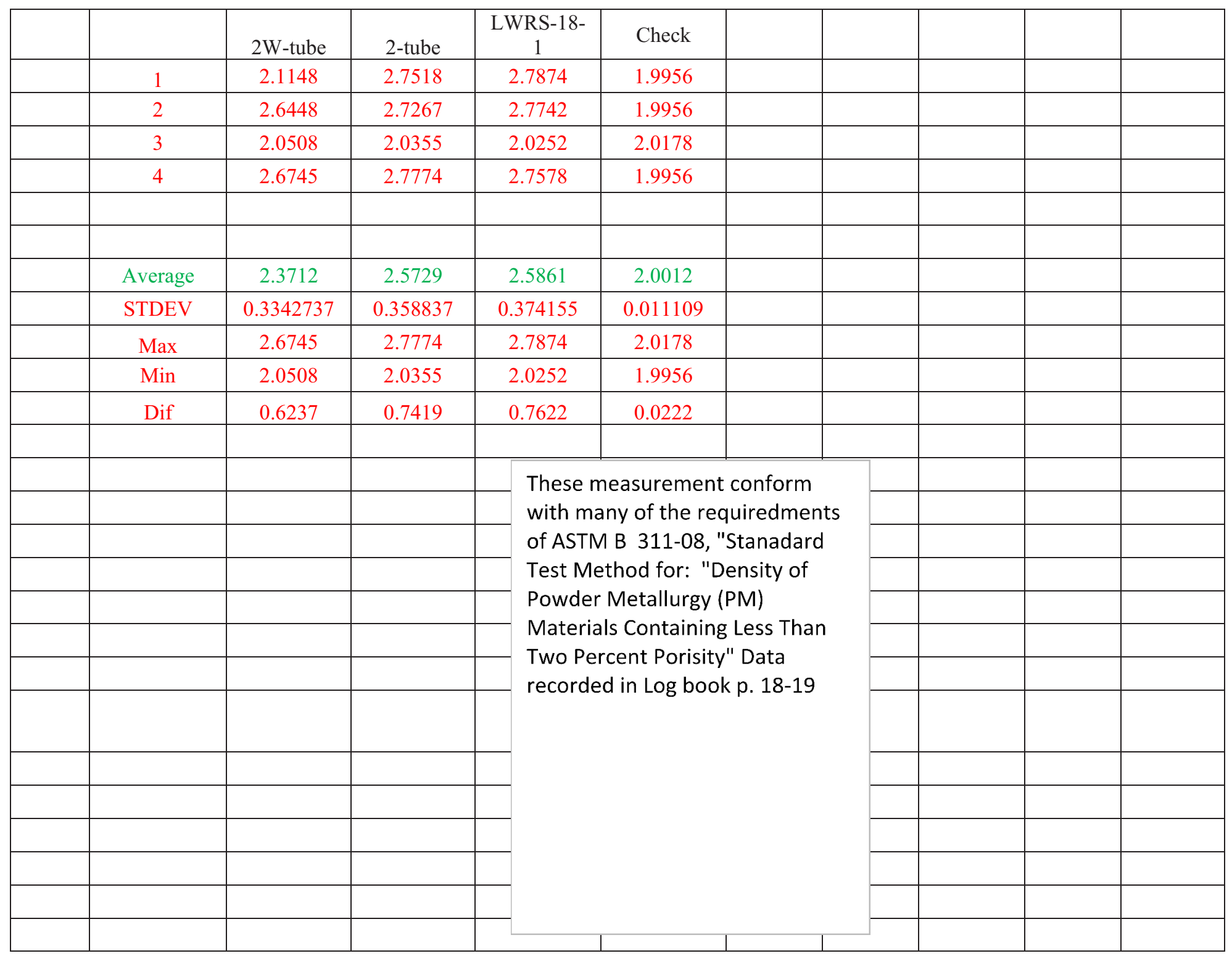


Appendix G

\section{Original XRD Results of Gamma Irradiation Test 1 Samples}
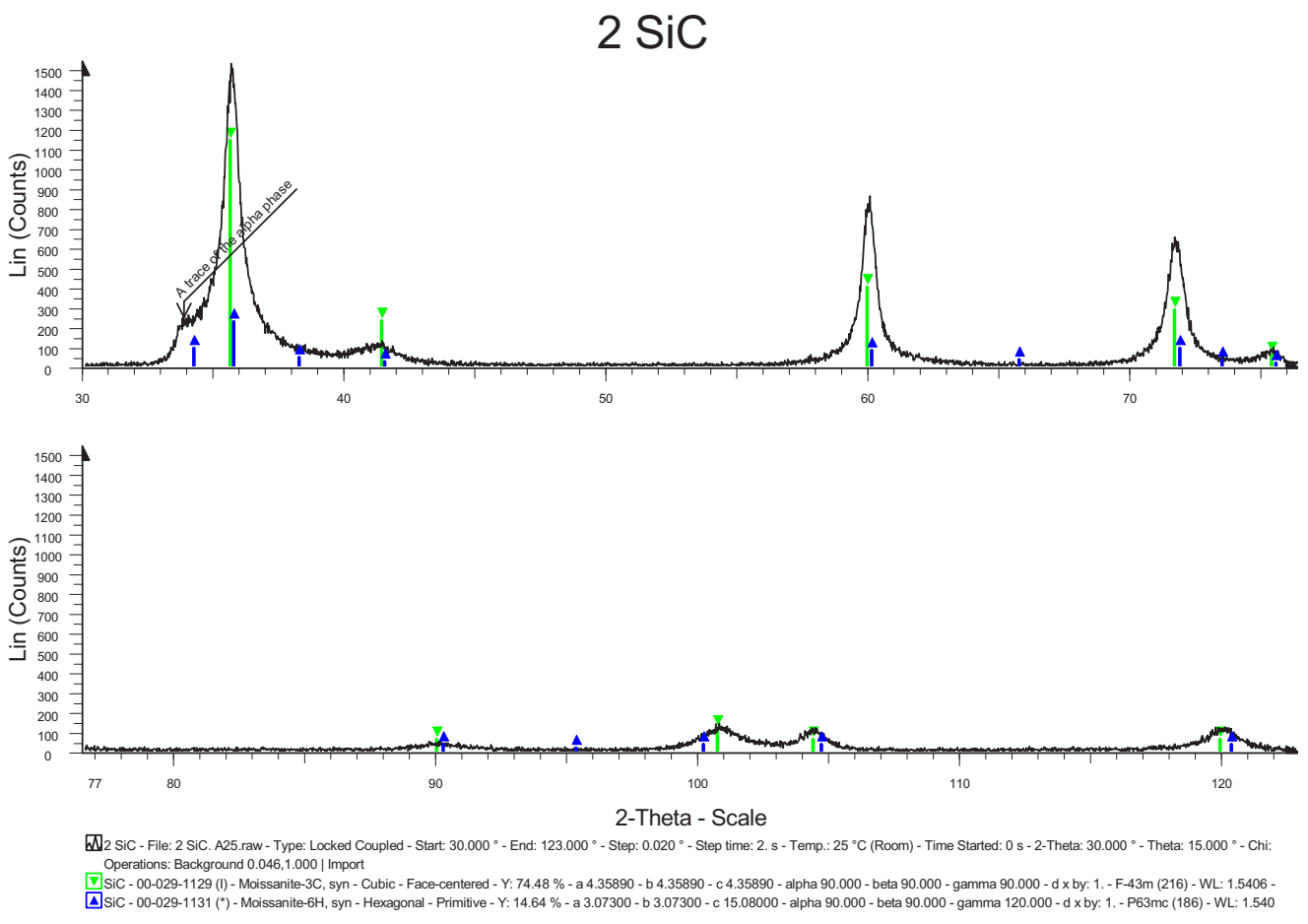

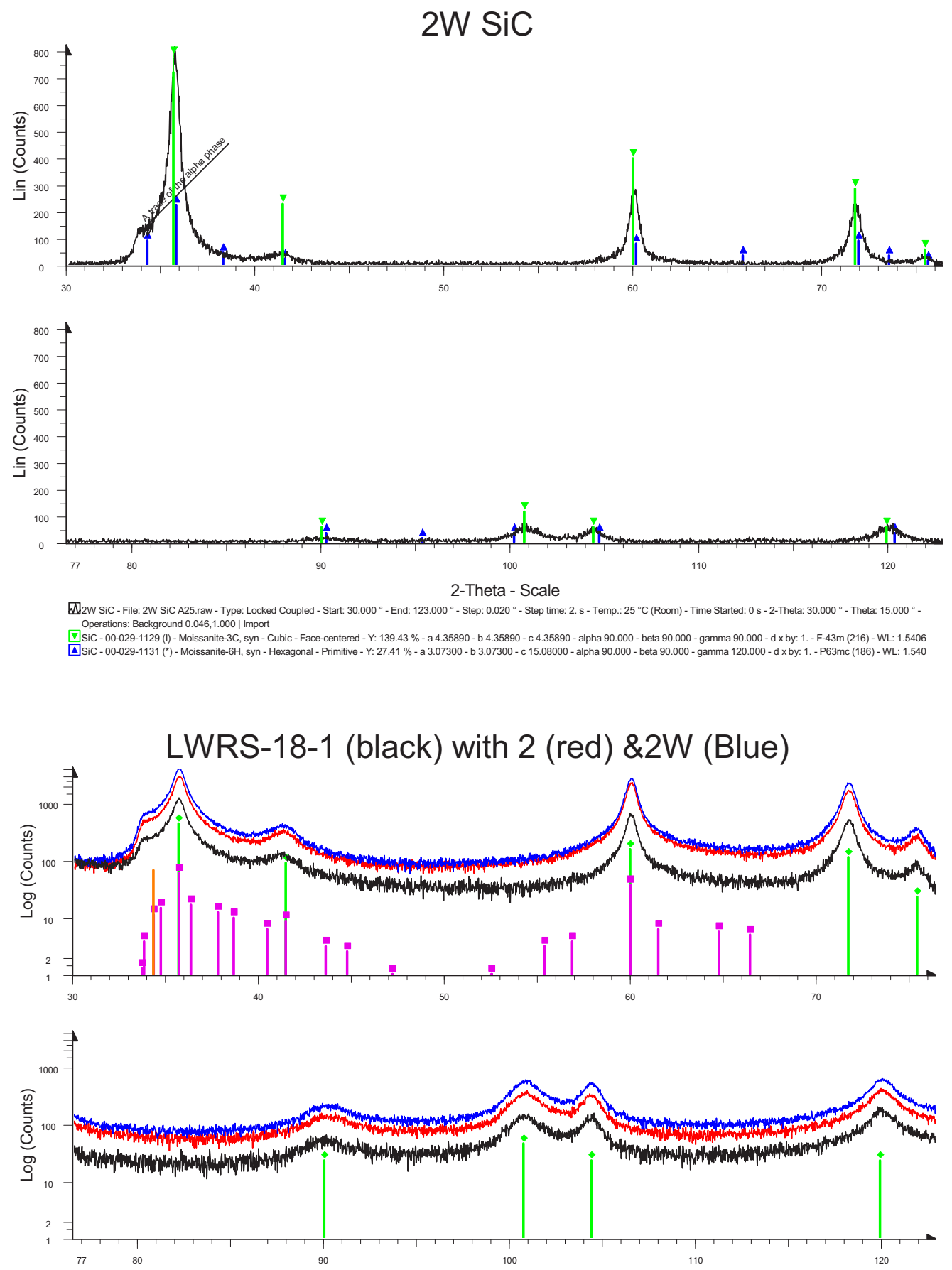

2-Theta - Scale

W Operations: Import

The reat raw - Type: Locked Coupled - Start: $30.000^{\circ}$ - End: $123.000^{\circ}$ - Step: $0.020^{\circ}$ - Step time: 6 s s - Temp.: $25^{\circ} \mathrm{C}$ (Room) - Time Started: 0 s - 2-Theta: $30.000^{\circ}$ - Thet Wherations: Impor

SiC - 00-029-1129 (I) - Moissanite-3C, syn - Cubic - Face-centered - a 4.35890 - b 4.35890 - c 4.35890 - alpha 90.000 - beta 90.000 - gamma 90.000 - F-43m (216) - WL: 1.5406 L.J C - 00-050-0926 (I) - Carbon - Hexagonal - a 11.92800 - b 11.92800 - c 10.62000 - alpha 90.000 - beta 90.000 - gamma 120.000 - WL: 1.5406 

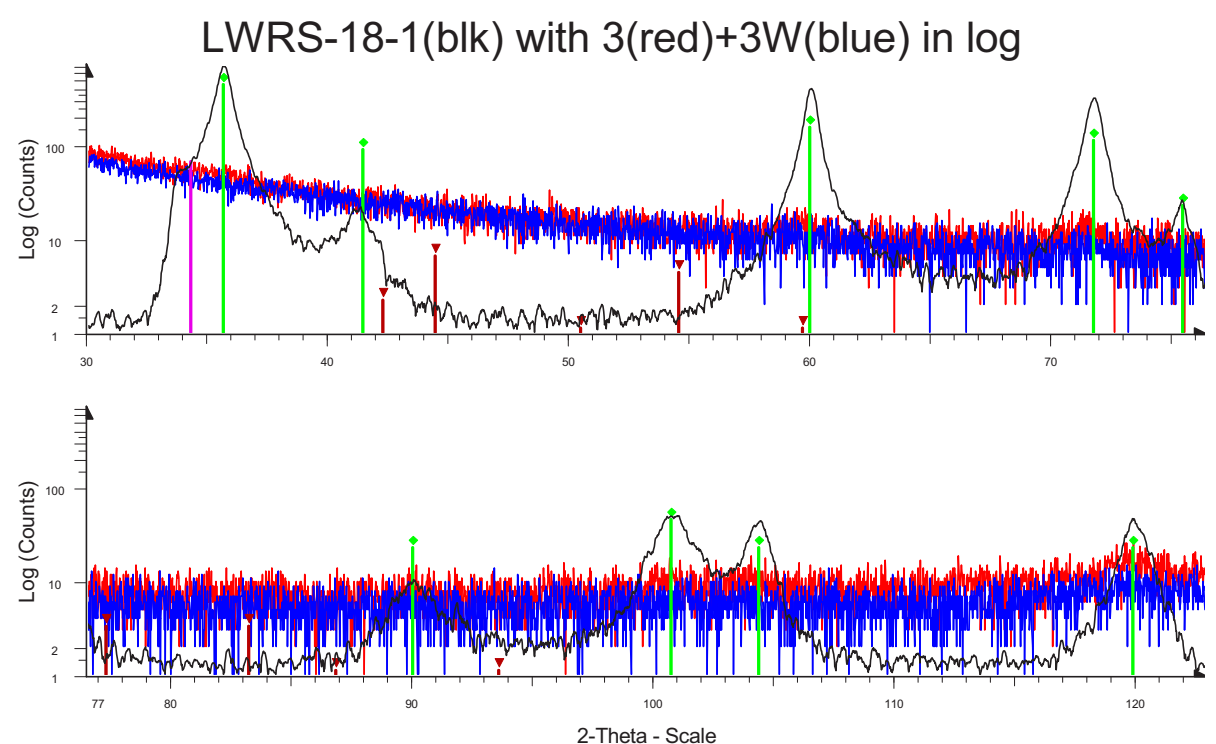

WLWRS-18-1(bl) with 3(red)+3W(blue) in log - File: LWRS-18-1 ×3 A25 90d.raw - Type: Locked Coupled - Start: $30.000^{\circ}$ - End: $123.000^{\circ}$ - Step: $0.020^{\circ}$ - Step time: 6. s - Temp: $25^{\circ} \mathrm{C}$ (Roo 四 3 - Feratio: 3 ×3 3 A25 90dr. raw - Type: Locked Coupled - Start: $30.000^{\circ}$ - End: $123.000^{\circ}$ - Step: $0.020^{\circ}$ - Step time: 6. s - Temp.: $25^{\circ} \mathrm{C}$ (Room) - Time Started: 0 s - 2-Theta: $30.000^{\circ}$ - Theta: 15 团 3 3W - File: 3 W $\times 3$ A25 90d. raw - Type: Locked Coupled - Start: $30.000^{\circ}$ - End: $123.000^{\circ}$ - Step: $0.020^{\circ}$ - Step time: $6 . \mathrm{s}$ - Temp: $25^{\circ} \mathrm{C}$ (Room) - Time Started: 0 s - 2-Theta: $30.000^{\circ}$ - Theta Operations: Import

SiC - 00-029-1129 (I) - Moissanite-3C, syn - Cubic - Face-centered - a 4.35890 - b 4.35890 - c 4.35890 - alpha 90.000 - beta 90.000 - gamma 90.000 - F-43m (216) - WL: 1.5406 U

LWRS-18-1 with 4+200\&4W+100 in log
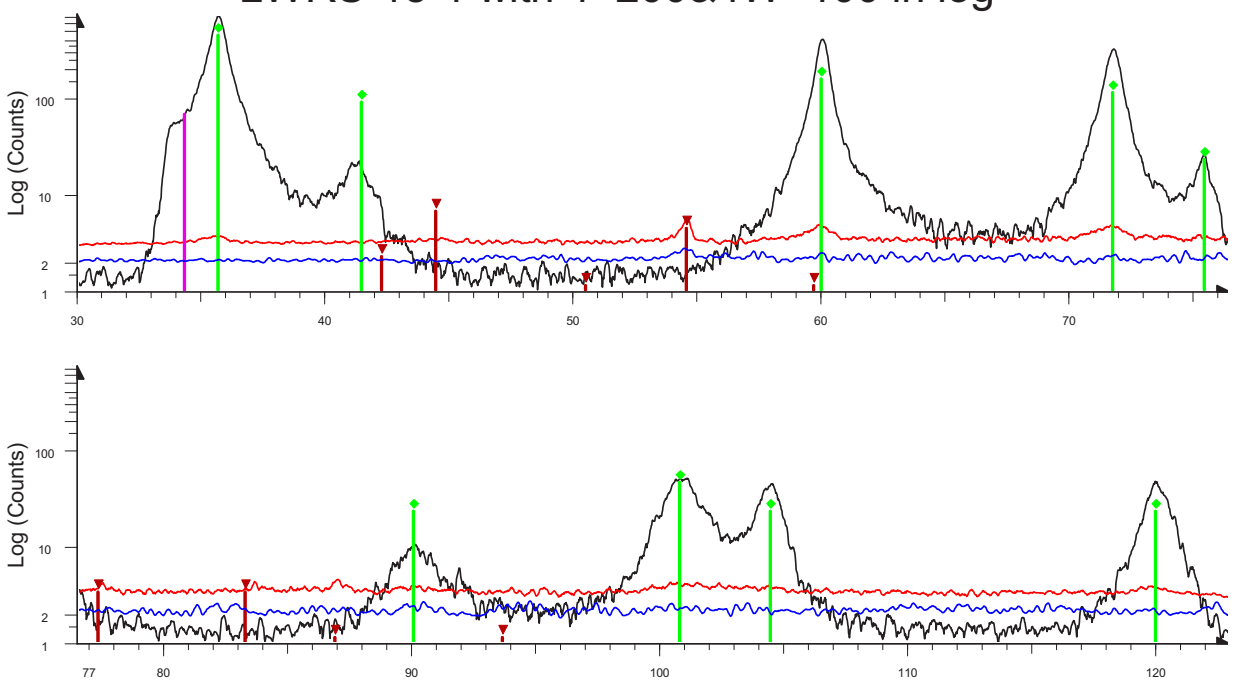

2-Theta - Scale

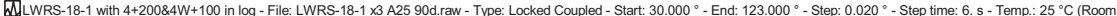

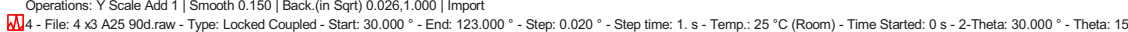

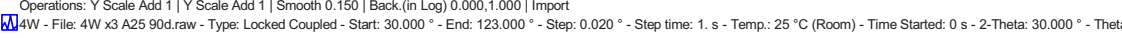

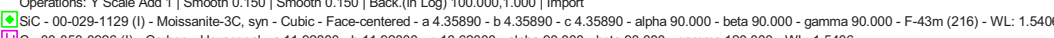



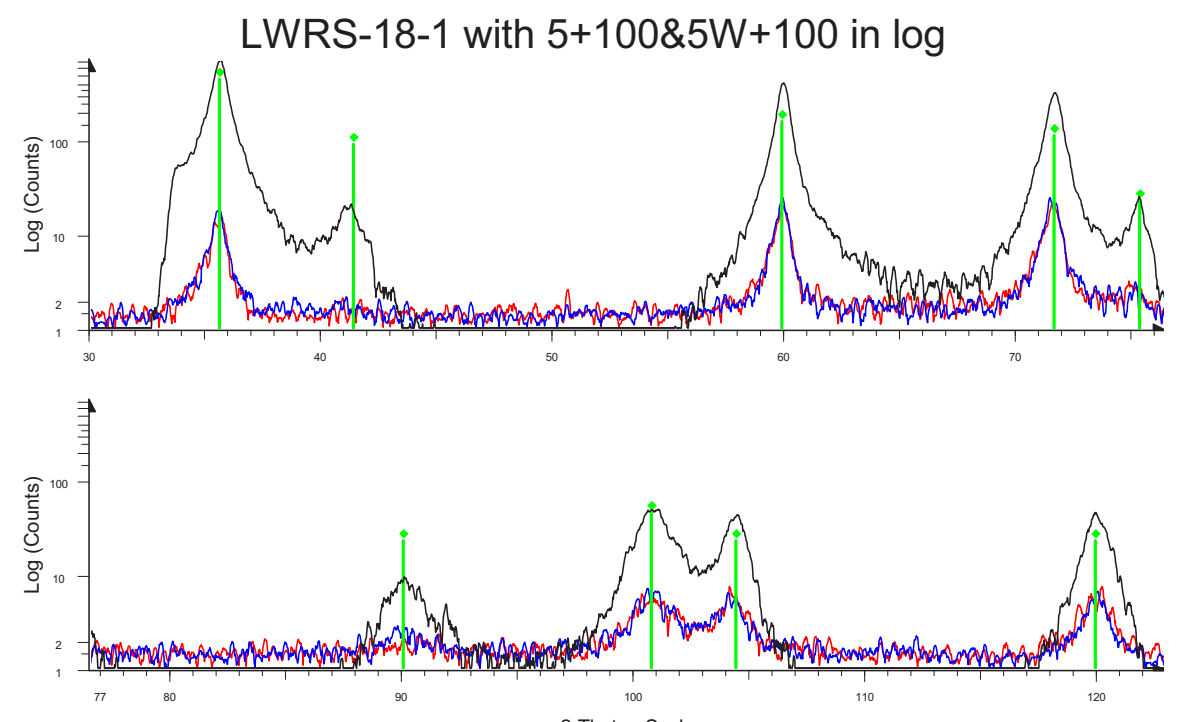

$$
\text { 2-Theta - Scale }
$$

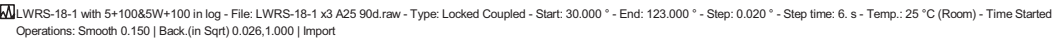

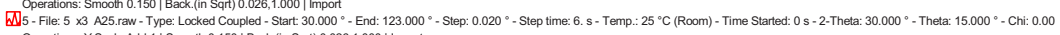

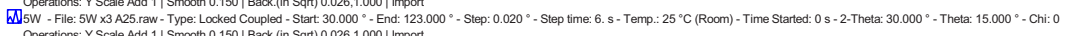
[1] Sic - 00-029-1129 (I) - Moissanite-3C, syn - Cubic - Face-centered - a 4.35890 - 6 4.35890 - c 4.35890 - alpha 90.000 - beta 90.000 - gamma 90.000 - F-43m (216) - WL: 1.5406 


\section{Appendix $\mathrm{H}$}

\section{Detail of Dimensional Measurements: Gamma Irradiation Test 2}

Table H-1. Gamma irradiation test 2: SiC-CMC sleeve dimensional measurements prior and after gamma irradiation. (All numbers are following the designation LWRS-1-6- ).

\begin{tabular}{|c|c|c|c|c|c|c|c|c|}
\hline \multirow[b]{2}{*}{$\begin{array}{c}\text { Sample } \\
\text { No. }\end{array}$} & \multirow{2}{*}{$\begin{array}{c}\begin{array}{c}\text { Before } \\
\text { Gamma } \\
\text { Irradiation }\end{array} \\
\\
\text { Length } \\
\text { SiC }(\mathrm{mm}) \\
\end{array}$} & \multicolumn{2}{|c|}{$\begin{array}{c}\text { After Gamma } \\
\text { Irradiation }\end{array}$} & \multirow{2}{*}{$\begin{array}{c}\text { Variance } \\
\text { in } \mathrm{SiC} \\
\text { length } \\
(\%)\end{array}$} & \multirow{2}{*}{$\begin{array}{c}\begin{array}{c}\text { Prior } \\
\text { Gamma } \\
\text { Irradiation }\end{array} \\
\text { Diameter } \\
\text { SiC }(\mathbf{m m})\end{array}$} & \multicolumn{2}{|c|}{$\begin{array}{l}\text { After Gamma } \\
\text { Irradiation }\end{array}$} & \multirow{2}{*}{$\begin{array}{c}\text { Variance } \\
\text { in } \mathrm{SiC} \\
\text { Diameter } \\
(\%)\end{array}$} \\
\hline & & $\begin{array}{c}\text { Length } \\
\mathrm{SiC} \\
\text { (inches) }\end{array}$ & $\begin{array}{c}\text { Length } \\
\mathrm{SiC} \\
(\mathrm{mm}) \\
\end{array}$ & & & $\begin{array}{c}\text { Diamete } \\
\text { r SiC } \\
\text { (inches) }\end{array}$ & $\begin{array}{c}\text { Diamet } \\
\text { er SiC } \\
(\mathrm{mm})\end{array}$ & \\
\hline A-1-2 & 29.22 & 1.147 & 29.1338 & -0.30 & 11.9 & 0.457 & 11.6078 & -2.46 \\
\hline A-1-3 & 31.27 & 1.237 & 31.4198 & 0.48 & 11.53 & 0.455 & 11.557 & 0.23 \\
\hline A-3-1 & 18.29 & 0.718 & 18.2372 & -0.29 & 11.05 & 0.433 & 10.9982 & -0.47 \\
\hline
\end{tabular}

Table H-2. Weight measurements of SiC-CMC sleeves.

\begin{tabular}{|l|c|c|c|}
\hline $\begin{array}{c}\text { Sample } \\
\text { Number }\end{array}$ & $\begin{array}{c}\text { Weight (g) } \\
\text { Before gamma } \\
\text { Irradiation }\end{array}$ & $\begin{array}{c}\text { Weight (g) } \\
\text { After Gamma } \\
\text { Irradiation }\end{array}$ & \multicolumn{2}{|c|}{$\begin{array}{c}\text { Variance in } \\
\text { Weight } \\
(\%)\end{array}$} \\
\hline A-1-2 & 1.7412 & 1.7265 & -0.8 \\
\hline A-1-3 & 1.8939 & 1.8060 & -4.6 \\
\hline A-3-1 & 0.5854 & 0.5674 & -3.1 \\
\hline
\end{tabular}




\section{Appendix I}

\section{Detail of Density Measurements: Gamma Irradiation Test 2}

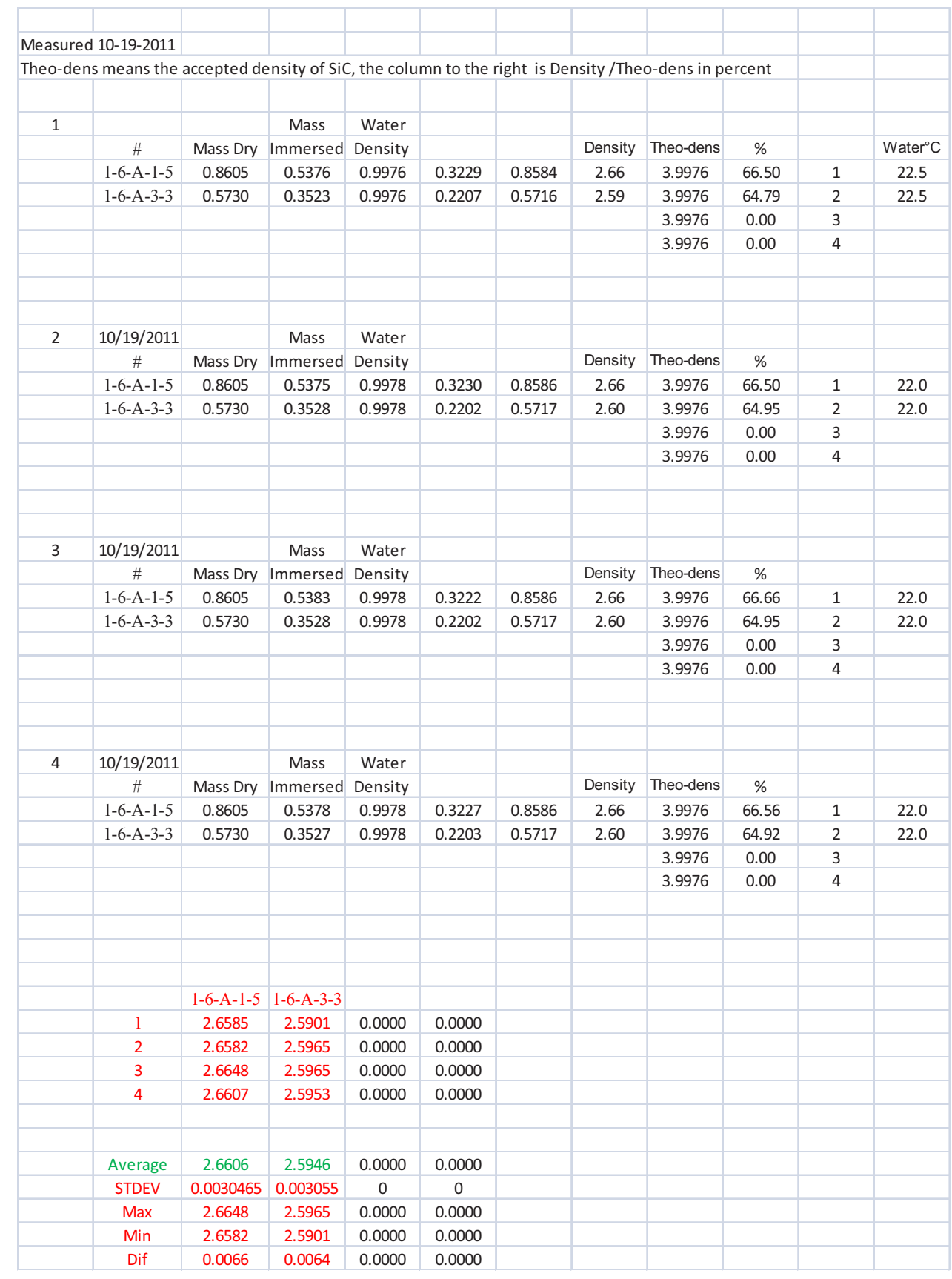




\begin{tabular}{|c|c|c|c|c|c|c|c|c|c|c|c|}
\hline \multicolumn{12}{|c|}{$\begin{array}{l}\text { AfterGammaIradiation } \\
\text { Rep. }\end{array}$} \\
\hline \multirow[t]{5}{*}{1} & $12 / 14 / 2011$ & & Mass & Water & & & & & & Immersion & \\
\hline & \# & $\begin{array}{l}\text { Mass } \\
\text { Dry }\end{array}$ & Immersed & Density & & & Density & $\begin{array}{l}\text { Theo- } \\
\text { dens }\end{array}$ & $\%$ & Container & Water ${ }^{\circ} \mathrm{C}$ \\
\hline & $1-6-A-1-2$ & 1.7150 & 1.0763 & 0.9976 & 0.6387 & 1.7109 & 2.6787 & 3.9976 & 67.01 & 1 & 21.0 \\
\hline & $1-6-A-3-1$ & 0.5653 & 0.3499 & 0.9976 & 0.2154 & 0.5639 & 2.6181 & 3.9976 & 65.49 & 2 & 21.0 \\
\hline & $1-6-A-1-3$ & 1.7967 & 1.1270 & 0.9978 & 0.6697 & 1.7927 & 2.6769 & 3.9976 & 66.96 & 3 & 21.0 \\
\hline \multirow[t]{5}{*}{2} & $12 / 14 / 2011$ & & Mass & Water & & & & & & & \\
\hline & \# & $\begin{array}{l}\text { Mass } \\
\text { Dry }\end{array}$ & Immersed & Density & & & Density & $\begin{array}{l}\text { Theo- } \\
\text { dens }\end{array}$ & $\%$ & & \\
\hline & $1-6-A-1-2$ & 1.7150 & 1.0770 & 0.9980 & 0.6380 & 1.7116 & 2.6827 & 3.9976 & 67.11 & 1 & 21.0 \\
\hline & $1-6-A-3-1$ & 0.5653 & 0.3503 & 0.9980 & 0.2150 & 0.5642 & 2.6240 & 3.9976 & 65.64 & 2 & 21.0 \\
\hline & $1-6-A-1-3$ & 1.7967 & 1.1251 & 0.9980 & 0.6716 & 1.7931 & 2.6699 & 3.9976 & 66.79 & 3 & 21.0 \\
\hline \multirow[t]{5}{*}{3} & $12 / 14 / 2011$ & & Mass & Water & & & & & & & \\
\hline & \# & $\begin{array}{l}\text { Mass } \\
\text { Dry }\end{array}$ & Immersed & Density & & & Density & $\begin{array}{l}\text { Theo- } \\
\text { dens }\end{array}$ & $\%$ & & \\
\hline & $1-6-A-1-2$ & 1.7150 & 1.0755 & 0.9980 & 0.6395 & 1.7116 & 2.6764 & 3.9976 & 66.95 & 1 & 21.0 \\
\hline & $1-6-A-3-1$ & 0.5653 & 0.3511 & 0.9980 & 0.2142 & 0.5642 & 2.6338 & 3.9976 & 65.89 & 2 & 21.0 \\
\hline & $1-6-A-1-3$ & 1.7967 & 1.1271 & 0.9980 & 0.6696 & 1.7931 & 2.6779 & 3.9976 & 66.99 & 3 & 21.0 \\
\hline \multirow[t]{18}{*}{4} & $12 / 14 / 2011$ & & Mass & Water & & & & & & & \\
\hline & \# & $\begin{array}{l}\text { Mass } \\
\text { Dry }\end{array}$ & Immersed & Density & & & Density & $\begin{array}{l}\text { Theo- } \\
\text { dens }\end{array}$ & $\%$ & & \\
\hline & $1-6-A-1-2$ & 1.7150 & 1.0745 & 0.9978 & 0.6405 & 1.7112 & 2.6717 & 3.9976 & 66.83 & 1 & 22.0 \\
\hline & $1-6-A-3-1$ & 0.5653 & 0.3510 & 0.9978 & 0.2143 & 0.5641 & 2.6321 & 3.9976 & 65.84 & 2 & 22.0 \\
\hline & $1-6-A-1-3$ & 1.7967 & 1.1257 & 0.9978 & 0.6710 & 1.7927 & 2.6718 & 3.9976 & 66.83 & 3 & 22.0 \\
\hline & & $1=$ & $2=$ & $3=$ & & & & & & & \\
\hline & Rep.1 & $\begin{array}{c}1-6-A-1- \\
2\end{array}$ & $1-6-A-3-1$ & $1-6-A-1-3$ & & & & & & & \\
\hline & 1 & 2.6787 & 2.6181 & 2.6769 & & & & & & & \\
\hline & 2 & 2.6827 & 2.6240 & 2.6699 & & & & & & & \\
\hline & 3 & 2.6764 & 2.6338 & 2.6779 & & & & & & & \\
\hline & 4 & 2.6717 & 2.6321 & 2.6718 & & & & & & & \\
\hline & & $1=$ & $2=$ & $3=$ & & & & & & & \\
\hline & & $\begin{array}{c}\text { 1-6-A-1- } \\
2 \\
\end{array}$ & 1-6-A-3-1 & 1-6-A-1-3 & & & & & & & \\
\hline & Average & 2.68 & 2.63 & 2.67 & & & & & & & \\
\hline & STDEV & 0.004593 & 0.00731 & 0.0038925 & & & & & & & \\
\hline & Max & 2.6827 & 2.6338 & 2.6779 & & & & & & & \\
\hline & Min & 2.6717 & 2.6181 & 2.6699 & & & & & & & \\
\hline & Dif & 0.0110 & 0.0157 & 0.0080 & & & & & & & \\
\hline
\end{tabular}




\section{Appendix $\mathbf{J}$}

\section{Detail of Chemical Analysis: Gamma Irradiation Test 2}

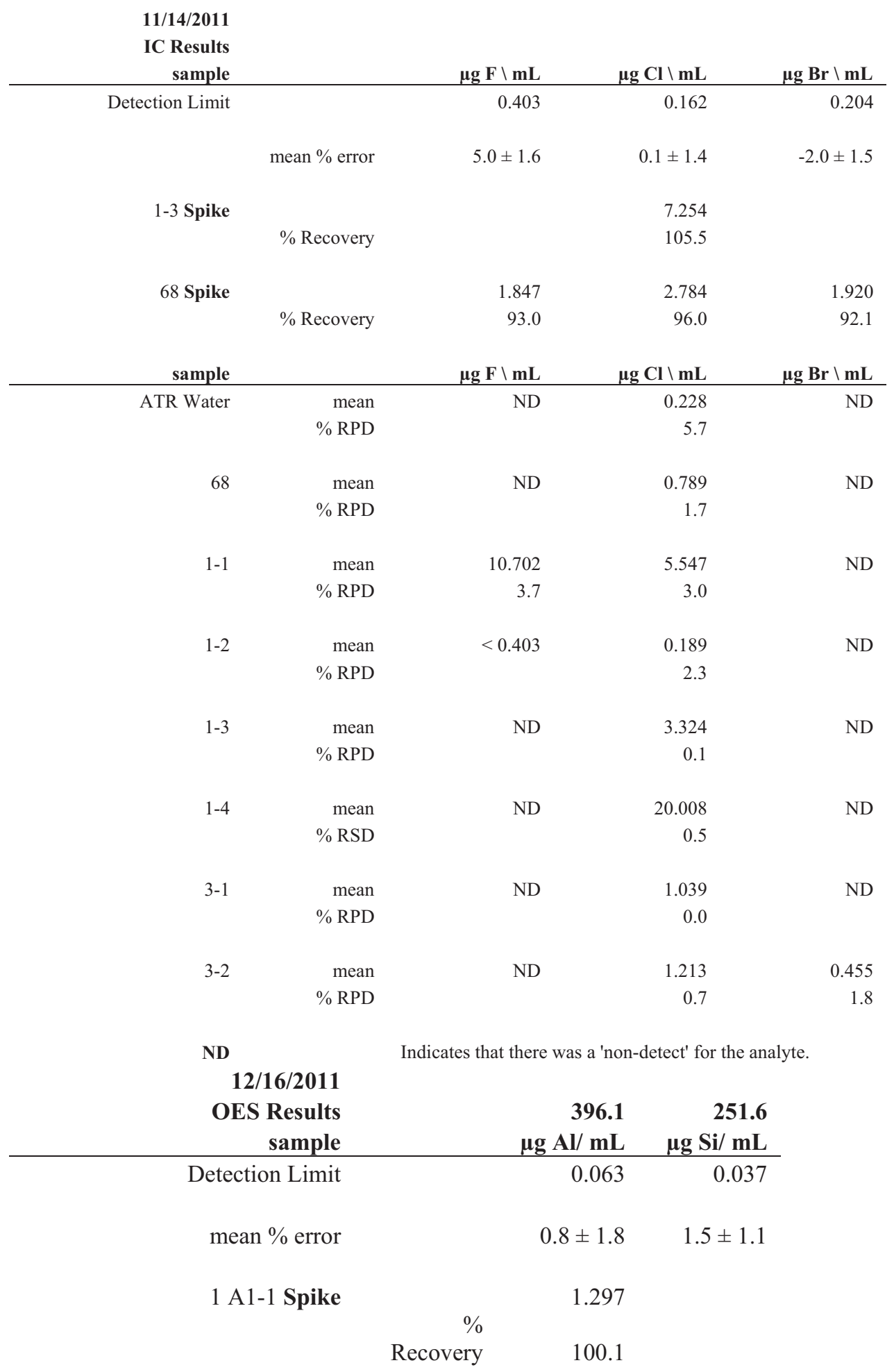




\begin{tabular}{rrrr} 
16 A1-3 Spike & \multicolumn{1}{c}{} & 17.810 \\
& Recovery & & 99.6 \\
sample & & $\mathbf{\mu g ~ A l} / \mathbf{~ m L}$ & $\boldsymbol{\mu g ~ S i} / \mathbf{~ m L}$ \\
\hline 6W & $<0.158$ & \\
& & \\
Standard ATR Water & $<0.158$ & $<0.093$ \\
LWRA 680 & $<0.158$ & 0.530 \\
LWRS 1-A 1-1 & 0.695 & 42.000 \\
LWRS 1-6 A 1-2 & 0.408 & 34.850 \\
LWRS 1-6 A 1-3 & $<0.158$ & 21.720 \\
LWRS 1-6 A 1-4 & $<0.158$ & 77.100 \\
LWRS 1-6 A 3-1 & $<0.158$ & 15.905 \\
LWRS 1-6 A 3-2 & $<0.158$ & 46.950
\end{tabular}

